IFAS Extension

\title{
Field Observations During the Eighth Microwave Water and Energy Balance Experiment (MicroWEX-8): from June 16 through August 24, $2009^{1}$
}

\author{
Tara Bongiovanni, Heather Enos, Alejandro Monsivais-Huertero, Blaire Colvin, Karthik \\ Nagarajan, Jasmeet Judge, Pang-Wei Liu, Juan Fernandez-Diaz, Roger De Roo, Yuriy \\ Goykhman, Xueyang Duan, Daniel Preston, Ramesh Shrestha, Clint Slatton, Mahta \\ Moghaddam, and Anthony England ${ }^{2}$
}

1. This document is AE476, one of a series of the Agricultural and Biological Engineering Department, Florida Cooperative Extension Service, Institute of Food and Agricultural Sciences, University of Florida. First published August 2011. Please visit the EDIS website at http://edis.ifas.ufl.edu.

2. Heather Enos and Blaire Colvin are undergraduate research assistants of the Center for Remote Sensing (CRS) at the University of Florida (UF); Tara Bongiovanni and Pang-Wei Liu are graduate research assistants of CRS at UF; Alejandro Monsivais-Huertero and Karthik Nagarajan are post-doctoral researchers of CRS at UF; Jasmeet Judge is an assistant professor and director of CRS at UF (email: jasmeet@ufl.edu); Juan Fernandez-Diaz is a graduate research assistant of the National Center for Airborne Laser Mapping (NCALM) currently located at the University of Houston (UH); Roger De Roo is a professor at the University of Michigan (UM); Yuriy Goykhman and Xueyang Duan are graduate research assistants at UM; Daniel Preston is an engineering technician of CRS at UF; Ramesh Shrestha is a professor director of NCALM at UH; Clint Slatton is an associate professor at UF; Mahta Moghaddam is a professor at UM; Anthony England is a professor at UM. Heather Enos, Blaire Colvin, Tara Bongiovanni, Alejandro Monsivais-Huertero, Karthik Nagarajan, Jasmeet Judge, Pang-Wei Liu, and Daniel Preston are affiliated with the Agricultural and Biological Engineering Department, Institute of Food and Agricultural Sciences, University of Florida, Gainesville, FL 32611. Juan Fernandez-Diaz and Ramesh Shrestha are affiliated with the Civil Engineering Department, University of Houston, Houston, TX 77204. Roger De Roo, Yuriy Goykhman, Xueyang Duan, Mahta Moghaddam, and Anthony England are affiliated with the Electrical Engineering and Computer Sciences Department, University of Michigan, Ann Arbor, MI 48109. Clint Slatton is affiliated with the Electrical and Computer Engineering and the Civil and Coastal Engineering Department, University of Florida, Gainesville, FL 32611. 


\section{Table of Contents}

1. INTRODUCTION

2. OBJECTIVES

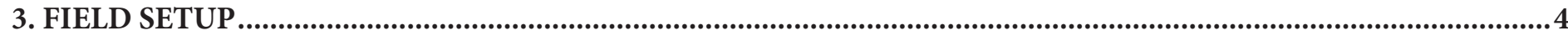

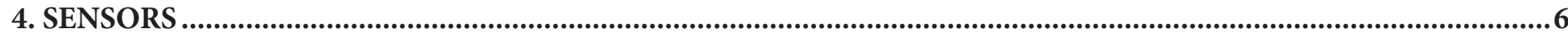

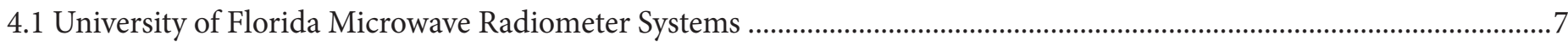

4.1.1 University of Florida C-band Microwave Radiometer (UFCMR) …........................................................................

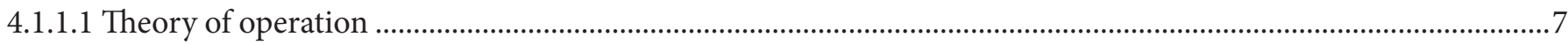

4.1.2 University of Florida L-band Microwave Radiometer (UFLMR) ............................................................................

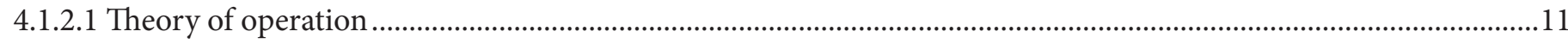

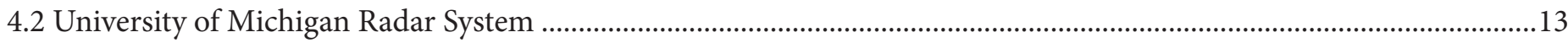

4.2.1 Microwave Observatory of Subcanopy and Subsurface (MOSS) ………..................................................................13

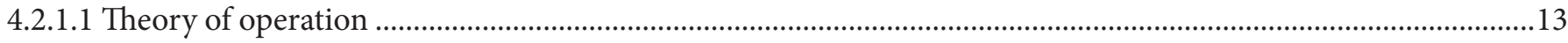

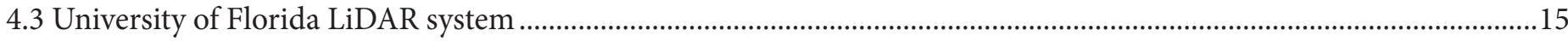

4.3.1 University of Florida Mobile Terrestrial Laser Scanning (M-TLS) ...........................................................................15

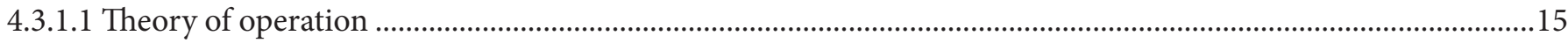

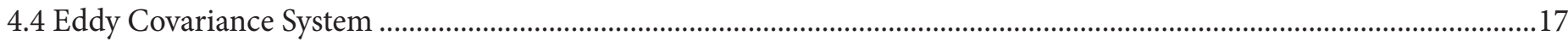

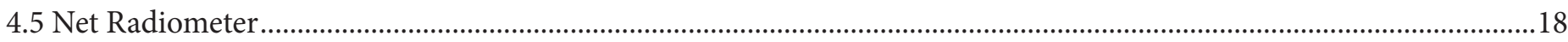

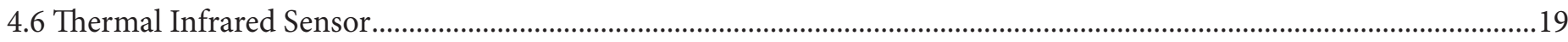

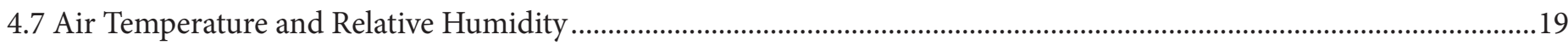

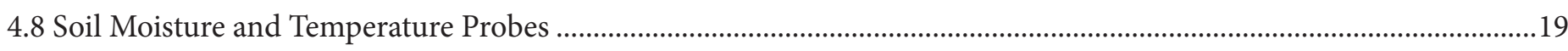

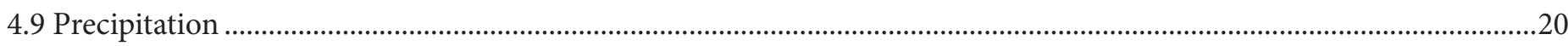

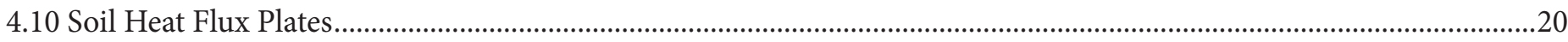

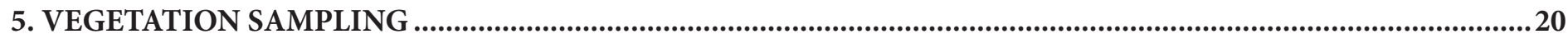

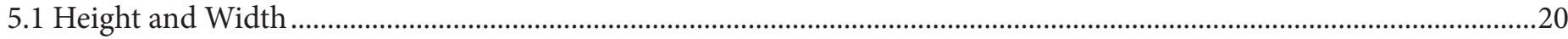

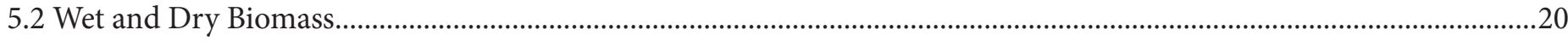

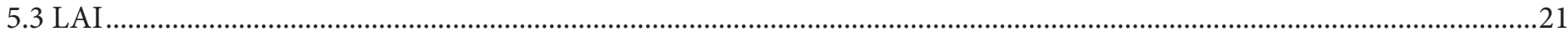

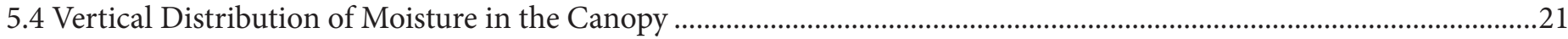




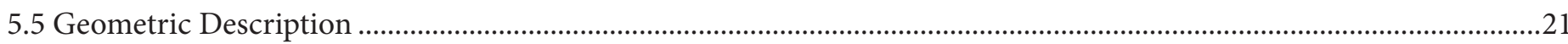

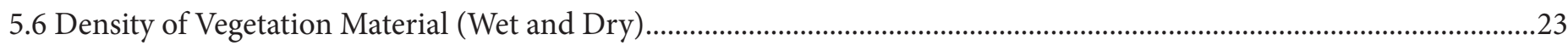

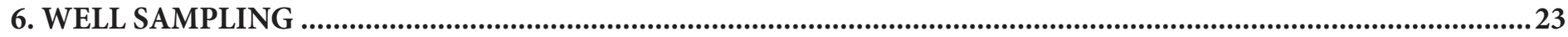

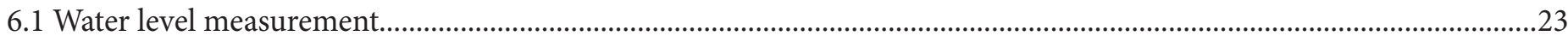

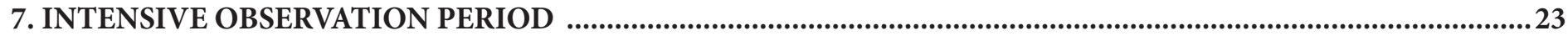

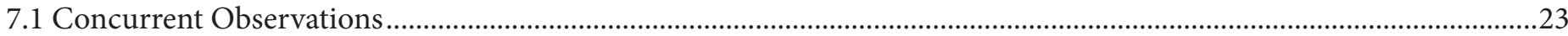

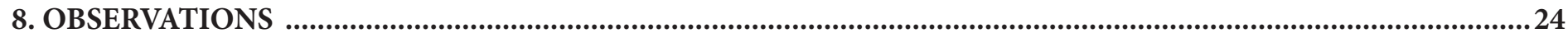

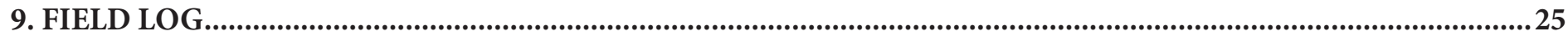

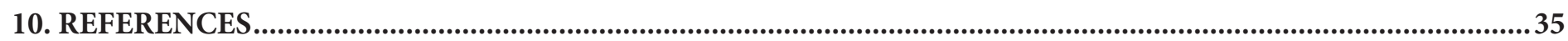

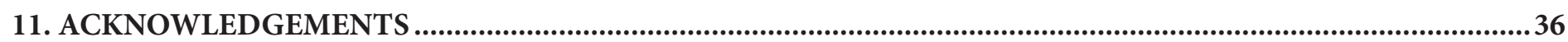

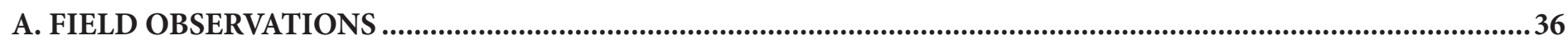




\section{INTRODUCTION}

For accurate prediction of weather and near-term climate, root-zone soil moisture is one of the most crucial components driving the surface hydrological processes. Soil moisture in the top meter governs moisture and energy fluxes at the landatmosphere interface, and it plays a significant role in partitioning of the precipitation into runoff and infiltration.

Energy and moisture fluxes at the land surface can be estimated by Soil-Vegetation-Atmosphere-Transfer (SVAT) models. These models are typically used in conjunction with numerical weather and near-term climate prediction models and surface-subsurface hydrological models. Even though the biophysics of moisture and energy transport is well-captured in most current SVAT models, the errors in initialization, forcings, and computation accumulate over time, and the model estimates of soil moisture in the root zone diverge from reality. Remotely sensed microwave observations can be assimilated in these models to improve root zone soil moisture estimates.

The microwave signatures at low frequencies, particularly at $1.4 \mathrm{GHz}$ (L-band), are very sensitive to soil moisture in the top few centimeters in most vegetated surfaces. Many studies have been conducted in agricultural areas, such as bare soil, grass, soybean, wheat, pasture, and corn, to understand the relationship between soil moisture and microwave remote sensing. It is important to know how microwave signatures vary with soil moisture, evapotranspiration (ET), and biomass in a dynamic agricultural canopy with a significant biomass $\left(4-6 \mathrm{~kg} / \mathrm{m}^{2}\right)$ throughout the growing season.

\section{OBJECTIVES}

The goal of MicroWEX-8 was to conduct a pilot study that incorporated active and passive microwave observations as well as Light Detection and Ranging (LiDAR) observations for a growing season of sweet corn. The variety of instruments would allow for further understanding of the land-atmosphere interactions during the growing season and their effect on observed passive microwave signatures at $6.7 \mathrm{GHz}$ and $1.4 \mathrm{GHz}$, active microwave signatures at $1.14 \mathrm{GHz}$, and LiDAR scans. These observations match that of the satellite-based passive microwave radiometers, Advanced Microwave Scanning Radiometer (AMSR), and the Soil Moisture and Ocean Salinity (SMOS) mission, respectively, and the upcoming NASA Soil Moisture Active Passive (SMAP) mission. Specific objectives of MicroWEX-8 included the following:

1. To field-test the micrometeorological, microwave radiometer, radar, LiDAR, and other sensors to characterize errors.

2. To collect passive and active microwave, LiDAR, and other ancillary data to develop preliminary algorithms to estimate microwave signatures for corn.

3. To evaluate feasibility of soil moisture retrievals using passive microwave data at 6.7 and $1.4 \mathrm{GHz}$ and active microwave data at $1.14 \mathrm{GHz}$ for the growing corn canopy.

\section{FIELD SETUP}

MicroWEX-8 was conducted by the Center for Remote Sensing, Agricultural and Biological Engineering Department at the Plant Science Research and Education Unit (PSREU) $\left(29.4^{\circ} \mathrm{N}, 82.17^{\circ} \mathrm{W}\right)$, Institute of Food and Agricultural Sciences (IFAS), Citra, FL. Figures 1 and 2 show the location of the PSREU and the study site for the MicroWEX-8, respectively. The study site was located at the west side of the PSREU. The dimensions of the study site were $183 \mathrm{~m} \times 183 \mathrm{~m}$. A linear move system was used for irrigation. The corn of variety Yellow Supersweet Hybrid $\left(\mathrm{SH}_{2}\right)$ Saturn was planted on June 16 (Day of Year (DoY) 167) in 2009, at an orientation $0^{\circ}$ from the east. The plant spacing was $15.9 \mathrm{~cm}\left(6^{1 / 4}\right.$ inches) and the row spacing was $76.2 \mathrm{~cm}$ (30 inches). Instrument installation began on June 19 (DoY 170). The instruments consisted of a ground-based microwave radiometer system, a ground-based microwave radar system, a mobile LiDAR system, and micrometeorological stations. The ground-based microwave radiometer system was installed at the location shown in Figure 3, facing south to avoid the radiometer shadow interfering with the field of view. The ground-based microwave radar system was installed adjacent to the radiometer with a portion of the radar footprint overlapping the radiometer footprint, facing the same direction as the radiometer system. The LiDAR system was mounted in a truck bed that would be consecutively positioned near the west and east corners of the north edge of the field. 


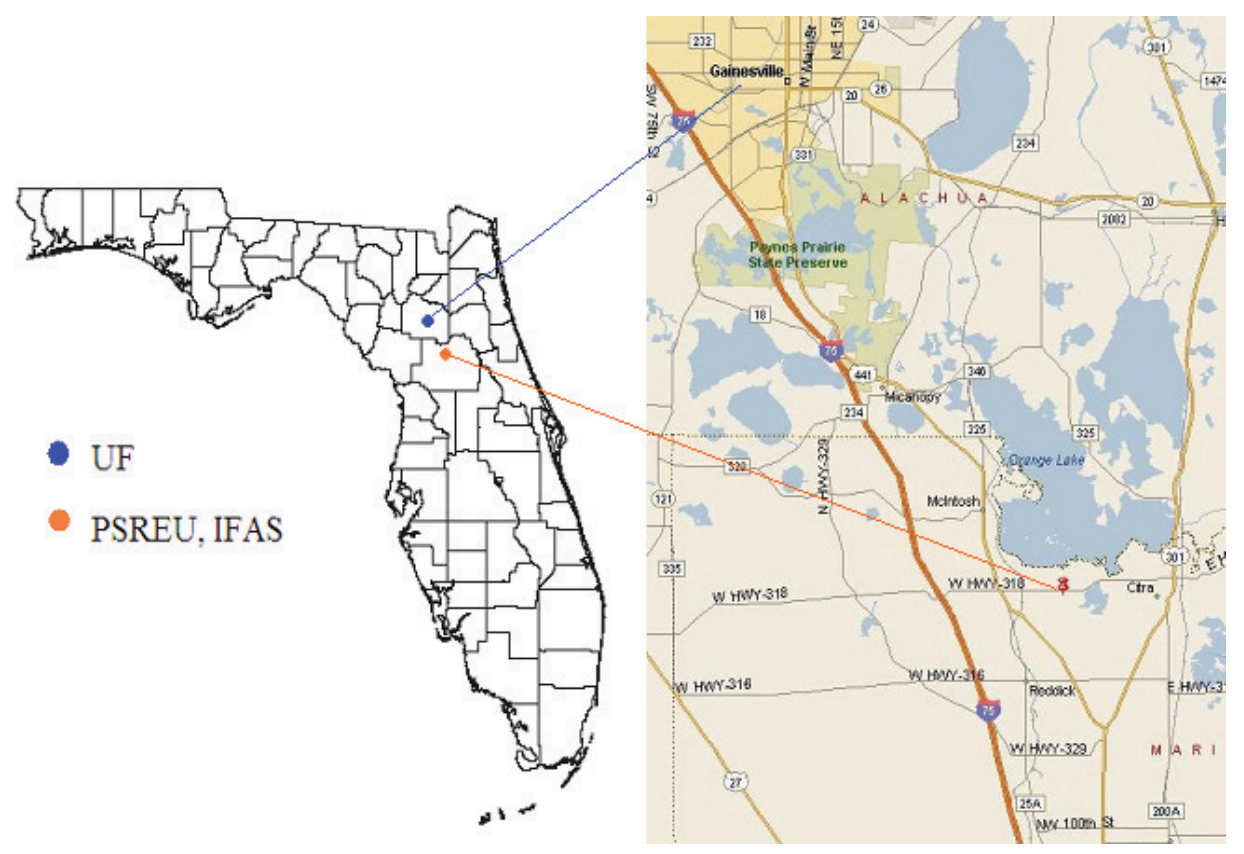

Figure 1. Location of PSREU/IFAS (from http://plantscienceunit.ifas.ufl.edu/directions.shtml).

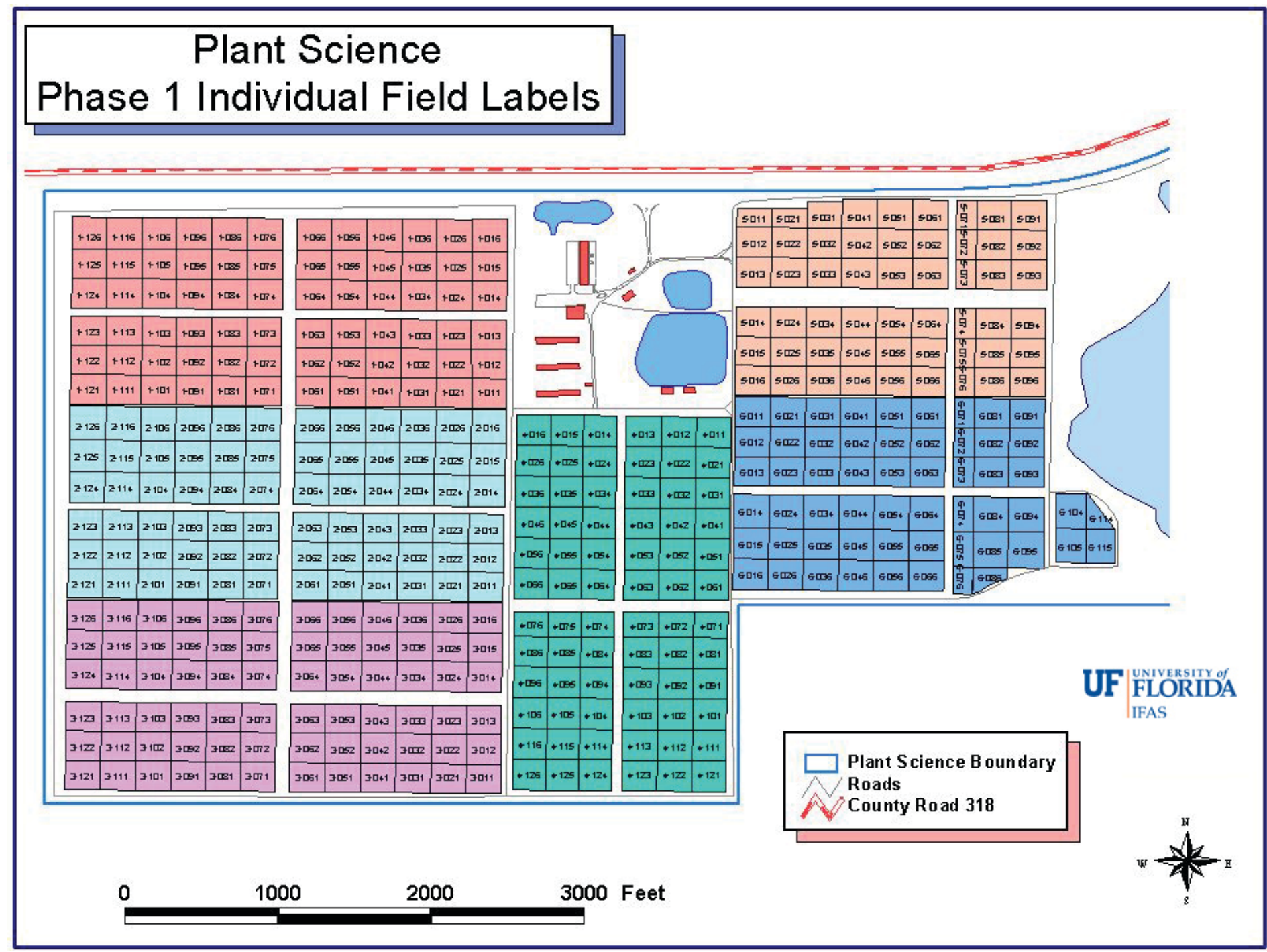

Figure 2. Location of the field site for MicroWEX-8 at the UF/IFAS PSREU (from http://plantscienceunit.ifas.ufl.edu/images/location/p1.jpg). 
A micrometeorological station was installed at the center of the field and included soil heat flux plates and the eddy covariance system. Four rain gauges, at different heights, were installed in line with the outer edge of the radiometer footprints. Two additional rain gauges were installed near the southeast and northwest edge of the field to capture the irrigation. Two micrometeorological stations with soil moisture, soil heat flux, and soil temperature sensors were installed at the locations shown in Figure 3. A relative humidity $(\mathrm{RH})$ sensor, temperature sensor, and net radiometer were installed at the North station. This report provides detailed information regarding sensors deployed and data collected during the MicroWEX-8.

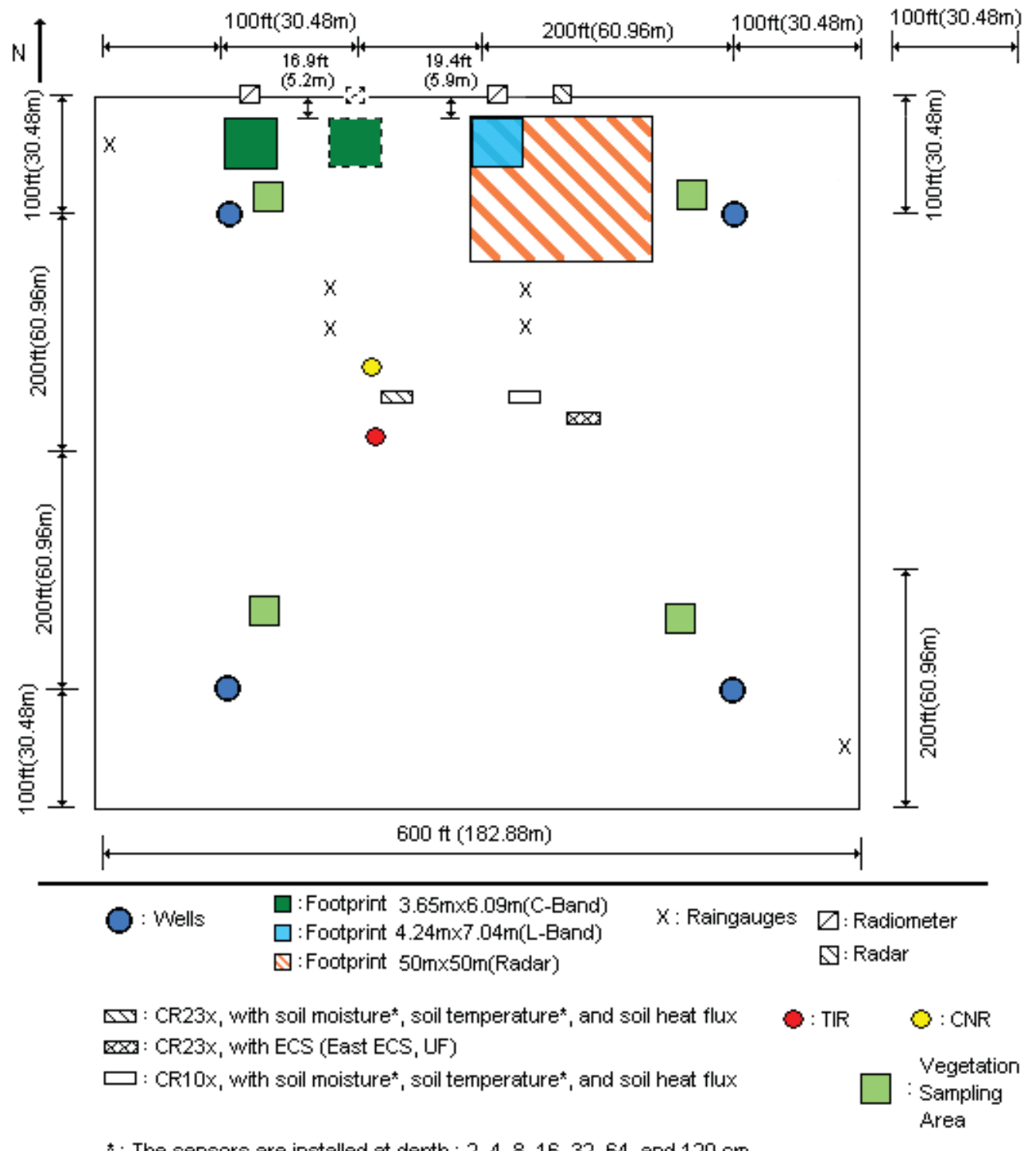

Figure 3. Layout of the sensors during MicroWEX-8.

\section{SENSORS}

MicroWEX-8 had five major types of instrument subsystems: the ground-based University of Florida L-band and C-band Radiometers, the ground-based University of Michigan L-band Radar, the mobile University of Florida LiDAR, the micrometeorological, and the soil subsystem. 


\subsection{University of Florida Microwave Radiometer Systems}

\subsubsection{UNIVERSITY OF FLORIDA C-BAND MICROWAVE RADIOMETER (UFCMR)}

Microwave brightness temperatures at $6.7 \mathrm{GHz}(\lambda=4.48 \mathrm{~cm})$ were measured every 15 minutes using the University of Florida's C-band Microwave Radiometer system (UFCMR) (Figure 4 (a)). The radiometer system consisted of a dual polarization total power radiometer operating at the center frequency of $6.7 \mathrm{GHz}$ housed atop a $10 \mathrm{~m}$ tower installed on a 16 ' trailer bed. The UFCMR was designed and built by the Microwave Geophysics Group at the University of Michigan. It operates at the center frequency at $6.7 \mathrm{GHz}$, which is identical to one of the center frequencies on the space-borne AMSR aboard the NASA Aqua Satellite Program. The UFCMR observed the $3.65 \mathrm{~m}$ x $6.09 \mathrm{~m}$ footprint from a height of $6.10 \mathrm{~m}$. A rotary system was used to rotate the look angle of the UFCMR for both field observations and sky measurements. The brightness temperatures were observed at an incidence angle of $50^{\circ}$. The radiometer was calibrated at least once every week with a microwave absorber as warm load and measurement of sky as cold load. Figures 4 (b) and 4 (c) show the close-up of the rotary system and the antenna of the UFCMR, respectively. Table 1 lists the specifications of the UFCMR. Figure A-1 shows the V-and H-pol brightness temperatures observed at C-band during MicroWEX-8.

Table 1. UFCMR specifications

\begin{tabular}{|c|c|c|}
\hline Parameter & Qualifier & Value \\
\hline Frequency & Center & $6.7 \mathrm{GHz}$ \\
\hline Bandwidth & $3 \mathrm{~dB}$ & $20 \mathrm{MHz}$ \\
\hline \multirow[t]{4}{*}{ Beamwidth } & $3 \mathrm{~dB}$ V-pol elevation ${ }^{\mathrm{a}}$ & $23^{\circ}$ \\
\hline & $3 \mathrm{~dB}$ V-pol azimuth ${ }^{\mathrm{b}}$ & $21^{\circ}$ \\
\hline & $3 \mathrm{~dB} \mathrm{H}$-pol elevation ${ }^{c}$ & $21^{\circ}$ \\
\hline & $3 \mathrm{~dB} H$-pol azimuth ${ }^{d}$ & $23^{\circ}$ \\
\hline Isolation & & $>27 \mathrm{~dB}$ \\
\hline Polarizations & Sequential & $\mathrm{V} / \mathrm{H}$ \\
\hline Receiver temp & & $437 \mathrm{~K}$ \\
\hline Noise Figure & From $\mathrm{T}_{\text {rec }}$ & $3.99 \mathrm{~dB}$ \\
\hline RF gain & & $85 \mathrm{~dB}$ \\
\hline \multirow[t]{2}{*}{$\mathrm{NE} \Delta \mathrm{T}$} & $1 \mathrm{sec}$ & $0.71 \mathrm{~K}$ \\
\hline & $8 \mathrm{sec}$ & $0.25 \mathrm{~K}$ \\
\hline
\end{tabular}

(a). sidelobes $<-33 \mathrm{~dB}$, (b). sidelobes $<-28 \mathrm{~dB}$,

(c). sidelobes $<-27 \mathrm{~dB},(\mathrm{~d})$. sidelobes $<-35 \mathrm{~dB}$

\subsubsection{Theory of operation}

The UFCMR uses a thermoelectric cooler (TEC) for thermal control of the Radio Frequency (RF) stages for the UFCMR. This is accomplished by the Oven Industries "McShane" thermal controller. McShane is used to cool or heat by the Proportional-Integral-Derivative (PID) algorithm with a high degree of precision at $0.01^{\circ} \mathrm{C}$. The aluminum plate to which all the RF components are attached is chosen to have sufficient thermal mass to eliminate short-term thermal drifts. All components attached to this thermal plate, including the TEC, use thermal paste to minimize thermal gradients across junctions.

The majority of the gain in the system is provided by a gain and filtering block designed by the University of Michigan for the STAR-Light instrument (De Roo 2003). The main advantage of this gain block is the close proximity of all the amplifiers, simplifying the task of thermal control. This gain block was designed for a radiometer working at the radio astronomy window of 1400-1427 MHz, and so the receiver is a heterodyne type with downconversion from the C-band RF to L-band. To minimize the receiver noise figure, a C-band low-noise amplifier (LNA) is used just prior to downconversion. To protect the amplifier from saturation due to out-of-band interference, a relatively wide bandwidth, but low insertion loss, 
a bandpass filter is used just prior to the amplifier. There are three components between the filter and the antenna: a switch for choosing polarization, a switch for monitoring a reference load, and an isolator to minimize changes in the apparent system gain due to differences in the reflections looking upstream from the LNA.

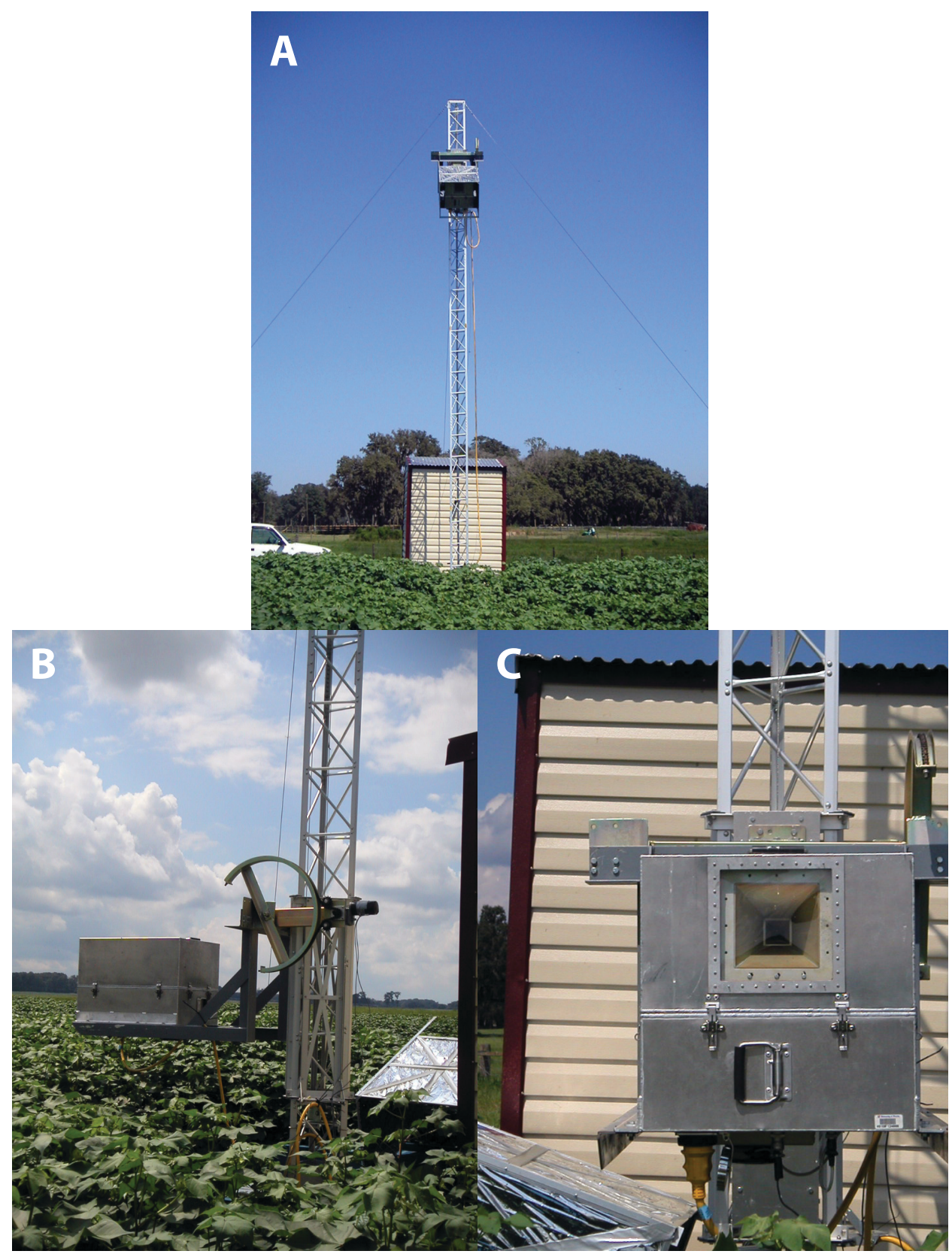

Figure 4 (a) The UFCMR system, (b) the side view of the UFCMR showing the rotary system, and (c) the front view of the UFCMR showing the receiver antenna.

The electrical penetrations use commercially available weatherproof bulkhead connections (Deutsch connectors or equivalent). The heat sinks have been carefully located employing RTV (silicone sealant) to seal the bolt holes. The radome uses 15 mil polycarbonate for radiometric signal penetration. It is sealed to the case using a rubber gasket held down to the case by a square retainer.

The first SMA connection is an electromechanical latching, driven by the Z-World control board switches between V-and H-polarization sequentially. The SMA second latching, which switches between the analog signal from the first switch and the reference load signal from a reference load resistor, sends the analog signal to an isolator, where the signals within 6.4-7.2 GHz in radiofrequency are isolated. Then, the central frequency is picked up by a $6.7 \mathrm{GHz}$ bandpass filter, which 
also protects the amplifier from saturation. A Low Noise Amplifier (LNA) is used to eliminate the noise figure and adjust gain. A mixer takes the input from the LNA and a local oscillator to output a $1.4 \mathrm{GHz}$ signal to STAR-Light. After the Power Amplifier and Filtering Block (Star-Light back-end), the signal is passed through a Square Law Detector and a Post-Detection Amplifier (PDA). The UFCMR is equipped with a microcontroller that has the responsibility for taking measurements, monitoring the thermal environment, and storing data until a download is requested. A laptop computer is used for running the user interface named FluxMon to communicate with the radiometer through Radiometer Control Language (RadiCL). The radiometer is configured to maintain a particular thermal set point and make periodic measurements of the brightness at both polarizations sequentially and the reference load. The data collected by the radiometer are not calibrated within the instrument, since calibration errors could corrupt an otherwise useful dataset. Figure 5 shows the block diagram of the UFCMR.

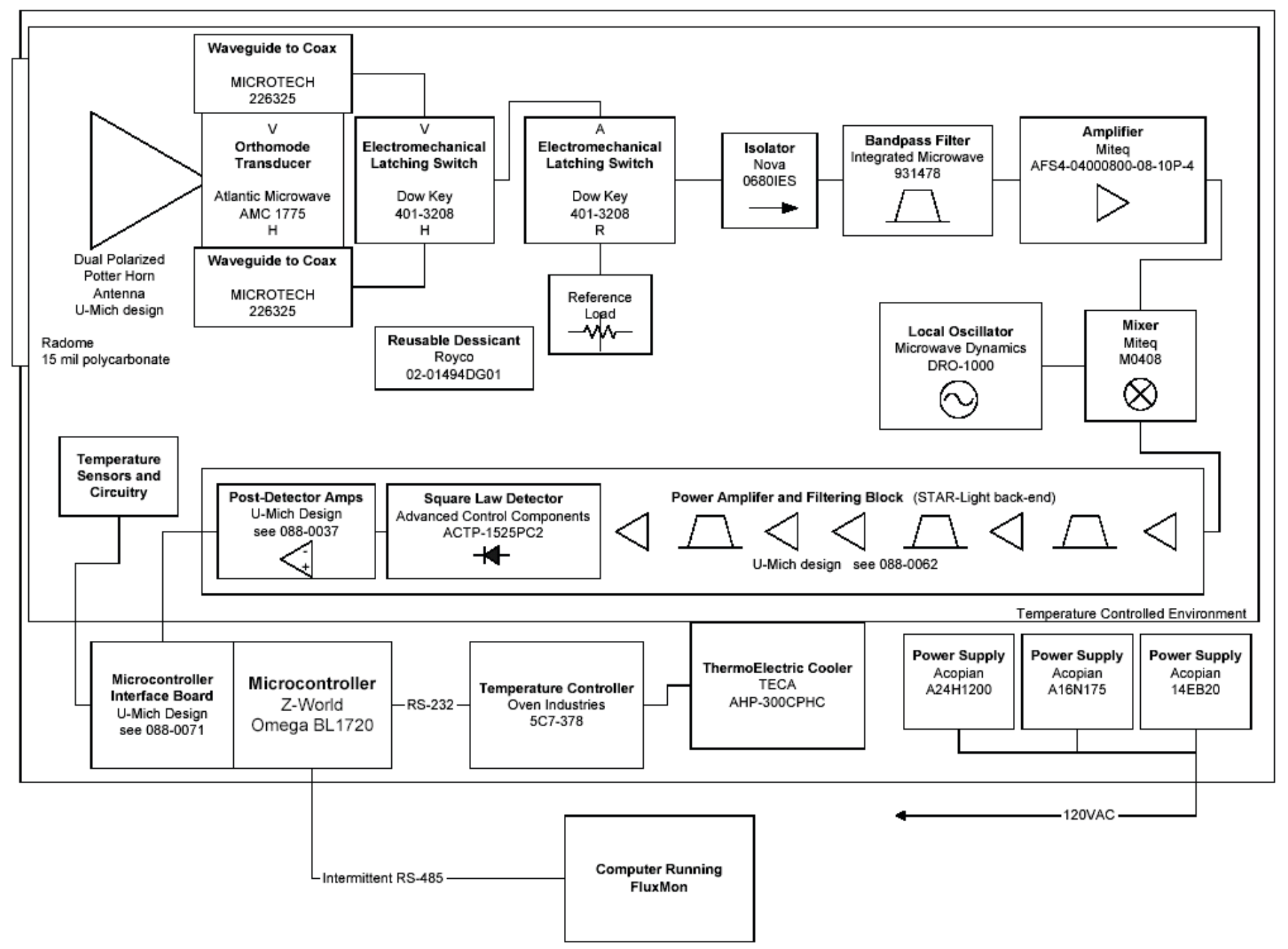

Figure 5. Block diagram of the University of Florida C-band Microwave Radiometer (De Roo 2002).

\subsubsection{University of Florida L-band Microwave Radiometer (UFLMR)}

Microwave brightness temperatures at $1.4 \mathrm{GHz}(\lambda=21.0 \mathrm{~cm})$ were measured every 15 minutes using the University of Florida's L-band Microwave Radiometer system (UFLMR) (Figure 6 (a)). The radiometer system consisted of a single polarization total power radiometer operating at the center frequency of $1.4 \mathrm{GHz}$ housed atop a $9.14 \mathrm{~m}$ tower installed on a 16' trailer bed. The UFLMR was designed and built by the Microwave Geophysics Group at the University of Michigan. It operates at the center frequency at $1.4 \mathrm{GHz}$, which is identical to one of the center frequencies on the space-borne SMOS mission. The UFLMR observed the $4.24 \mathrm{~m}$ x $7.04 \mathrm{~m}$ footprint from a height of $6.12 \mathrm{~m}$. A rotary system was used to rotate the look angle of the UFLMR for both field observations and sky measurements. The brightness temperatures 
were observed at an incidence angle of $50^{\circ}$. The radiometer was calibrated at least every week with a microwave absorber as warm load and measurement of sky as cold load. Figures 6 (b) and 6 (c) show the close-up of the rotary system and the antenna of the UFLMR, respectively. Table 2 lists the specifications of the UFLMR. Figure A-1 shows the horizontally polarized brightness temperatures observed by the UFLMR during MicroWEX-8.

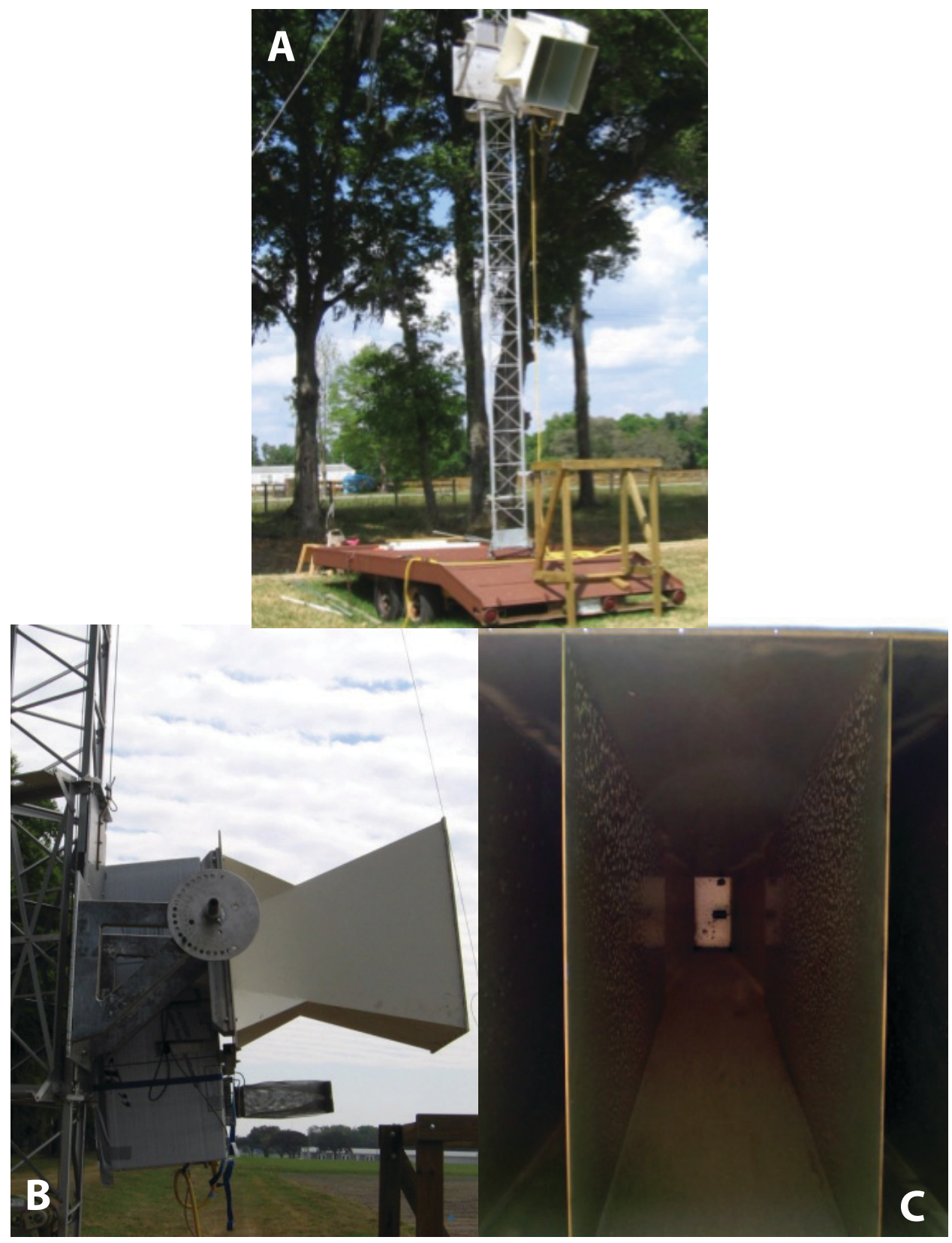

Figure 6 (a) The UFLMR system, (b) the side view of the UFLMR showing the rotary system, and (c) the front view of the UFLMR showing the receiver antenna. 
Table 2. UFLMR specifications

\begin{tabular}{|c|c|c|}
\hline Parameter & Qualifier & Value \\
\hline Frequency & Center & $1.4 \mathrm{GHz}$ \\
\hline Bandwidth & $3 \mathrm{~dB}$ & $20 \mathrm{MHz}$ \\
\hline \multirow[t]{2}{*}{ Beamwidth } & $3 \mathrm{~dB}$ H-pol elevation ${ }^{\mathrm{a}}$ & $22.5^{\circ}$ \\
\hline & $3 \mathrm{~dB}$ H-pol azimuth ${ }^{\mathrm{b}}$ & $20.0^{\circ}$ \\
\hline Polarizations & Single & $\mathrm{H}$ \\
\hline Receiver temp & & $179 \mathrm{~K}$ \\
\hline Noise Figure & From $\mathrm{T}_{\text {rec }}$ & $2.1 \mathrm{~dB}$ \\
\hline RF gain & & $79 \mathrm{~dB}$ \\
\hline $\mathrm{NE} \Delta \mathrm{T}$ & & $0.5 \mathrm{~K}$ \\
\hline
\end{tabular}

(a). sidelobes $<-20 \mathrm{~dB}$, (b). sidelobes $<-30 \mathrm{~dB}$

\subsubsection{THEORY OF OPERATION}

The UFLMR is similar to the UFCMR in many respects, using a thermoelectric cooler (TEC) for thermal control, a similar electromechanical switching mechanism and a Z-World controller; the PDA is the same, and the software is a newer version of RadiCL. The RF block is designed for V-and H-pol switching; however, the UFLMR's septum horn antenna is single-polarized. As a result, only the H-pol signal is guided from antenna to coax to the RF block, and the V-pol input to the RF block is a cold load (ColdFET).

In the RF block, the first switch alternates between "V"- and H-pol, and the second alternates between the reference load and the signal from the first switch. An isolator prevents reflections of the input signal. After the isolator, the signal goes through a bandpass filter and then an LNA, followed by a series of bandpass filters and Power Amplifiers before the Square Law Detector and the PDA. The microcontroller logs voltage and physical temperature measurements. Figure 7 shows the block diagram of the UFLMR. 


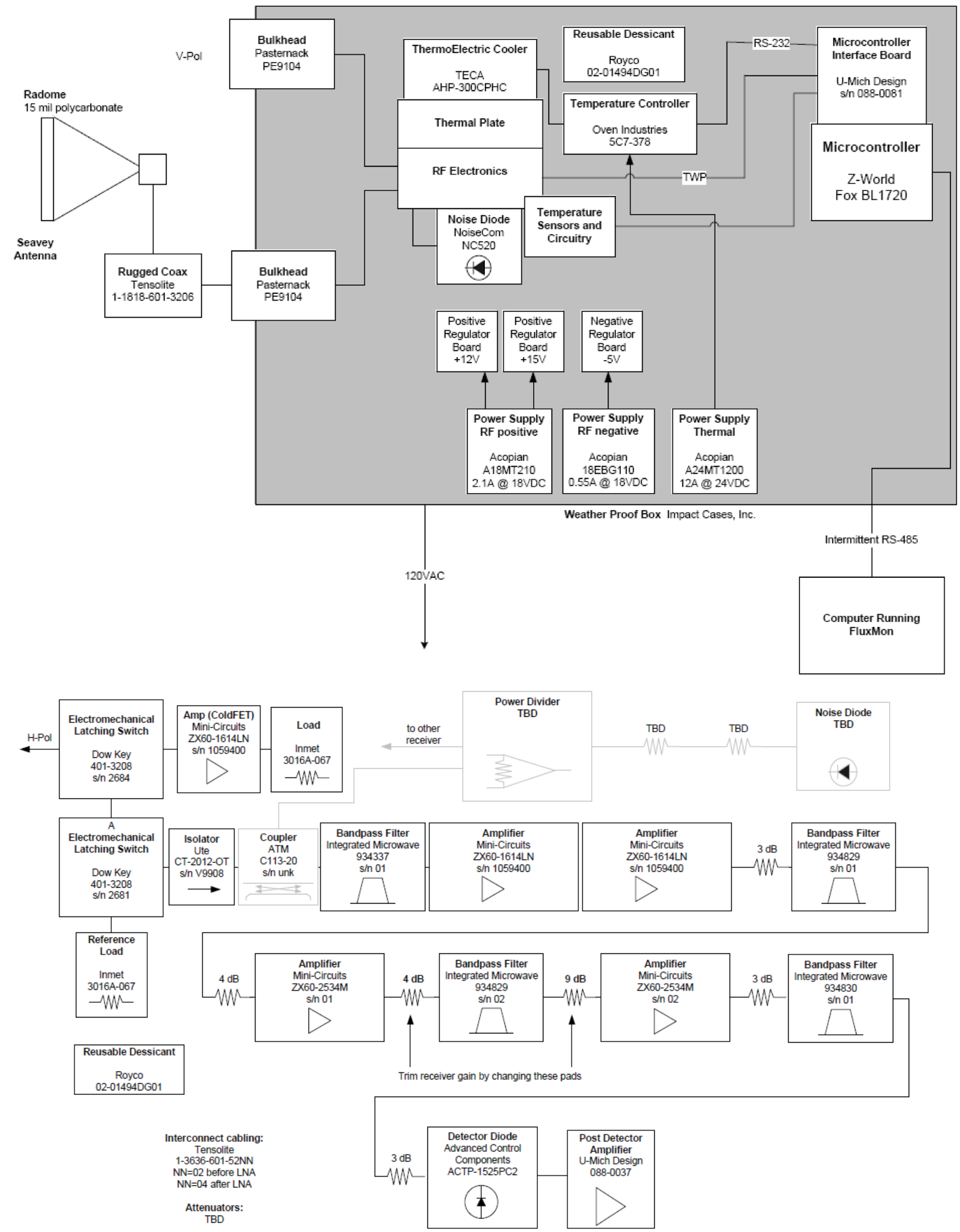

Figure 7. Block diagram of the University of Florida L-band Microwave Radiometer (De Roo 2010).

Field Observations During the Eighth Microwave Water and Energy Balance Experiment (MicroWEX-8): 12 from June 16 through August 24, 2009 


\subsection{University of Michigan Radar System \\ 4.2.1 MICROWAVE OBSERVATORY OF SUBCANOPY AND SUBSURFACE (MOSS)}

The Microwave Observatory of Subcanopy and Subsurface (MOSS) is an L-band tower-mounted radar (Figure 8 (a)) from the University of Michigan that measured the scattering from the cornfield during the Intensive Observation Period (IOP). Figure 8 (b) shows the corner reflector; Figure 8 (c) shows the antennae and top-mounted electronics of the radar system; and Figure $8(\mathrm{~d})$ shows its ground-mounted electronics. This radar system operates at a center frequency of $1.14 \mathrm{GHz}$. It has two independent channels transmitting and receiving pulses of $50 \mathrm{~ns}$ yielding $20 \mathrm{MHz}$ bandwidth. Polarization of each channel is determined by the orientation of the antenna mounted. Because of the very small cross-pol ( $\mathrm{HV}$ and VH) components scattered from the corn, only co-pol (HH and VV) components were measured, though cross-pol channels could also be measured by rotating one of the antennas. The look angle of the antennas was $\sim 40^{\circ}$, which is the same as the look angle used in the SMAP mission. The yagi antenna used has half-power beamwidths (HPBWs) of $\sim 32.4^{\circ}$ in E-plane and $\sim 41.4^{\circ}$ in H-plane, which result in a minimum footprint size of $12 \mathrm{~m} \times 18 \mathrm{~m}(50 \mathrm{~m} \times 25 \mathrm{~m}$ assured during the measurements) at tower height of $12 \mathrm{~m}$. To further focus the antenna beam in the vertical direction, the tower was raised stepwise from $\sim 10 \mathrm{~m}$ to $\sim 11.5 \mathrm{~m}$ during each measurement, and data were taken at more than 20 locations equally spaced with a quarter-wavelength interval. The synthesized beamwidth was $\sim 15.3^{\circ}$. Calibration of the radar system had been done in the anechoic chamber at the University of Michigan before the IOP started. Sky calibration was taken before and after each full set of observations. Internal (the overall system except the antennae) calibration was done with every datatake, and a corner reflector was measured at the end of the IOP for absolute calibration in data post-processing. The cornfield radar measurements were done intensively during the IOP. Observations of field scattering in L-band were obtained for the morning/evening, before/after rain, and before/after harvest. Table 3 summarizes the system specifications.

\subsubsection{Theory of operation}

Figure 9 shows a high-level system block diagram of the radar. This radar system was designed for measurements at multiple frequencies. For this experiment the measurement frequency was specified to be $1.14 \mathrm{GHz}$. An arbitrary waveform generator is used to produce an L-band continuous wave signal for transmit. The transmit signal is routed through a switching network to either the V- (or 1-) or H- (or 2-) channels determined by the antenna orientation as mounted on the tower. The transmit/receive switches (fast switches) switch at $50 \mathrm{~ns}$ yielding $\sim 20 \mathrm{MHz}$ bandwidth is the radar single receive path. The network of switches that determine the transmit and receive paths are used to sequentially select the channel combinations (11 122122 ). The received signal is filtered by the L-band filter in the multi-frequency bank. The received signal is then mixed down to baseband and sampled in-phase and quadrature. The data are then stored on a PC for in-field and post analysis.

The spectral content of a returned signal from a point target is given as:

where G is the two-way complex gain, $W(\omega)$ is the transmit pulse spectrum, $H(\omega)$ is the system frequency response and

$$
E(\omega)=\frac{G \exp [-2 i \omega r / c] W(\omega) H(\omega) \sigma(\omega)}{r^{2}}
$$

$\sigma(\omega)$ is the (potentially frequency dependent) radar cross-section. For nominal field operation, it is necessary to characterize the parameters $G, W(\omega)$, and $H(\omega)$ as a function of time, and for each tower (antenna) position. The three steps to obtain these terms in full are the internal calibration loop; the "passive," or corner reflector calibration; and the "active," or transponder calibration. The internal calibration loop seen in Figure 9 characterizes the entire system except for the antennas. Therefore, it gives $W(\omega), H(\omega)$, and all of G excluding the complex antenna gain. Internal calibration data are collected automatically at the beginning and end of every datatake as detailed subsequently, and the internal calibration drift can be monitored on-screen. Figure A-2(a-d) shows the Radar observations observed during MicroWEX-8, including observations of the corner reflector. 


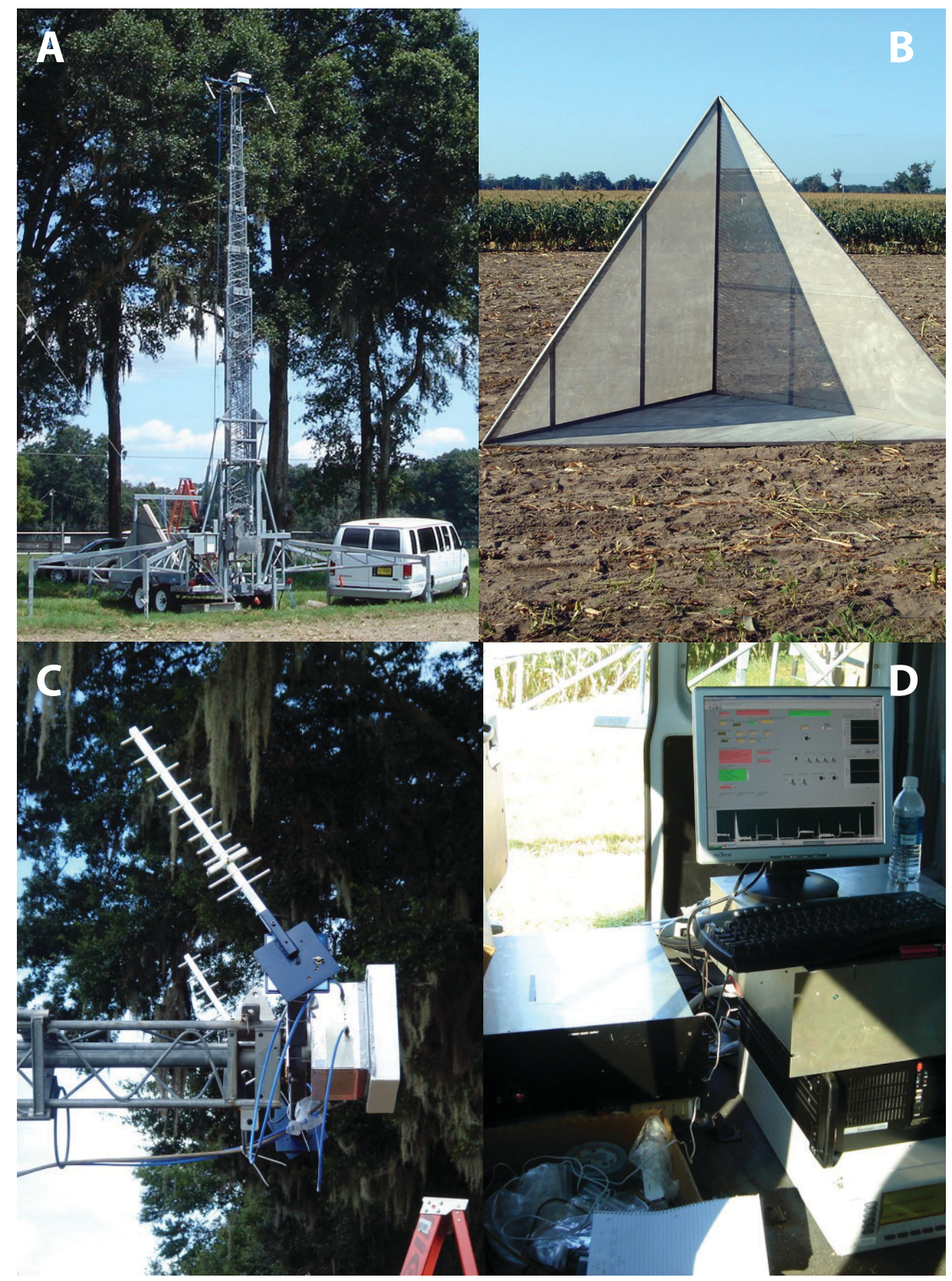

Figure 8 (a) The MOSS system, (b) corner reflector, (c) antennae and tower-mounted electronics, and (d) ground-mounted electronics.

Table 3. MOSS specifications

\begin{tabular}{|l|l|}
\hline Parameter & Value \\
\hline Center frequency & $1.14 \mathrm{GHz}$ \\
\hline Bandwidth & $20 \mathrm{MHz}$ \\
\hline Number of channels & 4 \\
\hline Antenna HPBW & $32.4^{\circ}$ (E-plane) \\
\hline $\begin{array}{l}\text { Synthesized } \\
\text { beamwidth }\end{array}$ & $15.4^{\circ}$ (H-plane) \\
\hline
\end{tabular}




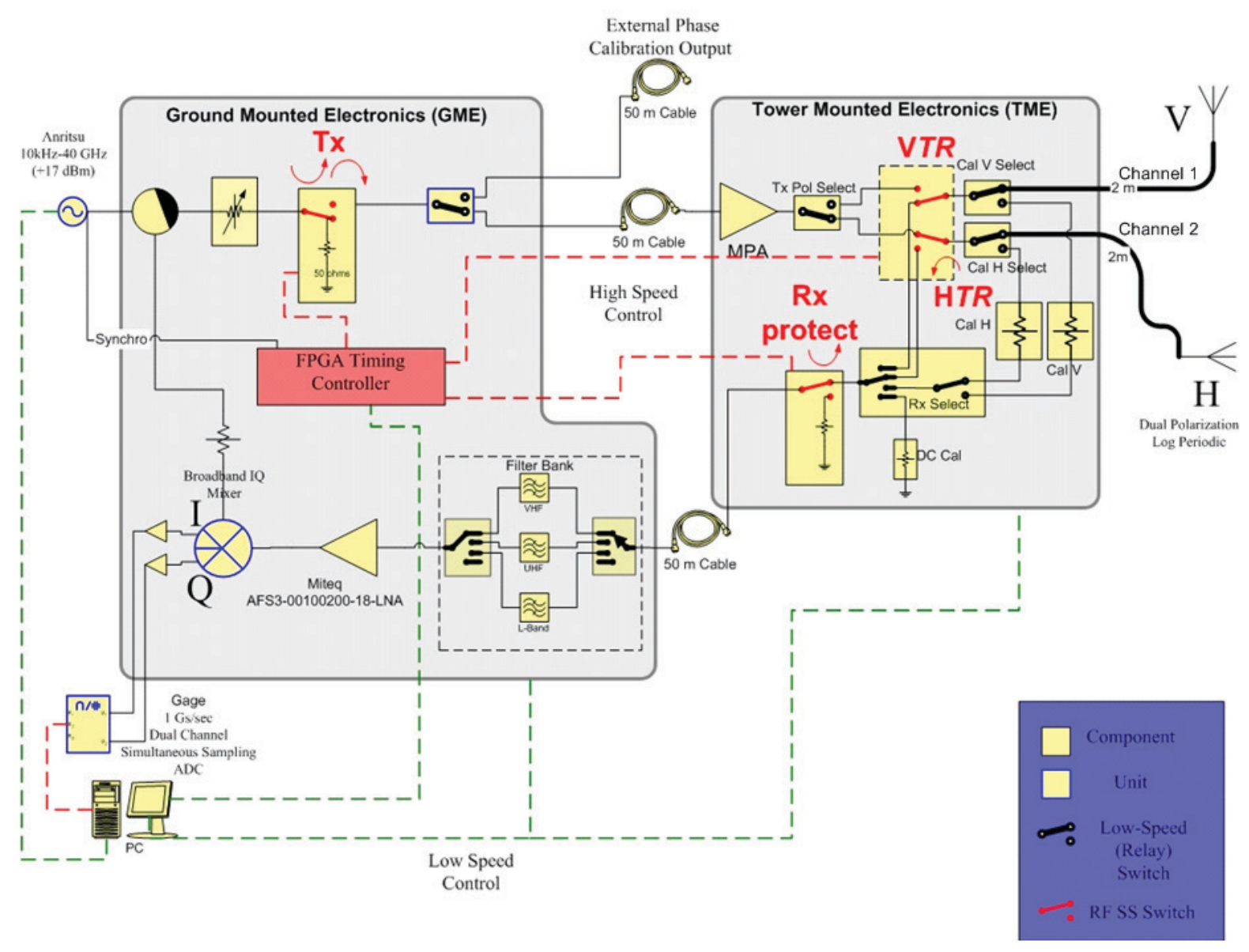

Figure 9. Block diagram of the University of Michigan L-band Radar.

\subsection{University of Florida LiDAR system}

\subsubsection{UNIVERSITY OF FLORIDA MOBILE TERRESTRIAL LASER SCANNING (M-TLS)}

The Mobile Terrestrial Laser Scanning system (M-TLS), also known as the terrestrial LiDAR mapping system, was integrated by the Geosensing Systems Engineering at the University of Florida. The core of the M-TLS is a commercial 2-axis ground-based laser scanner, ILRIS 3D, produced by Optech Inc., which enables to acquire high density laser clouds from terrestrial geometry and records these laser points in a XYZ coordinate system with return pulse intensity. Operating on a mobile telescoping, rotating, and tilting platform up to 6 degrees of freedom are provided for $360^{\circ}$ profile scanning. In addition, a scanner built-in 6 megapixel digital camera is capable of generating not only the laser intensity but also the RGB colored textured from the targets, which enables the M-TLS 3D colored mapping. The laser scanner in this system operates at a wavelength of $1535 \mathrm{~nm}$, with a pulse width less than 10 nanoseconds and energy of less than 10 microjoules. The sample separation can be adjusted down to $0.00115^{\circ}$, and the scanning speed is 2,000 points per second. Figure 10 shows that the M-TLS was equipped on a lift to scan the experimental field.

\subsubsection{Theory of operation}

The ILRIS 3D laser scanner is a very precise instrument composed of two basic subsystems. The first subsystem is a laser ranging device commonly called LiDAR; the second one is an optical and/or mechanical device capable of steering the laser beam in a scanning fashion over the area of interest (Fröhlich and Mettenleiter 2004). The fundamental function of LiDAR is to measure the distance between the scanner and the target by laser pulse flight time. Thus, precisely determining the pulse transmitted and received time is the critical work of the system. Figure 11 shows a block diagram of the ILRIS laser scanner unit.

A central microprocessor controls the subsystems and collects, analyzes, and displays data and scanning information. The laser beam is generated by Nd YAG laser, and then a small amount of photons are diverted through the fiber optic (FO) 
cable to start the time of flight timer. After it is expanded, the laser beam passes through an optical element and then is deflected by the vertical and horizontal scanning mirror to transmit to the target.

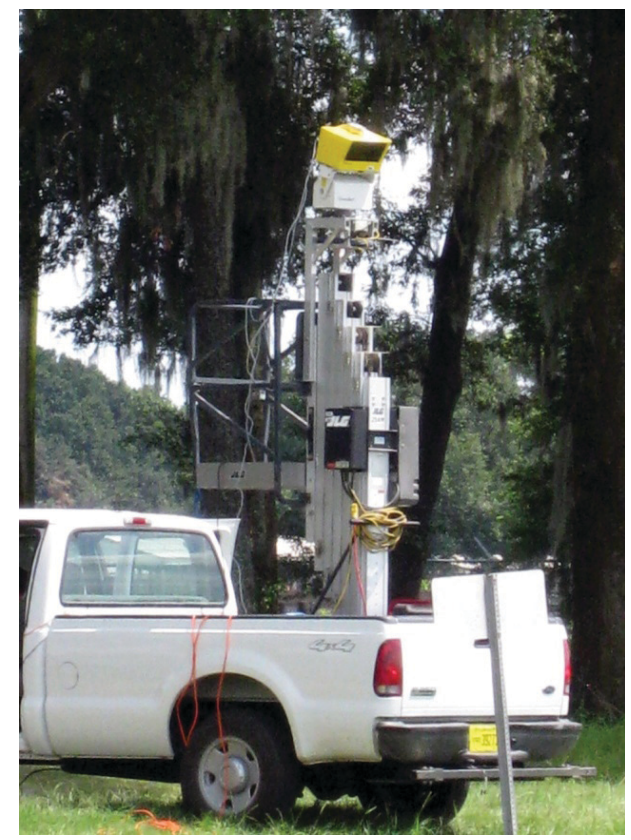

Figure 10. The M-TLS

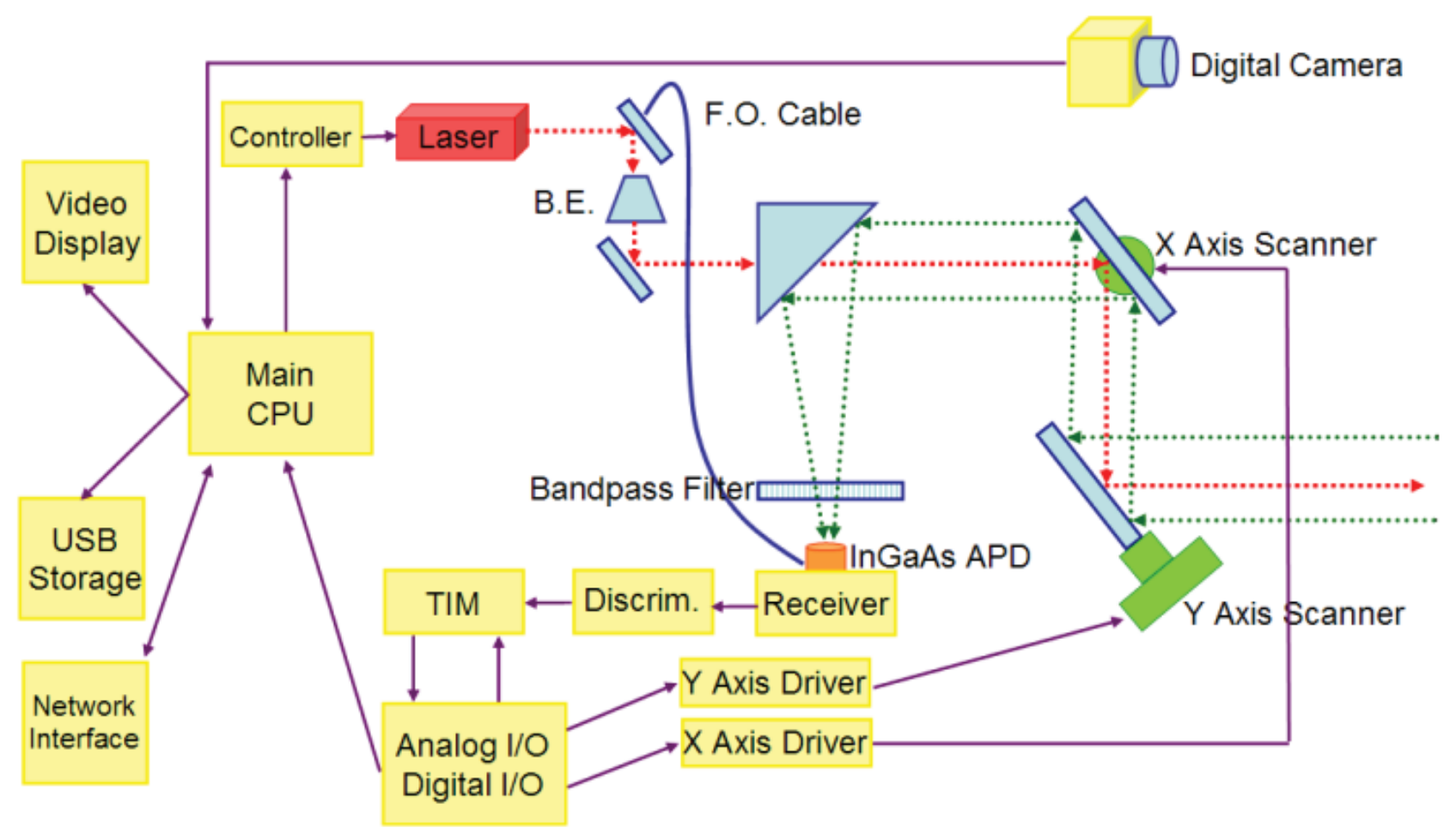

Figure 11. Optech ILRIS 3D laser scanner block diagram.

The laser beam is reflected as a distorted waveform from the targets, so the incoming waveform needs to be tuned to focus on the detector by a fixed parabolic mirror to generate an output voltage. This voltage signal is digitized in an A/D converter and then sent to a Constant Fraction Discriminator (CFD). The CFD is a device to trigger a timing signal at a 
constant fraction of the input amplitude. By computing the timing interval of outgoing and incoming pulse, the 2-way time-of-flight is determined in the Time Interval Meter (TIM). Finally, the computer calculates the range to the target, records it on its internal memory, and commands the emission of a new pulse. This entire process is repeated until the end of the scan mission. Figure A-3 shows the LiDAR observations observed during MicroWEX-8.

\subsection{Eddy Covariance System}

A Campbell Scientific eddy covariance system was located near the center of the field, as shown in Figure 3 . The system included a CSAT3 anemometer and $\mathrm{KH}_{2} 0$ hygrometer as shown in Figure 12. The CSAT3 is a three-dimensional sonic anemometer, which measures wind speed and the speed of sound on three non-orthogonal axes. Orthogonal wind speed and sonic temperature are computed from these measurements. The $\mathrm{KH}_{2} 0$ measures the water vapor in the atmosphere. Its output voltage is proportional to the water vapor density flux. Latent and sensible heat fluxes were measured every 30 minutes. The height of the eddy covariance system was $1.0 \mathrm{~m}$ from the ground, and the orientation of the system was $220^{\circ}$ toward southwest. On DoY 212, the sensor was moved to a height of $1.91 \mathrm{~m}$. On DoY 219, the sensor was moved to a height of $2.41 \mathrm{~m}$. A list of specifications of the CSAT3 is shown in Table 4. Data collected by the eddy covariance system have been processed for coordinate rotation (Kaimal and Finnigan 1994; Wilczak, Oncley, and Stage 2001), WPL (Webb, Pearman, and Leuning 1980), oxygen (van Dijk, Kohsiek, and de Bruin 2003), and sonic temperature corrections (Schotanus, Nieuwstadt, and de Bruin 2003). Figure A-4 shows the processed latent and sensible heat fluxes observed during MicroWEX-8.

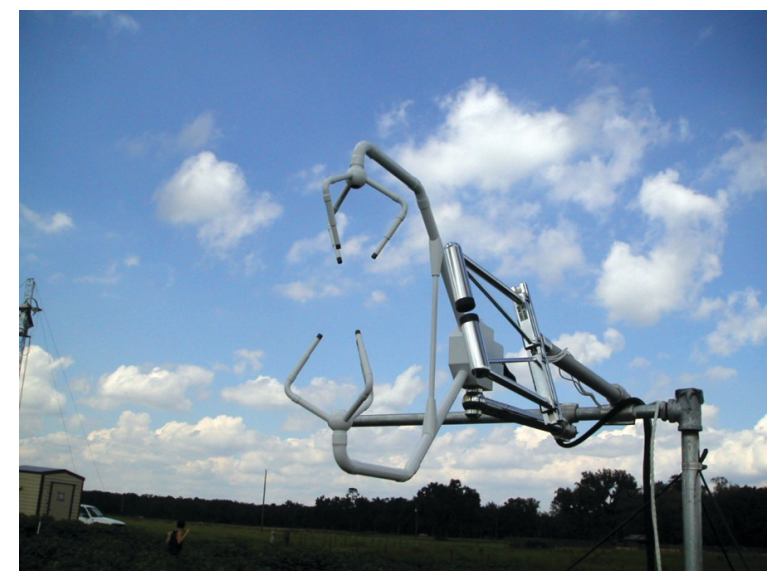

Figure 12. Eddy covariance system.

Table 4. Specifications of the CSAT3 (Campbell Scientific 1998)

\begin{tabular}{|l|l|}
\hline \multicolumn{1}{|c|}{ Description } & \multicolumn{1}{c|}{ Value } \\
\hline Measurement rate & $1-60 \mathrm{~Hz}$ \\
\hline Noise equivalent wind & $\begin{array}{l}1 \mathrm{~mm} / \mathrm{sec} \text { in horizontal wind speed and } \\
0.5 \mathrm{~mm} / \mathrm{sec} \text { in vertical wind speed }\end{array}$ \\
\hline Wind measurement offset & $< \pm 4 \mathrm{~cm} / \mathrm{sec}$ over $-30^{\circ} \mathrm{C}-50^{\circ} \mathrm{C}$ \\
\hline Output signals & Digital SDM or RS- 232 and Analog \\
\hline Digital output signal range & $\pm 65.535 \mathrm{~m} / \mathrm{sec}$ in wind speed and $300-366 \mathrm{~m} / \mathrm{sec}$ in speed of sound \\
\hline Digital output signal resolution & $0.25-2 \mathrm{~mm} / \mathrm{sec}$ in vertical wind speed and $1 \mathrm{~mm} / \mathrm{s} \mathrm{in} \mathrm{speed} \mathrm{of} \mathrm{sound}$ \\
\hline Analog output signal range & $\pm 32.768- \pm 65.536 \mathrm{~m} / \mathrm{sec}$ in wind speed and $300-366 \mathrm{~m} / \mathrm{sec}$ in speed of sound \\
\hline Analog output signal resolution & $\pm 8.192 \mathrm{~mm} / \mathrm{sec}$ in vertical wind speed and $16 \mathrm{~mm} / \mathrm{sec}$ in speed of sound \\
\hline Measurement path length & $10.0 \mathrm{~cm}$ vertical and $5.8 \mathrm{~cm}$ horizontal \\
\hline Transducer path angle from horizontal & $60 \mathrm{degrees}$ \\
\hline Transducer & $0.64 \mathrm{~cm}$ in diameter \\
\hline
\end{tabular}




\begin{tabular}{|l|l|}
\hline \multicolumn{1}{|c|}{ Description } & \\
\hline Transducer mounting arms & $0.84 \mathrm{~cm}$ in diameter \\
\hline Support arms & $1.59 \mathrm{~cm}$ in diameter \\
\hline Dimensions: anemometer head & $47.3 \mathrm{~cm} \times 42.4 \mathrm{~cm}$ \\
\hline Dimensions: electronics box & $26 \mathrm{~cm} \times 16 \mathrm{~cm} \times 9 \mathrm{~cm}$ \\
\hline Dimensions: carry case & $71.1 \mathrm{~cm} \times 58.4 \mathrm{~cm} \times 33 \mathrm{~cm}$ \\
\hline Weight: anemometer head & $1.7 \mathrm{~kg}$ \\
\hline Weight: electronics box & $2.8 \mathrm{~kg}$ \\
\hline Weight: shipping & $16.8 \mathrm{~kg}$ \\
\hline Operating temperature range & $-30^{\circ} \mathrm{C}-50^{\circ} \mathrm{C}$ \\
\hline Power requirement: voltage supply & $10-16 \mathrm{VDC}$ \\
\hline Power requirement: current & $200 \mathrm{~mA}$ at $60 \mathrm{~Hz}$ measurement rate and $100 \mathrm{~mA}$ at $20 \mathrm{~Hz}$ measurement rate \\
\hline
\end{tabular}

\subsection{Net Radiometer}

A Kipp and Zonen CNR-1 four-component net radiometer (Figure 13) was located near the center of the field to measure up- and down-welling short- and long-wave infrared radiation. The sensor consists of two pyranometers (CM-3) and two pyrgeometers (CG-3). The sensor was installed at the height of $2.66 \mathrm{~m}$ above ground and facing south. Table 5 shows the list of specifications of the CNR-1 net radiometer. Figure A-5 shows the down- and up-welling solar (shortwave) and far infrared (longwave) radiation observed during MicroWEX-8.

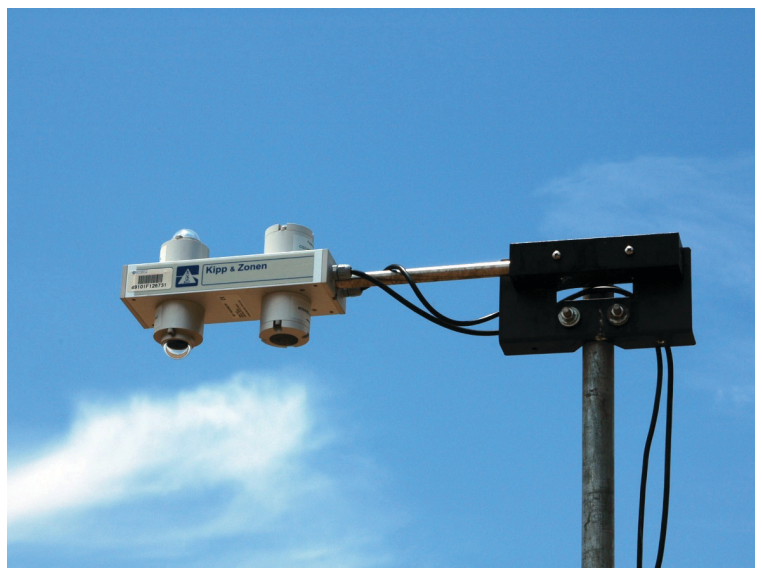

Figure 13. CNR-1 net radiometer.

Table 5. Specifications of the CNR-1 net radiometer (Campbell Scientific 2005a)

\begin{tabular}{|l|l|}
\hline \multicolumn{1}{|c|}{ Description } & \multicolumn{1}{c|}{ Value } \\
\hline Measurement spectrum: CM-3 & $305-2800 \mathrm{~nm}$ \\
\hline Measurement spectrum: CG-3 & $5000-50000 \mathrm{~nm}$ \\
\hline Response time & $18 \mathrm{sec}$ \\
\hline Sensitivity & $10-35 \mu \mathrm{V} /\left(\mathrm{W} / \mathrm{m}^{2}\right)$ \\
\hline Pt-100 sensor temperature measurement & DIN class A \\
\hline Accuracy of the Pt-100 measurement & $\pm 2 \mathrm{~K}$ \\
\hline Heating & Resistor $24 \mathrm{ohms}, 6 \mathrm{VA}$ at 12 volt \\
\hline Maximum error due to heating: CM-3 & $10 \mathrm{~W} / \mathrm{m}^{2}$ \\
\hline
\end{tabular}




\begin{tabular}{|l|l|}
\hline \multicolumn{1}{|c|}{ Description } & \multicolumn{1}{c|}{ Value } \\
\hline Operating temperature & $-40^{\circ}-70^{\circ} \mathrm{C}$ \\
\hline Daily total radiation accuracy & $\pm 10 \%$ \\
\hline Cable length & $10 \mathrm{~m}$ \\
\hline Weight & $4 \mathrm{~kg}$ \\
\hline
\end{tabular}

\subsection{Thermal Infrared Sensor}

An Everest Interscience thermal infrared sensor (4000.3ZL) was installed at the East station to observe skin temperature at nadir. On July 17 (DoY 198), Apogee instruments IRR-PN was installed on the North station, and the Everest was removed due to technical problems. Table 6 shows the list of specifications of the thermal infrared sensor. Figure A- 6 shows the surface thermal infrared temperature observed during MicroWEX-8.

\begin{tabular}{|c|c|c|}
\hline & Description & Value \\
\hline Field of view & & $18^{\circ}$ half angle \\
\hline \multirow[t]{2}{*}{ Output } & Target temp. & $40 \mu \mathrm{V}$ per ${ }^{\circ} \mathrm{C}$ difference from sensor body \\
\hline & Sensor body temp. & $0-2500 \mathrm{mV}$ \\
\hline \multirow[t]{2}{*}{ Accuracy } & $-10-65^{\circ} \mathrm{C}$ & $\begin{array}{l} \pm 0.2^{\circ} \mathrm{C} \text { absolute accuracy } \\
\pm 0.1^{\circ} \mathrm{C} \text { uniformity } \\
\pm 0.05^{\circ} \mathrm{C} \text { repeatability }\end{array}$ \\
\hline & $-40-70^{\circ} \mathrm{C}$ & $\begin{array}{l} \pm 0.5^{\circ} \mathrm{C} \text { absolute accuracy } \\
\pm 0.3^{\circ} \mathrm{C} \text { uniformity } \\
\pm 0.1^{\circ} \mathrm{C} \text { repeatability and uniformity }\end{array}$ \\
\hline Optics & & Germanium lens \\
\hline Wavelength range & & 8-14 $\mu \mathrm{m}$ (corresponds to atmospheric window) \\
\hline Response time & & $<1$ second to changes in target temperature \\
\hline Input power & & $2.5 \mathrm{~V}$ excitation \\
\hline $\begin{array}{l}\text { Operating } \\
\text { environment }\end{array}$ & & $\begin{array}{l}-55-80^{\circ} \mathrm{C} ; 0-100 \% \mathrm{RH} \text { (non-condensing) } \\
\text { Water resistant, designed for continuous outdoor use }\end{array}$ \\
\hline Cable & & 4.5 meters twisted, shielded 4 conductor wire with Santoprene casing \\
\hline Dimensions & & $6 \mathrm{~cm}$ long by $2.3 \mathrm{~cm}$ diameter \\
\hline Mass & & $190 \mathrm{~g}$ \\
\hline
\end{tabular}

\subsection{Air Temperature and Relative Humidity}

Air temperature and relative humidity were measured every 15 minutes at the North station using a Campbell Scientific HMP45C Temperature and Relative Humidity Probe (Campbell Scientific 2006c). Figure A-7 shows the relative humidity and the air temperature observations during MicroWEX-8.

\subsection{Soil Moisture and Temperature Probes}

Eighteen Campbell Scientific time-domain water content reflectometers (CS616) were used to measure soil volumetric water content of 2, 4, 8, 16,32, 64, and $120 \mathrm{~cm}$ every 15 minutes. The observations of soil moisture were duplicated at the depth of $2 \mathrm{~cm}$ and $4 \mathrm{~cm}$. The calibration coefficients for the CS616 probes are listed in Table 7. Figure A-8 shows the soil temperatures observed at the depths of $2 \mathrm{~cm}, 4 \mathrm{~cm}, 8 \mathrm{~cm}, 16 \mathrm{~cm}, 32 \mathrm{~cm}, 64 \mathrm{~cm}$, and $120 \mathrm{~cm}$ at the North station during MicroWEX-8. Figure A-9 shows the soil temperatures observed at the same depths at the East station. Figure A-10 shows 
the volumetric soil moisture content observed at the same depths for the North station. Figure A-11 shows the volumetric soil moisture content observed at the same depths for the East station.

Table 7. The calibration coefficients for the
CS616 probes (Campbell Scientific 2006b)
\begin{tabular}{|c|c|}
\hline Coefficient & Value \\
\hline$C_{0}$ & -0.187 \\
\hline$C_{1}$ & 0.037 \\
\hline$C_{2}$ & 0.335 \\
\hline
\end{tabular}

\subsection{Precipitation}

Precipitation was determined using six tipping-bucket rain gauges, two each in line with the outer edge of each radiometer footprint and one on the side of the field as shown in Figure 3. Figure A-12 shows the observed precipitation at the footprints and at the edge of the field.

\subsection{Soil Heat Flux Plates}

Five Campbell Scientific soil heat flux plates (HFT-3) were used to measure soil heat flux at three different stations. At the North station, one was placed at $5 \mathrm{~cm}$ and one at $8 \mathrm{~cm}$. At the East station, one was placed at $5 \mathrm{~cm}$ and one at $8 \mathrm{~cm}$. Figure A-13 shows the soil heat fluxes observed at depths of $5 \mathrm{~cm}$ and at $8 \mathrm{~cm}$ at the North and East station during MicroWEX-8.

\section{VEGETATION SAMPLING}

Vegetation properties in four spatially distributed sampling locations as shown in Figure 3 were measured weekly during the field experiment, with more frequent sub-samples after ear formation. A "full” vegetation sampling consisted of measurements of height, width, biomass, LAI, geometric description of the plant, and vertical distribution of moisture in the canopy. The sub-samples consisted of height, width, biomass, and ear geometry. The crop density derived from the stand density (51/2-7 plants per $\left.\mathrm{m}^{2}\right)$ and row spacing (30") was measured at the first two samplings (DoY 183 and DoY 191). On Aug 28 (DoY 240), the plant density of the vegetative materials was measured (see section 5.6).

The first vegetation sampling on July 2 (DoY 183) did not include measurements of moisture distribution in the canopy. After the initial vegetation sampling, 6 full vegetation samplings were conducted on July 10 (DoY 191), July 16 (DoY 197), July 24 (DoY 205), July 30 (DoY 211), Aug 7 (DoY 219), and Aug 14 (DoY 226). In the NE and NW sampling location, the measurements did not include moisture distribution on Aug 19 (DoY 231) and geometric description of the leaves on Aug 21 (DoY 233). The sub-samplings were conducted on Aug 11 (DoY 223) at the initiation of ear formation and on DoY 231 and DoY 233 in the SE and SW sampling areas.

\subsection{Height and Width}

Crop height and width were measured by placing a measuring stick at the soil surface adjacent to the stem up to the maximum height of the crop. The maximum canopy width of the plant (parallel or perpendicular to the row) was also measured. Four representative plants were selected to obtain heights and widths inside each vegetation sampling area. Figures A-14 and A-15 show the average maximum crop heights and widths during MicroWEX-8.

\subsection{Wet and Dry Biomass}

Each sampling included one row of corn in the four sampling locations. The sampling length started between two plants and ended at the next midpoint between plants that was greater than or equal to one meter away from the starting point. The plants within this length were cut at the base, separated into leaves, stems, and ears, and weighed immediately. The 
samples were dried in the oven at $60^{\circ} \mathrm{C}-70^{\circ} \mathrm{C}$ for 48 hours and weighed. Figure A-16 shows the wet and dry biomass observed during MicroWEX-8 for the four sampling areas.

\subsection{LAI}

LAI was measured using two methods, (1) LI-COR LAI-2000 and (2) destructive sampling using the following equations. Using the LI-COR LAI-2000, the LAI was measured in the inter-row region with 4 cross-row measurements. Each observation included one measurement above the canopy and 4 beneath the canopy: in the row, $1 / 4$ of the way across the row, $1 / 2$ of the way across the row, and $3 / 4$ of the way across the row as shown in Figure 14. This gave a spatial average during partial cover. Two measurements were taken for each sampling area. They were averaged to provide a single LAI measurement.

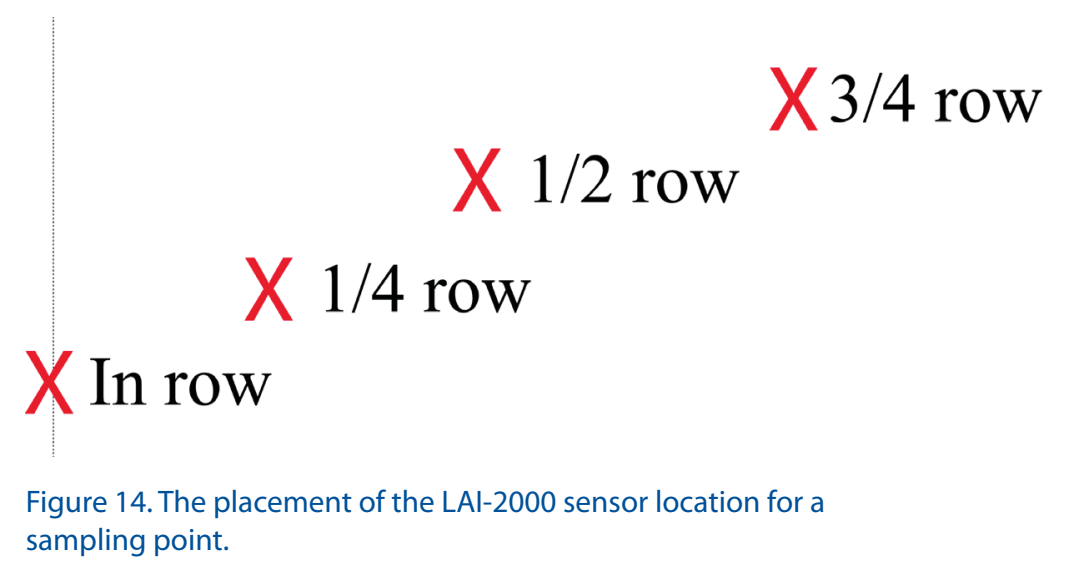

Destructive LAI was measured (except on DoY 183, DoY 191, and DoY 233) by taking four representative plants in the sampling area and separating the leaves. The leaves and the rest of the plant were then dried in an oven at $60^{\circ} \mathrm{C}-70^{\circ} \mathrm{C}$ for 48 hours to measure the dry weight of the leaf and the dry biomass of the sample. The ratio of the leaf dry weight to the dry

Equation 1

$$
L A I=D M \cdot F_{L E A F} \cdot S L A
$$

biomass was used to calculate the fraction of leaf $\left(\mathrm{F}_{\mathrm{LEAF}}\right)$ in Equation 1.

The length and width of each individual leaf of the four sample plants were also measured. Assuming a leaf as an ellipse, the area of the leaves was summed and divided by the dry mass of the leaves to calculate the specific leaf area (SLA) in Equation 1. The total dry biomass (DM) was found using the procedure in 5.2. Equation 1 was then used to determine the destructive LAI (Boote 1994). LAI obtained using both methods are shown in Figure A-17.

\subsection{Vertical Distribution of Moisture in the Canopy}

The wet and dry biomass of discrete vertical layers of individual corn plants was measured. Seven samplings were conducted during MicroWEX-8. Each sampling was conducted by selecting a representative plant at each sampling location. The plants were taken out of the ground with the roots still attached and taken indoors to prevent moisture loss. Each plant sample was carefully laid out on a metal sheet with grid spacing of $2 \mathrm{~cm}$, as shown in Figure 15. The leaves were "arranged" to closely match their natural orientation in the field. The stem was cut every $10 \mathrm{~cm}$ as shown in Figure 16 . The sample in each layer was weighed, both fresh and after drying in the oven at $70^{\circ} \mathrm{C}$ for 48 hours. Figure A-18 shows the wet and dry weights as a function of crop height during MicroWEX-8.

\subsection{Geometric Description}

A geometric description of the plant consisted of the maximum length and width of each leaf of the sample plants, as shown in Figure 17. The stem diameter was measured by projection using a ruler. The stem length was measured from the base of the plant to the base of the last leaf. The ear length was measured while still in the husk from the base of the cob near the stem to the top, and the maximum diameter of the ear was measured by projection with a tape measure. The 
stem length and diameter observed are shown in Figure A-19. Figure A-20 shows the height of each leaf. The leaf length and width are shown in Figures A-21 and A-22. Figure A-23 shows the height of each ear. The ear length and diameter are shown in Figure A-24. The ear and leaf angles were measured from a digital photograph of a single plant taken while still in the field at each sampling area using a reference length such as a meter stick. The angle between the leaf and the stem $\left(\theta_{1}\right)$, the angle of the leaf fold $\left(\theta_{2}\right)$, and the ear angle $\left(\theta_{\mathrm{e}}\right)$ were obtained. Figure 18 shows the location of the ear and leaf angles. See Figures A-25 and A-26 for the value of $\theta_{1}$ and $\theta_{2}$. Figure A-27 shows the ear angle for each ear.
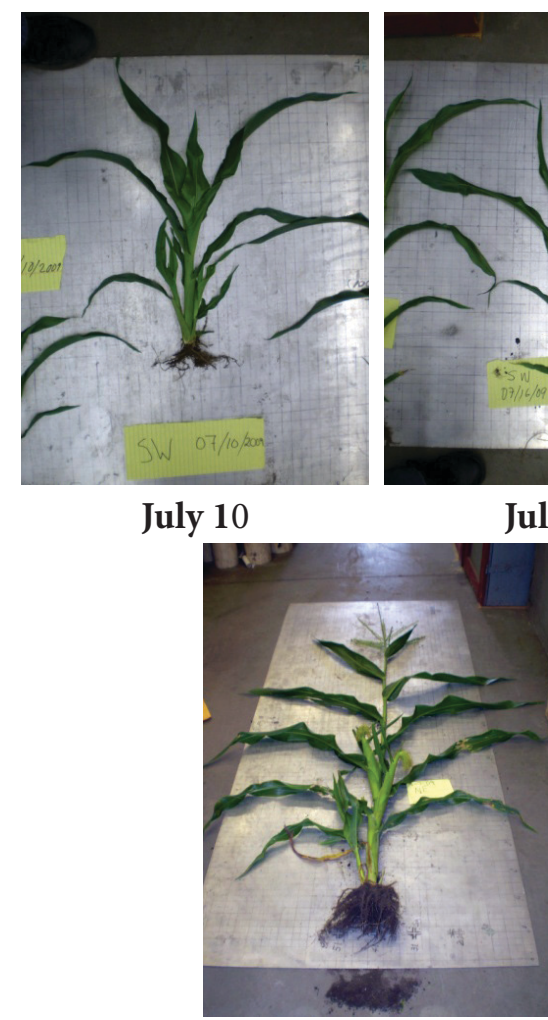

Aug 7

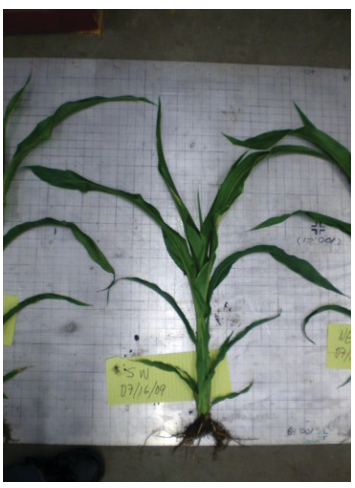

July 16

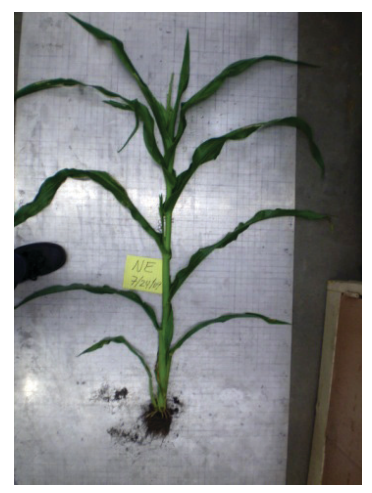

July 24

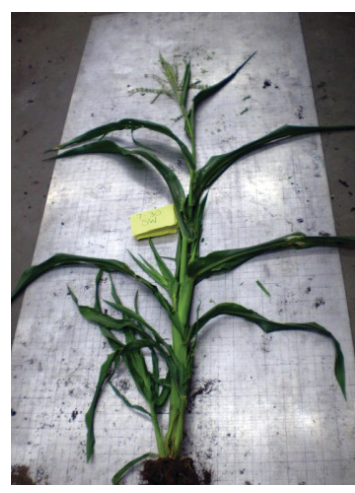

July 30

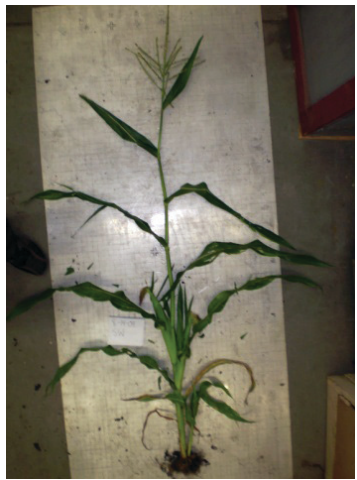

Aug 14

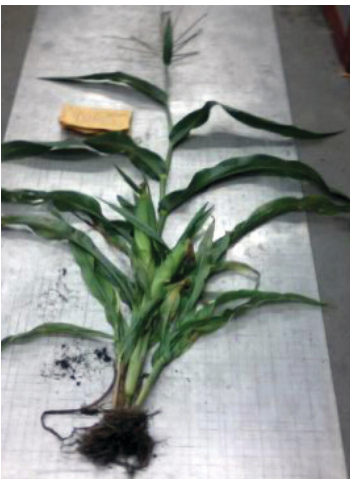

Aug 21

Figure 15. Plant samples for vertical distribution on different dates.

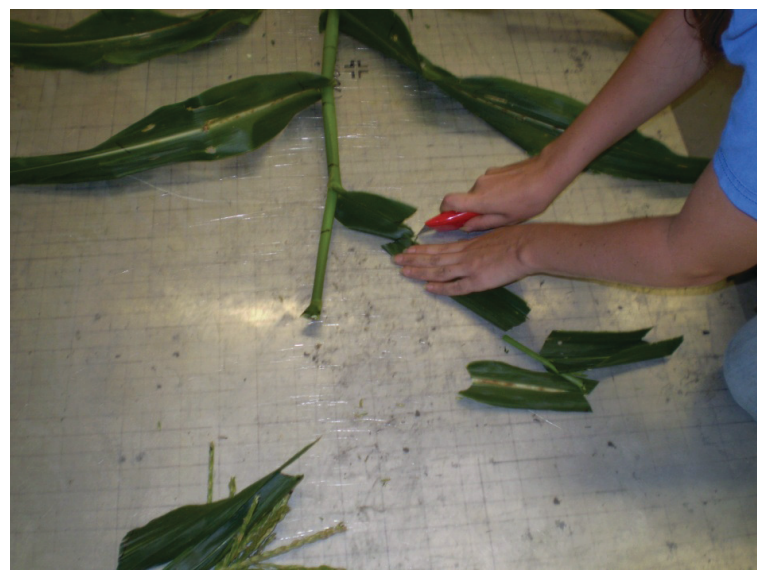

Figure 16. Subdividing plant samples into $10 \mathrm{~cm}$ layers.

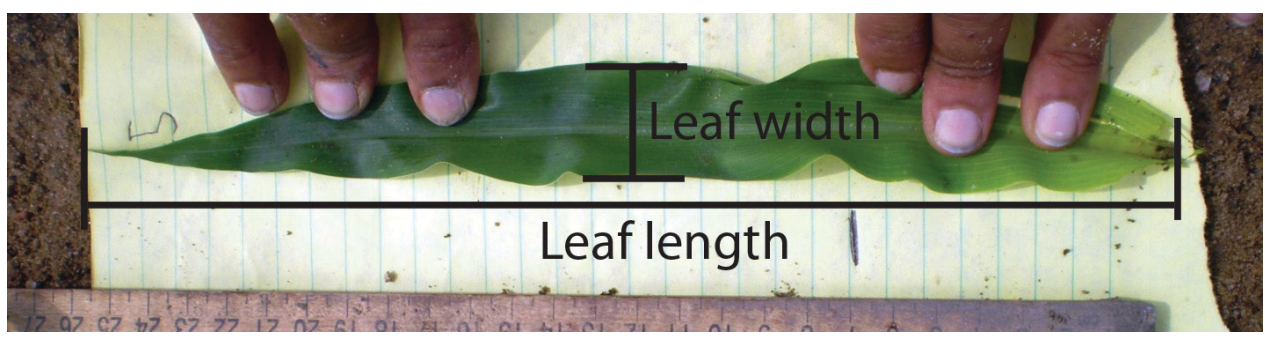

Figure 17. Leaf length and width. 


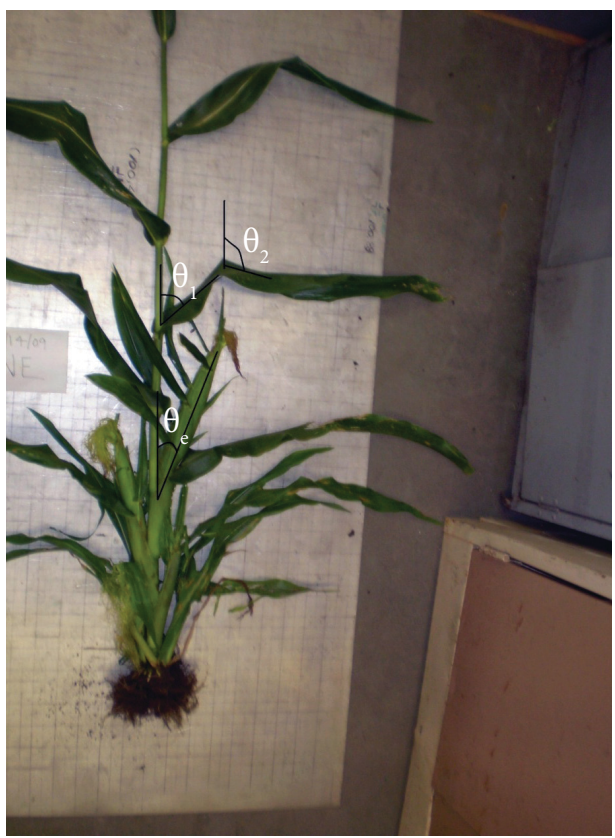

Figure 18. Leaf angles and ear angle location.

\subsection{Density of Vegetation Material (Wet and Dry)}

To determine the density of wet and dry vegetation matter, a representative plant collected on DoY 240 was separated into leaves, stems, and ears and weighed when fresh. The samples were then immersed in water in a graduated cylinder. The volume of the displaced water was observed. The density of each part was calculated as the ratio of the fresh weight to the volume displaced. The samples were then dried in an oven at $70^{\circ} \mathrm{C}$ for 48 hours and weighed, and the process was repeated. The densities of leaf, stem, and ear material were calculated as the ratio of the dry weight to the volume displaced (Table 8).

T able 8. Density measurements on DoY 240

\begin{tabular}{|l|l|l|}
\hline \multirow{2}{*}{} & \multicolumn{2}{|c|}{ Density (g/ml) } \\
\cline { 2 - 3 } & Wet & Dry \\
\hline Ears & 0.858 & 0.754 \\
\hline Leaves & 0.868 & 0.517 \\
\hline Stem & 0.780 & 0.402 \\
\hline
\end{tabular}

\section{WELL SAMPLING}

\subsection{Water level measurement}

The water level measurement was processed by the Levelogger from Solinst Canada Ltd. The Leveloggers were installed at each well and set to automatically record the water level every 30 minutes. The data were downloaded onto a laptop during the well sampling. Figure A-28 shows the water table elevation and depth during MicroWEX-8.

\section{INTENSIVE OBSERVATION PERIOD}

\subsection{Concurrent Observations}

The Intensive Observation Period (IOP) began August 19 (DoY 231) and ended August 22 (DoY 234). An observation also took place on August 24 (DoY 236). During this period, concurrent observations were taken by radiometer, radar, and LiDAR systems. A partial vegetation sampling, which consisted of height, width, biomass, geometric description of the plant, and LAI measurements, was conducted in the northeast and the northwest sampling areas on DoY 231. On DoY 233, sampling, which consisted of height, width, biomass, LAI, geometric description of the ears, and vertical distribution of moisture, was conducted and occurred in the same sampling areas. 
The L-band radiometer was calibrated once a day on DoY 231 through DoY 233. The C-band radiometer was calibrated once on DoY 231.

Two test measurements using the radar were conducted along with a sky calibration on DoY 231. On DoY 232 and 233 , two full measurements were conducted, one in the morning and one in the evening. On DoY 234, full measurements were conducted in the morning to test the effect of a large look angle of the radar.

The LiDAR measurements on DoY 231 consisted of one scan of the L-band radiometer footprint. On DoY 232 and 233 , the LiDAR recorded two scans, one from each corner of the L-band radiometer footprint.

On DoY 236, the radar footprint, which includes the L-band footprint, was cleared manually to obtain bare soil. Observations from the radiometer, LiDAR, and radar were obtained during the morning.

\section{OBSERVATIONS}

The horizontally-polarized brightness temperatures at C-band were found to be more sensitive to soil moisture than vertically-polarized brightness temperatures (Figure A-1). As the vegetation grew, the sensitivity decreased and both polarizations showed similar brightnesses. At lower frequencies (longer wavelengths), such as the L-band, the sensitivity to soil moisture was higher than at the higher frequencies of C-band. The backscattering coefficients at $\mathrm{HH}$ pol were found to be more sensitive to terrain conditions (bare vs. mature corn) than those at VV pol, for the active microwave measurements with the MOSS (Figure A-2 (b)). The LiDAR provided remote sensing estimates of soil roughness, row spacing, and vegetation height (Figure A-3).

The latent heat flux increased with increasing vegetation cover and was the highest at the end of the season when vegetation was the highest. On the other hand, the sensible heat flux was the highest during the beginning of the season, when the vegetation was the lowest (Figure A-4). The average down-welling shortwave radiation average was $231.76 \mathrm{~W} / \mathrm{m}^{2} \mathrm{during}$ the growing season while the average up-welling shortwave radiation was $41.96 \mathrm{~W} / \mathrm{m}^{2}$ (Figure A-5). The average thermal infrared temperature was $300.44 \mathrm{~K}$ (Figure A-6), while the average air temperature was $299.5 \mathrm{~K}$. The average relative humidity was 79.4\% (Figure A-7). The largest amount of precipitation in a fifteen minute interval occurred on DoY 195 (Figure A-12). The water table decreased as the season progressed (Figure A-28).

During the beginning of the season when vegetation was low, at the North station, soil temperature at $2 \mathrm{~cm}$ was the highest while the temperature at $4 \mathrm{~cm}$ was the highest later in the season. Diurnal variations for soil temperatures at 64 and 120 $\mathrm{cm}$ were minimal (Figure A-8). Similarly, at the East station, soil temperatures at $2 \mathrm{~cm}$ provided the highest temperatures (Figure A-9). At the North and the East stations, the furrow was wetter than the row (Figure A-10). The change in soil moisture in the deeper layers was minimal during light rains (Figure A-11). Soil heat flux measurements had large diurnal variations during the beginning of the season, with smaller variations toward the end of the season (Figure A-13).

The maximum height of the canopy was the highest at the NW vegetation sampling area, reaching $1.86 \mathrm{~m}$, while the NE area was the lowest, with a maximum height of $1.65 \mathrm{~m}$ (Figure A-14). The width of the canopy reached a maximum of 102 $m$ on DoY 219 (Figure A-15). The NE and SE areas had a lower green biomass than the other two sections (Figure A-16). The destructive method for LAI provided higher values than the sensor method due to the effects of the sun on the LAI sensor (Figure A-17). At $0.5 \mathrm{~m}$ from the base of the plant, there was an increase in biomass which started on DoY 211 due to ear formation (Figure A-18). The length of the stem reached a maximum on DoY 211 (Figure A-19). There were approximately 10 leaves per main stem by the end of the season (Figure A-20). The maximum leaf length was $0.84 \mathrm{~m}$ (Figure A-21) and the maximum leaf width was $0.094 \mathrm{~m}$ (Figure A-22). Each plant had 1-3 ears, with the highest ear not exceeding $0.47 \mathrm{~m}$ above the base (Figure A-23). The ear located highest on the plant was bigger in both length and diameter than the other ears on the plant (Figure A-24). For the leaf angles, $\theta_{1}$ ranged from $0-90^{\circ}$ from the vertical (Figure A-25) while $\theta_{2}$ ranged from $90-180^{\circ}$ (Figure A-26). The ear angle, $\theta_{\mathrm{e}}$, was larger for the bigger ears (Figure A-27). 


\section{FIELD LOG}

Note: Time is in Eastern Standard Time.

June 16 (DoY 167)

\begin{tabular}{|l|l|}
\hline $08: 00$ & $\begin{array}{l}\text { Land preparation and planting } \\
\text { Insecticide application: Counter } 8.7 \mathrm{lb} / \mathrm{acre}\end{array}$ \\
\hline $08: 45$ & Downloaded data from C-band and L-band radiometers \\
\hline $09: 00$ & C-band radiometer calibration, absorber temperature $=27.29 \sim 27.64^{\circ} \mathrm{C}$ \\
\hline $10: 15$ & L-band radiometer calibration, absorber temperature $=33.74 \sim 34.68^{\circ} \mathrm{C}$ \\
\hline $11: 00$ & Measured angles of L-band rotator \\
\hline
\end{tabular}

June 17 (DoY 168)

09:00 Marked tractor rows

June 18 (DoY 169)

09:00

Marked radiometer and radar footprints, locations of micrometeorological stations and TDRs

\section{June 19 (DoY 170)}

08:30 Downloaded data from C-band and L-band radiometers

09:00 Set up North, East, Eddy, and West stations and the northwest and southwest rain gauges

June 20 (DoY 171)

07:30 Downloaded data from C-band radiometer

07:45 C-band radiometer calibration, absorber temperature $=28.68 \sim 28.86^{\circ} \mathrm{C}$

08:30 Raised C-band radiometer to $\sim 4.57 \mathrm{~m}$ when the wire slipped off the pulley, C-band was left at that height until the pulley could be fixed

08:45

Downloaded data from L-band radiometer

09:00

$\mathrm{L}$-band radiometer calibration, absorber temperature $=32.17 \sim 32.68^{\circ} \mathrm{C}$

09:45

Raised L-band radiometer to $6.12 \mathrm{~m}$

First time radiometers were raised to full height

10:00

Installed TDRs and thermistors of North and East stations

Corn emergence observed

June 22 (DoY 173)

08:30

Installed TDRs and thermistors of West station and installed soil heat fluxes at North, East, and West stations

$22: 15$

Downloaded data from L-band and C-band radiometers

22:30

Replaced pulley on C-band tower-experiment was not halted during work

23:00

Launched new Hobos

23:15

Collected data and launched old Hobos

23:30

Downloaded data from East and North stations

June 23 (DoY 174)

07:00 Herbicide application: Atrazine $1 \mathrm{qt} / \mathrm{acre}$, Prowl 1 pt/acre, Dual $1 \mathrm{pt} / \mathrm{acre}$, Agridex $1 \mathrm{pt} / \mathrm{acre}$

June 24 (DoY 175)

$10: 00$

Completed two sets of five scans in panoramic mode by LiDAR between radiometers 


\section{June 25 (DoY 176)}

\begin{tabular}{|l|l|}
\hline $08: 40$ & Downloaded data from C-band radiometer \\
\hline $08: 45$ & Completed 6 scans in panoramic mode by LiDAR between radiometers \\
\hline $09: 00$ & $\begin{array}{l}\text { C-band radiometer calibration, absorber temperature }=30.23 \sim 30.29^{\circ} \mathrm{C} \\
\text { Set up Everest TIR on East station }\end{array}$ \\
\hline $09: 30$ & Raised C-band radiometer to $6.1 \mathrm{~m}$ \\
\hline $09: 40$ & Downloaded data from L-band radiometer \\
\hline $10: 00$ & L-band radiometer calibration, absorber temperature $=32.71 \sim 33.01^{\circ} \mathrm{C}$ \\
\hline $10: 30$ & Downloaded data from North, East, Eddy, and West stations and sent updated programs to all 4 stations \\
\hline
\end{tabular}

June 26 (DoY 177)

\begin{tabular}{|l|l|}
\hline $08: 30$ & Downloaded data from C-band and L-band radiometers \\
\hline $09: 00$ & Changed desiccants in C-band and L-band radiometers \\
\hline $09: 30$ & \begin{tabular}{l} 
Downloaded data from all 4 stations \\
Completed 6 scans in panoramic mode by LiDAR between radiometers \\
\hline $10: 00$
\end{tabular} \\
\hline $10: 30$ & $\begin{array}{l}\text { Completed } 5 \text { scans in panoramic mode by LiDAR in west end of field } \\
\text { Meshboard measurements }\end{array}$ \\
\hline $11: 00$ & $\begin{array}{l}\text { Completed } 6 \text { scans in panoramic mode by LiDAR in Radar footprint } \\
\text { Meshboard measurements }\end{array}$ \\
\hline
\end{tabular}

\section{June 29 (DoY 180)}

\begin{tabular}{|l|l|}
\hline $08: 45$ & Downloaded data from C-band radiometer \\
\hline $09: 00$ & $\begin{array}{l}\text { C-band radiometer calibration, absorber temperature }=30.14 \sim 30.24^{\circ} \mathrm{C} \\
\text { Noticed that the C-band internal clock was 4 minutes slower than the laptop's clock }\end{array}$ \\
\hline $09: 20$ & Downloaded data from L-band radiometer \\
\hline $09: 40$ & L-band radiometer calibration, absorber temperature $=31.50 \sim 31.89^{\circ} \mathrm{C}$ \\
\hline
\end{tabular}

July 1 (DoY 182)

09:00 $\quad$ Replaced wire nuts with power strips on the North station

July 2 (DoY 183)

\begin{tabular}{|l|l|}
\hline $08: 25$ & Vegetation sampling \#1 \\
\hline $08: 45$ & $\begin{array}{l}\text { Downloaded data from C-band and L-band radiometers } \\
\text { Downloaded data from Hobos } \\
\text { Tightened wire nuts on East and West stations }\end{array}$ \\
\hline $09: 15$ & Removed thermistor J015 at $16 \mathrm{~cm}$ at East station due to malfunction \\
\hline $12: 15$ & Downloaded level logger data \\
\hline $17: 00$ & Fertilizer application: $(19-5-19), 725 \mathrm{lb} /$ acre \\
\hline
\end{tabular}

July 6 (DoY 187)

\begin{tabular}{|l|l|}
\hline $08: 30$ & Downloaded data from C-band radiometer \\
\hline $08: 45$ & C-band radiometer calibration, absorber temperature $=29.93 \sim 30.05^{\circ} \mathrm{C}$ \\
\hline $09: 15$ & Downloaded data from L-band radiometer \\
\hline
\end{tabular}

Field Observations During the Eighth Microwave Water and Energy Balance Experiment (MicroWEX-8): 26 from June 16 through August 24, 2009 
09:30

10:00
L-band radiometer calibration, absorber temperature $=32.50 \sim 32.03^{\circ} \mathrm{C}$

Found wasp nest in L-band antenna and cleaned it out

Observed bare spots in the field where the corn was not growing well

One such spot covered the C-band radiometer footprint
July 8 (DoY 189)

08:30

09:00

09:30

\section{July 10 (DoY 191)}

07:30

08:15

08:30

09:00

09:20

10:00

10:30

11:00

11:30

July 13 (DoY 194)

\section{7:00}

$07: 15$

07:30

08:00

08:15

09:00

09:30

\section{July 14 (DoY 195)}

13:30

$14: 00$

$14: 30$
Downloaded data from North, East, and Eddy stations

Downloaded Hobo data from 4 interior rain gauges

Prepared for moving the C-band tower further west to look at corn growth similar to L-band radiometer footprint

Vegetation sampling \#2, included LAI and vertical distribution of moisture

Downloaded data from C-band radiometer

C-band radiometer calibration, absorber temperature $=27.84 \sim 28.11^{\circ} \mathrm{C}$

Changed desiccants in C-band radiometer

Downloaded data from L-band radiometer

L-band radiometer calibration, absorber temperature $=30.11 \sim 30.68^{\circ} \mathrm{C}$

Changed desiccants in L-band radiometer

Prepared for moving the C-band tower

Herbicide application: Ignite $34 \mathrm{fl} \mathrm{oz/acre}$

Downloaded data from C-band and L-band radiometers

C-band radiometer calibration, absorber temperature $=26.11 \sim 26.42^{\circ} \mathrm{C}$

Observed that the calibration load was saturated

Unplugged C-band radiometer in order to move its tower

L-band radiometer calibration, absorber temperature $=28.31 \sim 28.55^{\circ} \mathrm{C}$

Unplugged L-band radiometer in order to move C-band tower

Re-plugged L-band radiometer into alternate power source and began to run

Moved trailer holding C-band tower and shed so that C-band will be observing an area of full growth similar to

L-band footprint

Replaced guy-wires with encased braided steel

Replaced winch cable of the C-band tower

Downloaded station data

Downloaded data from Hobos

Cleaned hygrometer

Brought C-band radiometer back to the field from the lab after adjusting its offset

Leveled C-band tower

Cut down winch cable and rewound it

Mounted C-band radiometer on tower and aimed it at the sky to determine its performance

$\mathrm{Vcal}=2.0 \mathrm{~V}, \mathrm{~V}_{\mathrm{H}} \mathrm{pol}=0.68 \mathrm{~V}$

Began raising the $C$-band when the pulley snapped

Left C-band on the 4 th rung of the tower at an incidence angle of $65^{\circ}$ 


\begin{tabular}{|l|l|}
\hline $08: 30$ & Downloaded data from L-band radiometer \\
\hline $08: 45$ & Replaced pulley on C-band tower \\
\hline $09: 00$ & Downloaded data from C-band radiometer \\
\hline $09: 30$ & C-band radiometer calibration, absorber temperature $=32.45 \sim 32.67^{\circ} \mathrm{C}$ \\
\hline
\end{tabular}

July 16 (DoY 197)

\begin{tabular}{l|l} 
07:30 & Vegetation sampling \#3, included LAI (both with sensor and destructive) and vertical distribution of moisture
\end{tabular}

14:00

Fertilizer application: $19-5-19$ with minors at $725 \mathrm{lb} / \mathrm{A}$

July 17 (DoY 198)

08:30

Installed Apogee TIR on North station at $1.83 \mathrm{~m}$ high

July 20 (DoY 201)

\begin{tabular}{|l|l|}
\hline $08: 30$ & Downloaded data from C-band radiometer \\
\hline $08: 45$ & C-band radiometer calibration, absorber temperature $=26.73 \sim 27.36^{\circ} \mathrm{C}$ \\
\hline $09: 30$ & Downloaded data from L-band radiometer \\
\hline $09: 45$ & L-band radiometer calibration, absorber temperature $=28.12 \sim 28.49^{\circ} \mathrm{C}$ \\
\hline $10: 00$ & $\begin{array}{l}\text { Connected J009 TDR and thermistor at } 120 \mathrm{~cm} \text { to North station } \\
\text { Updated program on North station to include new TDR }\end{array}$ \\
\hline & \begin{tabular}{l} 
Tasseling observed \\
\hline
\end{tabular} \\
\hline
\end{tabular}

July 21 (DoY 202)

\begin{tabular}{|l|l|}
\hline $08: 30$ & Downloaded data from stations \\
\hline $09: 00$ & Downloaded data from Hobos from both interior and exterior rain gauges \\
\hline $\mathbf{0 9 : 3 0}$ & Fixed TDRs on North station \\
\hline $\mathbf{1 0 : 0 0}$ & Cleaned humidity sensor \\
\hline & Worms in corn observed \\
\hline $14: 00$ & $\begin{array}{l}\text { Insecticide application: Lannate } 1.5 \text { pt/acre, Warrior } 3.84 \text { fl oz/acre } \\
\text { Fungicide application: Tilt } 4 \text { fl oz/acre, Quadris } 15.5 \text { fl oz/acre }\end{array}$ \\
\hline
\end{tabular}

July 22 (DoY 203)

$50 \%$ of field with tassels observed

July 23 (DoY 204)

\begin{tabular}{l|l} 
09:00 Downloaded data from C-band and L-band radiometers \\
\hline
\end{tabular}

July 24 (DoY 205)

07:15 Vegetation sampling \#4, included LAl and vertical distribution of moisture

75 100\% of field with tassels observed

July 27 (DoY 208)

$08: 15$

Downloaded data from L-band radiometer

$08: 30$

L-band radiometer calibration, absorber temperature $=27.63 \sim 28.40^{\circ} \mathrm{C}$

Downloaded station data 


\begin{tabular}{|l|l|}
\hline $09: 00$ & Measured L-band offset, $\mathrm{V}_{\text {off }}=-5.89 \mathrm{~V}$ \\
\hline $09: 30$ & Changed desiccants in L-band radiometer \\
\hline $10: 00$ & Downloaded data from C-band radiometer \\
\hline $10: 15$ & C-band radiometer calibration, absorber temperature $=30.77 \sim 31.13^{\circ} \mathrm{C}$ \\
\hline $11: 00$ & Changed desiccants in C-band radiometer \\
\hline
\end{tabular}

July 28 (DoY 209)

\begin{tabular}{|l|l|}
\hline $08: 30$ & Downloaded data from C-band radiometer \\
\hline $09: 00$ & C-band radiometer calibration, absorber temperature $=30.37 \sim 31.39^{\circ} \mathrm{C}$ \\
\hline $09: 30$ & Downloaded data from L-band radiometer \\
\hline $10: 00$ & L-band radiometer calibration, absorber temperature $=31.38 \sim 31.90^{\circ} \mathrm{C}$ \\
\hline
\end{tabular}

July 29 (DoY 210)

Ear formation began

\section{July 30 (DoY 211)}

$07: 30$

July 31 (DoY 212)

08:30

August 3 (DoY 215)

\begin{tabular}{|c|c|}
\hline 08:30 & Downloaded data from C-band radiometer \\
\hline $08: 45$ & C-band radiometer calibration, absorber temperature $=32.18 \sim 32.89^{\circ} \mathrm{C}$ \\
\hline 09:30 & Downloaded data from L-band radiometer \\
\hline 09:45 & $\begin{array}{l}\text { L-band radiometer calibration, absorber temperature }=32.27 \sim 32.44^{\circ} \mathrm{C} \\
\text { Found wasp nest in central portion of L-band antenna and removed it }\end{array}$ \\
\hline 10:00 & Performed troubleshooting on North station and fixed relative humidity and air sensors \\
\hline $10: 30$ & Added J017 TDR and thermistor at $64 \mathrm{~cm}$ and J018 TDR and thermistor at $120 \mathrm{~cm}$ to East station \\
\hline $10: 45$ & Downloaded data from North and East stations \\
\hline
\end{tabular}

August 4 (DoY 216)

07:00 Insecticide application: Lannate $1.5 \mathrm{pt} / \mathrm{acre}$, Intrepid $8 \mathrm{fl}$ oz/acre

August 6 (DoY 218)

15:00

Insecticide application: Radiant 8 fl oz/acre

August 7 (DoY 219)

07:00

08:30

09:00

09:30
Vegetation sampling \#5, included LAI (both with sensor and destructive) and vertical distribution of moisture $10 \%$ of field with corn silk observed, mainly in Northwest and Southwest sampling areas

Downloaded data from C-band and L-band radiometers

Downloaded data from micrometeorological stations

Raised eddy covariance system to $1.91 \mathrm{~m}$ 


\begin{tabular}{|l|l|}
\hline $10: 00$ & Attempted to change CNR pole \\
\hline $10: 15$ & Placed thermal strips on thermistors J010 (at $2 \mathrm{~cm}), \mathrm{J} 011(\mathrm{at} 2 \mathrm{~cm}), \mathrm{J} 012$ (at $4 \mathrm{~cm})$, and J013 (at $4 \mathrm{~cm})$ of East station \\
\hline $10: 30$ & Downloaded data from C-band and L-band radiometers \\
\hline $11: 00$ & $\begin{array}{l}\text { Downloaded data from all stations except West } \\
\text { Downloaded data from Hobos } \\
\text { Found pollen in mouth of rain gauge sensors and cleaned it out }\end{array}$ \\
\hline
\end{tabular}

\section{August 10 (DoY 222)}

\begin{tabular}{|c|c|}
\hline 08:00 & Downloaded data from C-band radiometer \\
\hline 08:15 & C-band radiometer calibration, absorber temperature $=28.47 \sim 28.70^{\circ} \mathrm{C}$ \\
\hline 08:45 & Changed desiccants in C-band radiometer \\
\hline 09:00 & $\begin{array}{l}\text { Downloaded data from L-band radiometer } \\
\text { Antenna thermistor found physically disconnected from the antenna, it was reconnected with duct tape }\end{array}$ \\
\hline 09:30 & L-band radiometer calibration, absorber temperature $=31.89 \sim 32.18^{\circ} \mathrm{C}$ \\
\hline 10:00 & $\begin{array}{l}\text { Changed desiccants in L-band radiometer } \\
\text { Observed that coldFET voltage was saturated at } 0.0 \mathrm{~V}\end{array}$ \\
\hline $15: 00$ & Insecticide was applied, Baythroid $2.84 \mathrm{fl}$ oz/acre, Carbaryl 4L 1 qt/acre \\
\hline
\end{tabular}

\section{August 11 (DoY 223)}

\begin{tabular}{|l|l|}
\hline $07: 00$ & Vegetation sampling \#7, geometric description of ears only \\
\hline $08: 00$ & Downloaded data from C-band radiometer \\
\hline $08: 15$ & C-band radiometer calibration, absorber temperature $=30.17 \sim 30.23^{\circ} \mathrm{C}$ \\
\hline $09: 00$ & Downloaded data from L-band radiometer \\
\hline $09: 15$ & L-band radiometer calibration, absorber temperature $=32.71 \sim 33.01^{\circ} \mathrm{C}$ \\
\hline $10: 00$ & Increased offset voltage of L-band to $-305 \mathrm{mV}$ to correct the saturation of the coldFET voltage \\
\hline $10: 30$ & Daniel replaced a code \\
\hline
\end{tabular}

August 12 (DoY 224)

\begin{tabular}{|l|l|}
\hline $07: 45$ & Downloaded data from L-band radiometer \\
\hline $08: 00$ & $\begin{array}{l}\text { Observed that coldFET voltage was still saturated } \\
\text { Adjusted voltage offset again }\end{array}$ \\
\hline $08: 30$ & Raised radiometer to 5 th rung $(1.5 \mathrm{~m})$ to take test data \\
\hline $09: 00$ & $\begin{array}{l}\text { Observed that coldFET data steadily decreased } \\
\text { Raised voltage offset and left until more could be determined }\end{array}$ \\
\hline
\end{tabular}

\section{August 14 (DoY 226)}

07:00

Vegetation sampling \#8, included LAI (both with sensor and destructive) and vertical distribution of moisture

08:00

Downloaded data from C-band and L-band radiometers

Observed coldFET voltage in L-band was no longer saturated since 08:45 on DoY 224

09:00

L-band radiometer calibration, absorber temperature $=28.01 \sim 28.63^{\circ} \mathrm{C}$

$14: 30$

Fungicide application: Headline $9 \mathrm{fl}$ oz/acre, Folicur $6 \mathrm{fl}$ oz/acre

Insecticide application: Karate $1.92 \mathrm{fl} \mathrm{oz/acre,} \mathrm{Intrepid} 8 \mathrm{fl} \mathrm{oz/acre}$

\section{August 17 (DoY 229)}

08:00

Downloaded data from C-band and L-band radiometers 
09:00

$14: 30$

\section{August 18 (DoY 230)}

08:30

09:00

09:30

$14: 30$

\section{August 19 (DoY 231)}

Vegetation Management

06:00

$14: 30$

Vegetation sampling \#9, included LAI (both sensor and destructive) for Northeast and Northwest sampling areas Insecticide application: Baythroid $2.84 \mathrm{fl}$ oz/acre

\section{Radiometer}

08:00

08:15

$08: 30$

09:00

Radar

\begin{tabular}{|l|l|}
\hline $08: 00$ & Radar Sky calibration \\
\hline $08: 50$ & Radar field test measurement $(\mathrm{HH})$ \\
\hline $12: 00$ & Test measurement ends \\
\hline $17: 30$ & Evening full test measurement starts $(\mathrm{HH}, \mathrm{HV}, \mathrm{VH}$, and VV) \\
\hline $21: 00$ & Evening full test measurement ends \\
\hline
\end{tabular}

LiDAR

08:30

Single scan

August 20 (DoY 232)

Vegetation Management

$14: 30$

Insecticide application: Intrepid 8 fl oz/acre, Asana 9.6 fl oz/acre

\section{Radiometer}

08:00

Downloaded data from L-band radiometer

Antenna thermistor found physically disconnected from antenna, reapplied with duct tape

$08: 30$

L-band radiometer calibration, absorber temperature $=27.21 \sim 27.49^{\circ} \mathrm{C}$

$14: 00$

Returned to the field to check radiometers after power failure Observed both running smoothly

$14: 15$

Downloaded data from C-band and L-band radiometers

Radar

09:00

Morning measurement starts, both antennas are vertical oriented (VV)

Temperature at the end of the van is $103^{\circ} \mathrm{F}$

Temperature at the middle of the van is $95^{\circ} \mathrm{F}$

Humidity: $68 \%$

10:00

Power down 


\begin{tabular}{|c|c|}
\hline $11: 00$ & $\begin{array}{l}\text { Power resumed } \\
\text { Measurement of crosspol ( } \mathrm{HV} \text { and } \mathrm{VH}) \\
\text { Temperature at the end of the van is } 110^{\circ} \mathrm{F} \\
\text { Temperature at the middle of the van is } 100^{\circ} \mathrm{F} \\
\text { Humidity: } 37 \%\end{array}$ \\
\hline $12: 00$ & $\begin{array}{l}\text { Measurement with both antennas are horizontal oriented }(\mathrm{HH}) \\
\text { Temperature at the end of the van is } 116^{\circ} \mathrm{F}-118^{\circ} \mathrm{F} \\
\text { Temperature at the middle of the van is } 106^{\circ} \mathrm{F} \\
\text { Humidity: } 30 \%\end{array}$ \\
\hline $13: 00$ & Sky calibration \\
\hline $13: 20$ & Morning measurement ends \\
\hline $17: 30$ & Raining in the field \\
\hline $18: 50$ & $\begin{array}{l}\text { Evening measurement starts, measurement of } \mathrm{HH} \\
\text { Temperature at the end of the van is } 93.6^{\circ} \mathrm{F}-106.7^{\circ} \mathrm{F} \\
\text { Temperature at the middle of the van is } 84.4^{\circ} \mathrm{F} \\
\text { Humidity: } 61 \%-70 \%\end{array}$ \\
\hline 19:35 & Sky calibration \\
\hline 20:00 & $\begin{array}{l}\text { Measurement of } \mathrm{VV} \\
\text { Temperature at the end of the van is } 103.8^{\circ} \mathrm{F}-107^{\circ} \mathrm{F} \\
\text { Temperature at the middle of the van is } 85.7^{\circ} \mathrm{F} \\
\text { Humidity: } 68 \%-70 \%\end{array}$ \\
\hline 20:50 & $\begin{array}{l}\text { Sky calibration } \\
\text { Temperature at the end of the van is } 105.4^{\circ} \mathrm{F} \\
\text { Temperature at the middle of the van is } 83.1^{\circ} \mathrm{F} \\
\text { Humidity: } 70 \%\end{array}$ \\
\hline 21:00 & Evening measurement ends \\
\hline \multicolumn{2}{|l|}{ LiDAR } \\
\hline 09:30 & Completed two sets of single scan \\
\hline \multicolumn{2}{|c|}{$\begin{array}{l}\text { August } 21 \text { (DoY 233) } \\
\text { Vegetation Management }\end{array}$} \\
\hline 07:00 & $\begin{array}{l}\text { Vegetation sampling \#21, included LAI (both sensor and destructive) and vertical distribution of moisture for } \\
\text { Northeast and Northwest sampling areas }\end{array}$ \\
\hline \multicolumn{2}{|c|}{ Radiometer } \\
\hline 08:00 & Downloaded data from L-band radiometer \\
\hline 08:30 & L-band radiometer calibration, absorber temperature $=28.07 \sim 28.16^{\circ} \mathrm{C}$ \\
\hline \multicolumn{2}{|l|}{ Radar } \\
\hline 09:00 & Morning measurement starts, pre-meas sky calibration for $\mathrm{HH}$ \\
\hline 09:13 & $\begin{array}{l}\text { Measurement of } \mathrm{HH} \\
\text { Temperature at the end of the van is } 88.7^{\circ} \mathrm{F}-106.3^{\circ} \mathrm{F} \\
\text { Temperature at the middle of the van is } 79.5^{\circ} \mathrm{F}-88.3^{\circ} \mathrm{F} \\
\text { Humidity: } 66 \%-47 \%\end{array}$ \\
\hline $10: 06$ & $\begin{array}{l}\text { Post-meas sky calibration for } \mathrm{HH} \\
\text { Temperature at the end of the van is } 108^{\circ} \mathrm{F} \\
\text { Temperature at the middle of the van is } 88.9^{\circ} \mathrm{F} \\
\text { Humidity: } 49 \%\end{array}$ \\
\hline
\end{tabular}




\begin{tabular}{|c|c|}
\hline $10: 20$ & $\begin{array}{l}\text { Pre-meas sky calibration for } \mathrm{VV} \\
\text { Temperature at the end of the van is } 109.4^{\circ} \mathrm{F} \\
\text { Temperature at the middle of the van is } 90.9^{\circ} \mathrm{F} \\
\text { Humidity: } 50 \%\end{array}$ \\
\hline $10: 30$ & $\begin{array}{l}\text { Measurement of } \mathrm{VV} \\
\text { Temperature at the end of the van is } 111.9^{\circ} \mathrm{F}-115.5^{\circ} \mathrm{F} \\
\text { Temperature at the middle of the van is } 92.8^{\circ} \mathrm{F}-104.2^{\circ} \mathrm{F} \\
\text { Humidity: } 44 \%-37 \%\end{array}$ \\
\hline $11: 22$ & $\begin{array}{l}\text { Post-meas sky calibration for } \mathrm{VV} \\
\text { Temperature at the end of the van is } 115.9^{\circ} \mathrm{F} \\
\text { Temperature at the middle of the van is } 103.5^{\circ} \mathrm{F} \\
\text { Humidity: } 38 \%\end{array}$ \\
\hline $11: 30$ & Morning measurement ends \\
\hline $16: 45$ & $\begin{array}{l}\text { Evening measurement starts, pre-meas sky calibration for VV } \\
\text { Temperature at the end of the van is } 107.2^{\circ} \mathrm{F} \\
\text { Temperature at the middle of the van is } 95.7^{\circ} \mathrm{F} \\
\text { Humidity: } 42 \%\end{array}$ \\
\hline $16: 55$ & $\begin{array}{l}\text { Measurement of } \mathrm{VV} \\
\text { Temperature at the end of the van is } 110.1^{\circ} \mathrm{F}-113.4^{\circ} \mathrm{F} \\
\text { Temperature at the middle of the van is } 95.9^{\circ} \mathrm{F}-95.4^{\circ} \mathrm{F} \\
\text { Humidity: } 45 \%-43 \%\end{array}$ \\
\hline $17: 45$ & $\begin{array}{l}\text { Post-meas sky calibration for VV } \\
\text { Temperature at the end of the van is } 112.6^{\circ} \mathrm{F} \\
\text { Temperature at the middle of the van is } 95.5^{\circ} \mathrm{F} \\
\text { Humidity: } 44 \%\end{array}$ \\
\hline 17:55 & $\begin{array}{l}\text { Pre-meas sky calibration for } \mathrm{HH} \\
\text { Temperature at the end of the van is } 110.8^{\circ} \mathrm{F} \\
\text { Temperature at the middle of the van is } 95.4^{\circ} \mathrm{F} \\
\text { Humidity: } 44 \%\end{array}$ \\
\hline 18:03 & $\begin{array}{l}\text { Measurement of } \mathrm{HH} \\
\text { Temperature at the end of the van is } 108.2^{\circ} \mathrm{F}-110.3^{\circ} \mathrm{F} \\
\text { Temperature at the middle of the van is } 95.2^{\circ} \mathrm{F}-93.6^{\circ} \mathrm{F} \\
\text { Humidity: } 43 \%-49 \%\end{array}$ \\
\hline $18: 50$ & $\begin{array}{l}\text { Post-meas sky calibration for } \mathrm{HH} \\
\text { Temperature at the end of the van is } 112.5^{\circ} \mathrm{F} \\
\text { Temperature at the middle of the van is } 93.2^{\circ} \mathrm{F} \\
\text { Humidity: } 49 \%\end{array}$ \\
\hline 19:00 & Evening measurement ends \\
\hline \multicolumn{2}{|l|}{ LiDAR } \\
\hline 09:30 & Completed two sets of single scan \\
\hline
\end{tabular}

End of IOP

\section{August 22 (DoY 234)}

08:45

Pre-meas sky calibration for $\mathrm{HH}$ of Radar

Temperature at the end of the van is $82.9^{\circ} \mathrm{F}$

Temperature at the middle of the van is $76.6^{\circ} \mathrm{F}$

Humidity: $73 \%$

09:03

Measurement of $\mathrm{HH}$ (with large look angle) with Radar

Temperature at the end of the van is $96.1^{\circ} \mathrm{F}-108.9^{\circ} \mathrm{F}$

Temperature at the middle of the van is $77.9^{\circ} \mathrm{F}-87.4^{\circ} \mathrm{F}$

Humidity: $73 \%-58 \%$

Field Observations During the Eighth Microwave Water and Energy Balance Experiment (MicroWEX-8): 33 


\begin{tabular}{|l|l|}
\hline $09: 52$ & $\begin{array}{l}\text { Post-meas sky calibration for HH of Radar } \\
\text { Temperature at the end of the van is } 110.1^{\circ} \mathrm{F} \\
\text { Temperature at the middle of the van is } 89.8^{\circ} \mathrm{F} \\
\text { Humidity: } 58 \%\end{array}$ \\
\hline $10: 02$ & $\begin{array}{l}\text { Pre-meas sky cal for VV of Radar } \\
\text { Temperature at the end of the van is } 109.9^{\circ} \mathrm{F} \\
\text { Temperature at the middle of the van is } 92.3^{\circ} \mathrm{F} \\
\text { Humidity: } 55 \%\end{array}$ \\
\hline $10: 09$ & $\begin{array}{l}\text { Measurement of VV (with large look angle) with Radar } \\
\text { Temperature at the end of the van is: } 112.8^{\circ} \mathrm{F}-114.6^{\circ} \mathrm{F} \\
\text { Temperature at the middle of the van is } 92.8^{\circ} \mathrm{F}-96.3^{\circ} \mathrm{F} \\
\text { Humidity: } 50 \%-45 \%\end{array}$ \\
\hline $10: 56$ & $\begin{array}{l}\text { Post-meas sky calibration for } \mathrm{VV} \text { of Radar } \\
\text { Temperature at the end of the van is } 113.4^{\circ} \mathrm{F} \\
\text { Temperature at the middle of the van is } 96.4^{\circ} \mathrm{F} \\
\text { Humidity: } 45 \%\end{array}$ \\
\hline $11: 00$ & \begin{tabular}{l} 
Morning measurement ends \\
\hline
\end{tabular} \\
\hline
\end{tabular}

August 24 (DoY 236)

$07: 45$

Harvest began in north end

Cleared L-band's footprint by hand harvesting

08:45

Downloaded data from C-band radiometer

09:00

C-band radiometer calibration, absorber temperature $=27.06 \sim 28.05^{\circ} \mathrm{C}$

09:30

Changed desiccants in C-band radiometer

$11: 30$

Completed four sets of single scan by LiDAR

$15: 41$

Measurement of VV (lower height) with Radar

Temperature at the end of the van is $103.8^{\circ} \mathrm{F}-115.9^{\circ} \mathrm{F}$

Temperature at the middle of the van is $99.7^{\circ} \mathrm{F}-92.1^{\circ} \mathrm{F}$

Humidity: $27 \%-31 \%$

$16: 28$

Measurement of VV (higher height) with Radar

Temperature at the end of the van is $113.9^{\circ} \mathrm{F}-113.7^{\circ} \mathrm{F}$

Temperature at the middle of the van is $92.1^{\circ} \mathrm{F}-91.9^{\circ} \mathrm{F}$

Humidity: 32\%-31\%

$17: 25$

Post-meas sky calibration for VV of Radar

Temperature at the end of the van is $115.2^{\circ} \mathrm{F}$

Temperature at the middle of the van is $93.9^{\circ} \mathrm{F}$

Humidity: $30 \%$

$17: 37$

Measurement of $\mathrm{HH}$ (lower height) with Radar

Temperature at the end of the van is $115.3^{\circ} \mathrm{F}-112.1^{\circ} \mathrm{F}$

Temperature at the middle of the van is $93.6^{\circ} \mathrm{F}-95.7^{\circ} \mathrm{F}$

Humidity: $30 \%-36 \%$

18:19 Measurement of $\mathrm{HH}$ (higher height) with Radar

Temperature at the end of the van is $112.6^{\circ} \mathrm{F}-111.0^{\circ} \mathrm{F}$

Temperature at the middle of the van is $96.1^{\circ} \mathrm{F}-93.9^{\circ} \mathrm{F}$

Humidity: $36 \%-37 \%$

$19: 11$

Post-meas sky calibration for $\mathrm{HH}$ of Radar

Temperature at the end of the van is $108.0^{\circ} \mathrm{F}$

Temperature at the middle of the van is $93.9^{\circ} \mathrm{F}$

Humidity: $38 \%$

Field Observations During the Eighth Microwave Water and Energy Balance Experiment (MicroWEX-8): 34 from June 16 through August 24, 2009 


\begin{tabular}{|c|c|}
\hline $19: 51$ & $\begin{array}{l}\text { Measurement of corner reflector for } \mathrm{HH} \text { (lower height) with Radar } \\
\text { corner reflector, front edge @ } 24 \mathrm{ft} \text {, corner @ } 29 \mathrm{ft} \\
\text { Temperature at the end of the van is } 107.8^{\circ} \mathrm{F}-105.1^{\circ} \mathrm{F} \\
\text { Temperature at the middle of the van is } 90.5^{\circ} \mathrm{F}-87.4^{\circ} \mathrm{F} \\
\text { Humidity: } 43 \%-49 \%\end{array}$ \\
\hline $20: 19$ & $\begin{array}{l}\text { Measurement of corner reflector for } \mathrm{HH} \text { (higher height) with Radar } \\
\text { corner reflector, front edge @ } 34 \mathrm{ft} \text {, corner @ } \sim 39 \mathrm{ft} \\
\text { Temperature at the end of the van is } 104.2^{\circ} \mathrm{F}-105.1^{\circ} \mathrm{F} \\
\text { Temperature at the middle of the van is } 87.4^{\circ} \mathrm{F}-87.1^{\circ} \mathrm{F} \\
\text { Humidity: } 56 \%-61 \%\end{array}$ \\
\hline $20: 58$ & $\begin{array}{l}\text { Measurement of corner reflector for VV (higher height) with Radar } \\
\text { corner reflector, front edge @ } 34 \mathrm{ft} \text {, corner @ } \sim 39 \mathrm{ft} \\
\text { Temperature at the end of the van is } 102.2^{\circ} \mathrm{F}-102.2^{\circ} \mathrm{F} \\
\text { Temperature at the middle of the van is } 85.6^{\circ} \mathrm{F}-84.7^{\circ} \mathrm{F} \\
\text { Humidity: } 61 \%-64 \%\end{array}$ \\
\hline $21: 27$ & $\begin{array}{l}\text { Measurement of corner reflector for } \mathrm{VV} \text { (lower height) with Radar } \\
\text { corner reflector, front edge @ } 23.5 \mathrm{ft} \text {, corner @ } 28.5 \mathrm{ft} \\
\text { Temperature at the end of the van is } 100.8^{\circ} \mathrm{F}-101.7^{\circ} \mathrm{F} \\
\text { Temperature at the middle of the van is } 85.3^{\circ} \mathrm{F}-83.3^{\circ} \mathrm{F} \\
\text { Humidity: } 63 \%-66 \%\end{array}$ \\
\hline
\end{tabular}

\section{REFERENCES}

Apogee Instruments Inc. Infrared Radiometer Owner's Manual, Model: IRR-PN. Logan, UT: Apogee Instruments Inc., 2007.

Boote, K.J. "Data Requirements for Model Evaluation and Techniques for Sampling Crop Growth and Development." In: DSSAT version 3.5, Volume 4. ed. Gerrit Hoogenboom, Paul W. Wilken, and Gordon Y. Tsuji. (Honolulu, HI: University of Hawaii, 1994), 215-229.

Campbell Scientific. CSAT3 Three Dimensional Sonic Anemometer Instruction Manual. Logan, UT: Campbell Scientific Inc., 1998.

Campbell Scientific. HFT3 Soil Heat Flux Plate Instruction Manual. Logan, UT: Campbell Scientific Inc., 2003.

Campbell Scientific. CNR1 Net Radiometer Instruction Manual. Logan, UT: Campbell Scientific Inc., $2006 a$.

Campbell Scientific. CS616 and CS625 Water Content Reflectometers Instruction Manual. Logan, UT: Campbell Scientific Inc., 2006b.

Campbell Scientific. Campbell Scientific Model HMP45C Temperature and Relative Humidity Probe Instruction Manual. Logan, UT: Campbell Scientific Inc., 2006c.

De Roo, R.D. University of Florida C-band Radiometer Summary. Space Physics Research Laboratory, University of Michigan, Ann Arbor, Michigan, March, 2002.

De Roo, R.D. TMRS-3 Radiometer Tuning Procedures. Space Physics Research Laboratory, University of Michigan, Ann Arbor, Michigan, March, 2003.

De Roo, R.D. Personal communication, 2010.

Fernandez-Diaz, J.C. “Scientific applications of the Mobile Terrestrial Laser Scanner (M-TLS) system.” Unpublished Master's Thesis, University of Florida, Gainesville, Florida. Available at: http://purl.fcla.edu/fcla/etd/UFE0021101, 2007. 
Fröhlich, C., and M. Mettenleiter. “Terrestrial Laser Scanning - New Perspectives in 3d Surveying." International Society for Photogrammetry and Remote Sensing Working Group VIII/2 'Laser-Scanners for Forest and Landscape Assessment', Freiburg, Germany: (2004):7-13.

Kaimal, J.C., and J.J. Finnigan. Atmospheric Boundary Layer Flows:Their Structure and Measurement. New York: Oxford University Press, 2004.

Schotanus, P., F.T.M. Nieuwstadt, and H.A.R. de Bruin. "Temperature Measurement with a Sonic Anemometer and Its Application to Heat and Moisture Fluxes.” Boundary-Layer Meteorology 26 (2003):81-93.

University of Edinburgh. EdiRe data software. http://www.geos.ed.ac.uk/abs/research/micromet/EdiRe/.

Van Dijk, A., W. Kohsiek, and H.A.R. de Bruin. "Oxygen Sensitivity of Krypton and Lyman-alpha Hygrometer." Journal of Atmospheric and Ocean Technology 20 (2003):143-151.

Van Dijk, A., A.F. Moene, and H.A.R. de Bruin. The Principles of Surface Flux Physics: Theory, Practice and Description of the ECPACK Library. Internal Report, Wageningen University, Wageningen: Meteorology and Air Quality Group, 2004.

Webb, E.K., G.I. Pearman, and R. Leuning. "Correction of Flux Measurements for Density Effects Due to Heat and Water Vapor Transfer.” Quarterly Journal of the Royal Meteorological Society 106 (1980):85-100.

Wilczak, J.M., S.P. Oncley, and S.A. Stage. “Sonic Anemometer Tilt Correction Algorithms.” Boundary-Layer Meteorology 99 (2001):127-150.

\section{ACKNOWLEDGEMENTS}

The authors would like to acknowledge Mr. James Boyer and his team at the PSREU in Citra, Florida for excellent field management. MicroWEX-8 was supported by grants from NASA-NIP (Grant number: 0005065) and from the Earth Science Directorate, NSF (Grant number: EAR-0337277).

\section{A. FIELD OBSERVATIONS}

\section{Figure Captions}

Figure A-1 Microwave brightness at a) C-band at Vertical and Horizontal polarization and b) L-band at Horizontal polarization.

Figure A-2 Radar observations

Figure A-3 LiDAR observations.

Figure A-4 Latent (LE) and sensible (H) heat fluxes at eddy covariance station.

Figure A-5 Down- and up-welling short- and long-wave radiation.

Figure A-6 Surface temperature (TIR).

Figure A-7 Relative Humidity, Air Temperature. .47

Figure A-8 North station soil temperature. .48

Figure A-9 East station soil temperature 


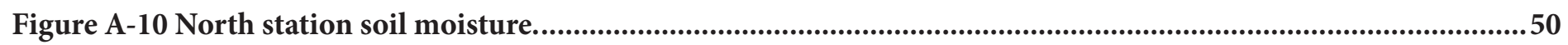

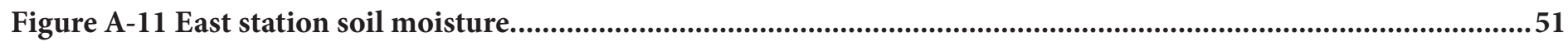

Figure A-12 Rainfall from the rain gauge at the east edge of footprint, west edge of footprint, and east edge of the

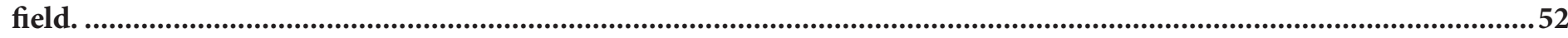

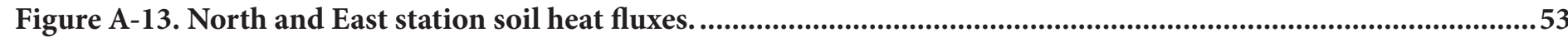

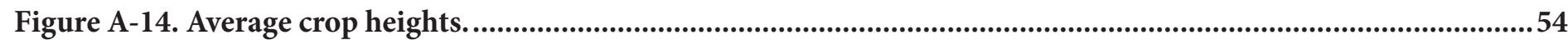

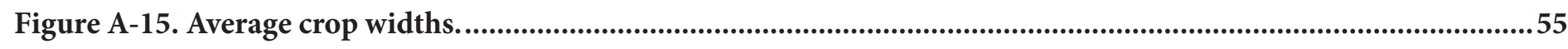

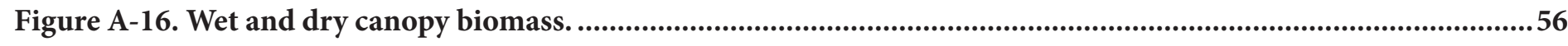

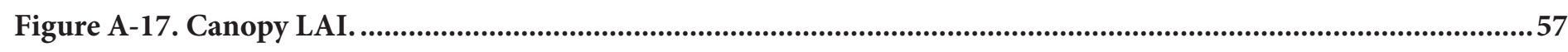

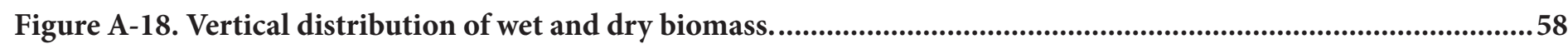

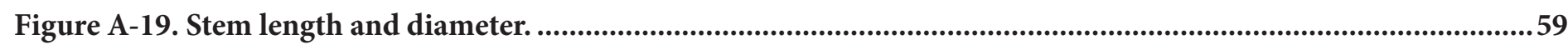

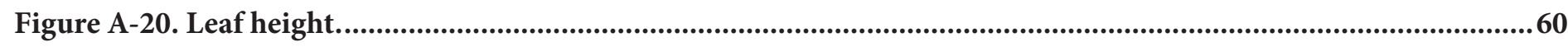

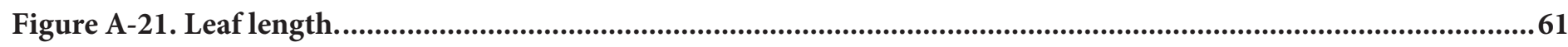

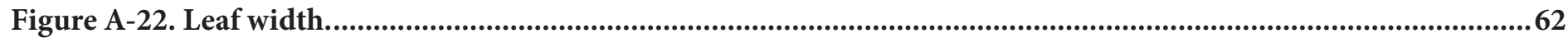

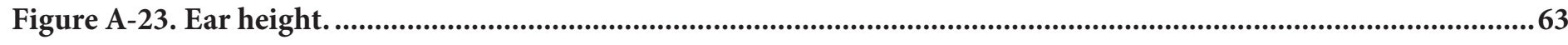

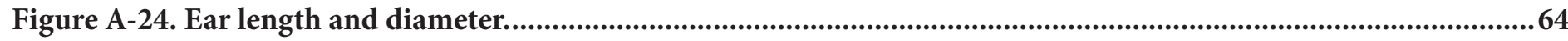

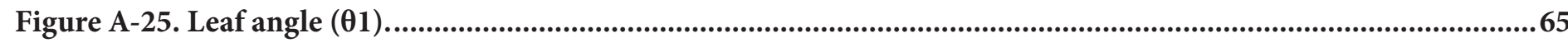

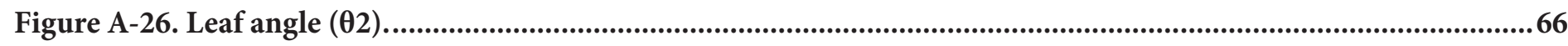

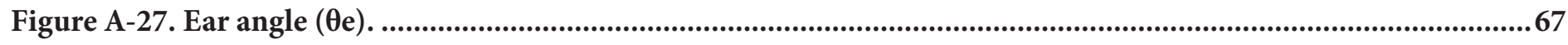

Figure A-28. Water table depth and elevation above sea level. ................................................................................68 

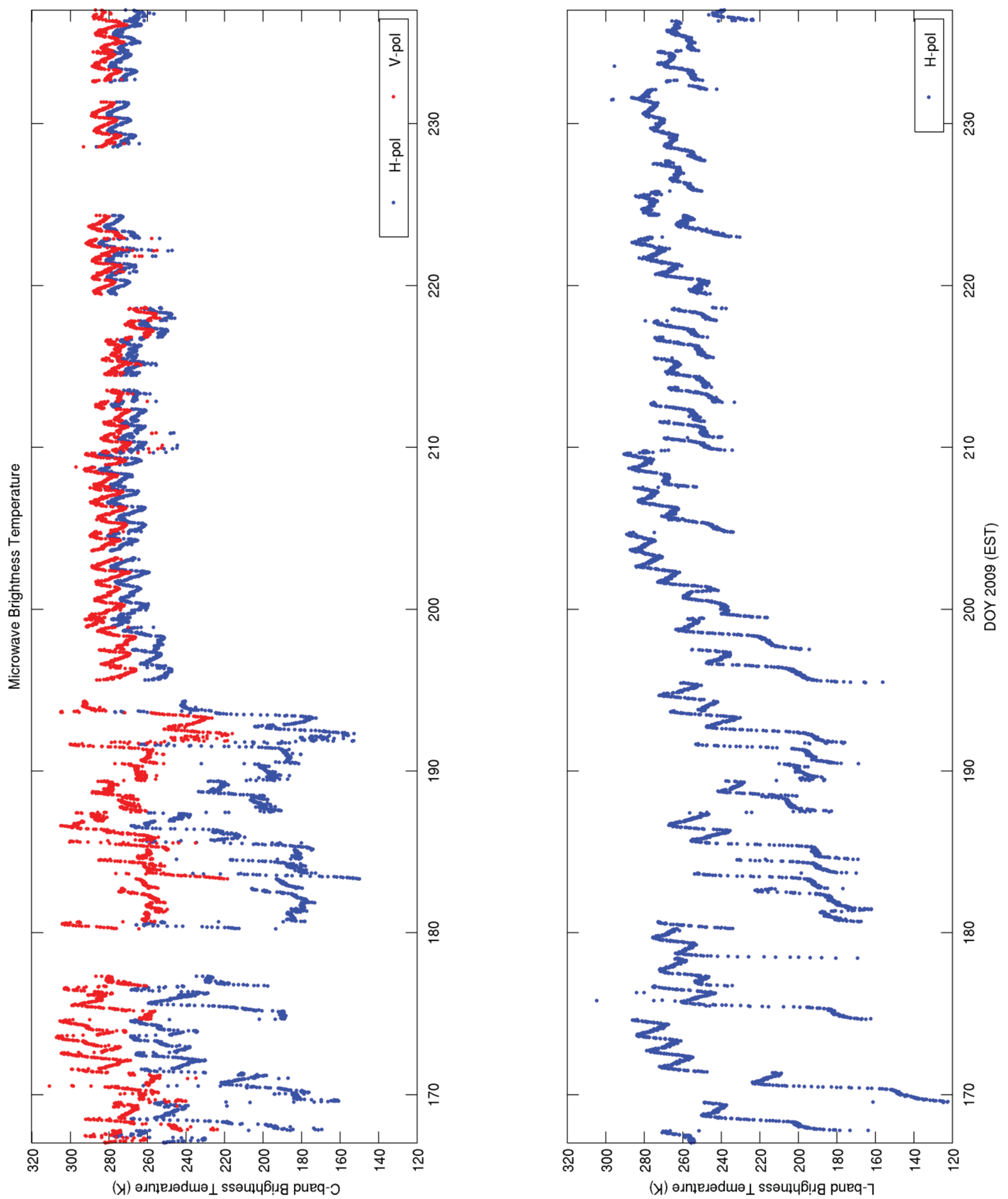

Figure A-1 Microwave brightness at a) C-band at Vertical and Horizontal polarization and b) L-band at Horizontal polarization.

Field Observations During the Eighth Microwave Water and Energy Balance Experiment (MicroWEX-8): 38 from June 16 through August 24, 2009 

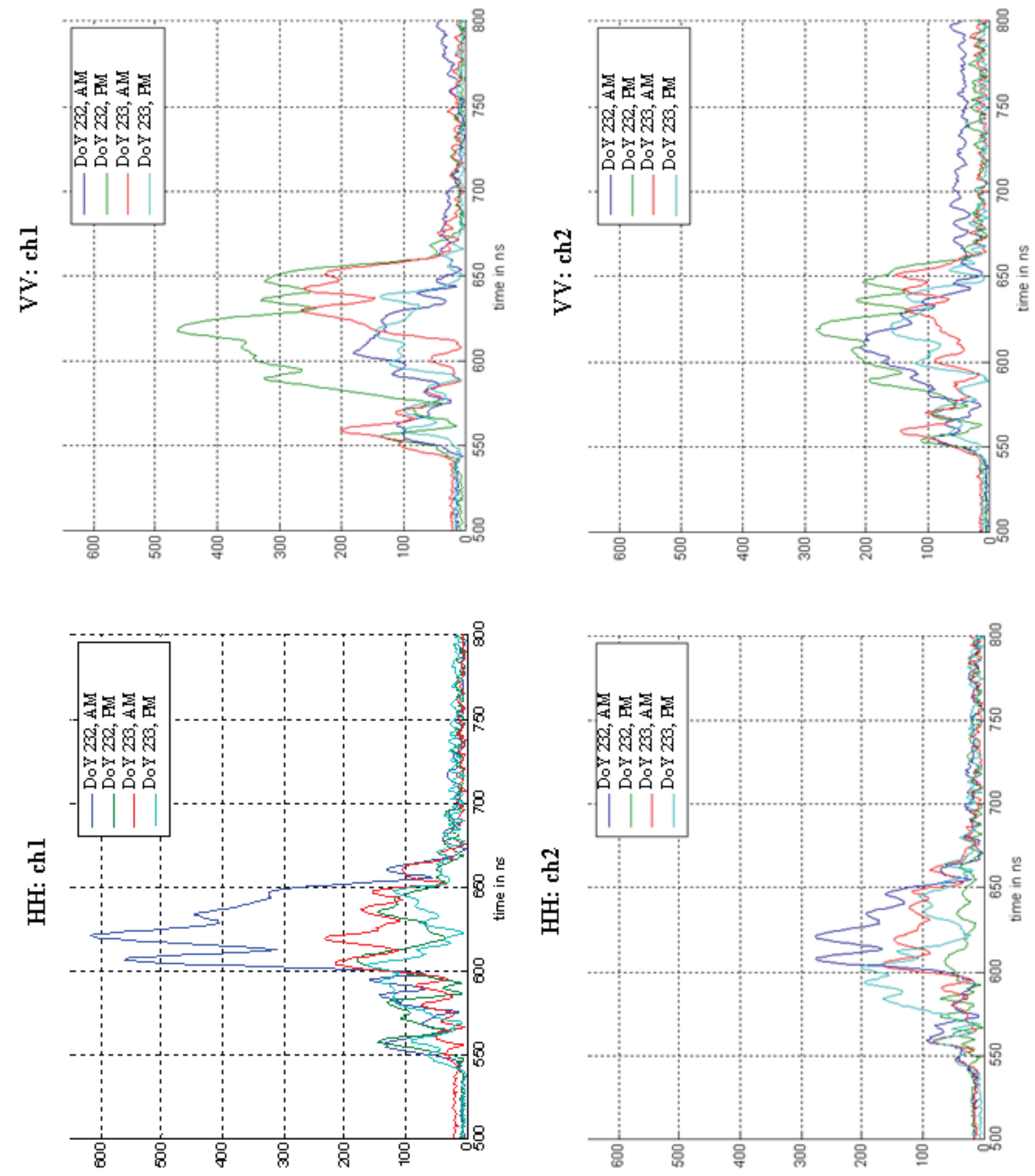

Figure A-2(a). Radar observations for DoY 232 and DoY 233; 'VV' and 'HH' refer to antenna arrangement (vertically or horizontally). Ch refers to channel. 

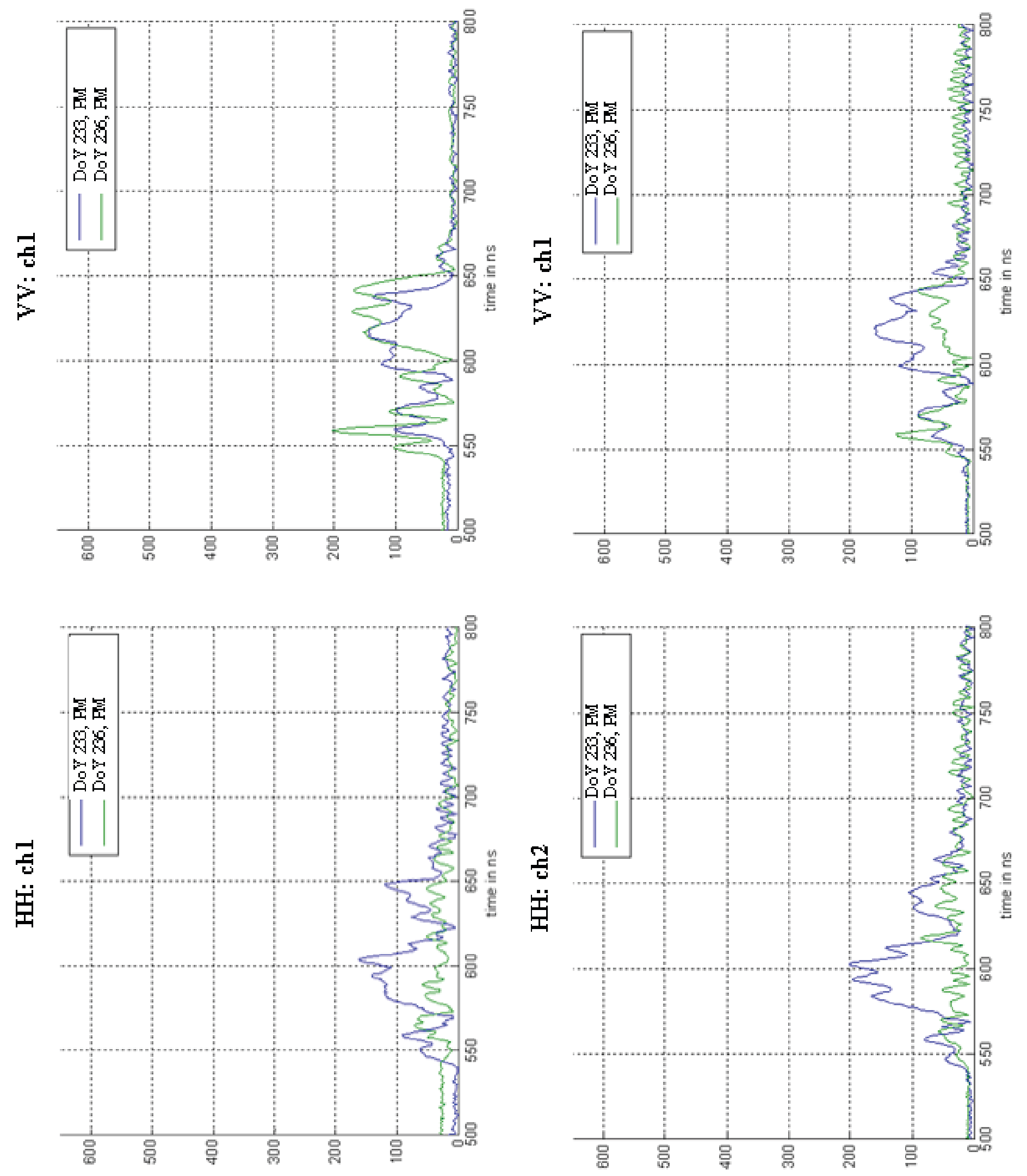

Figure A-2(b). Radar observations for DoY 233 (mature corn canopy) and DoY 236 (bare soil); 'VV' and 'HH' refer to antenna arrangement (vertically or horizontally). Ch refers to channel. 

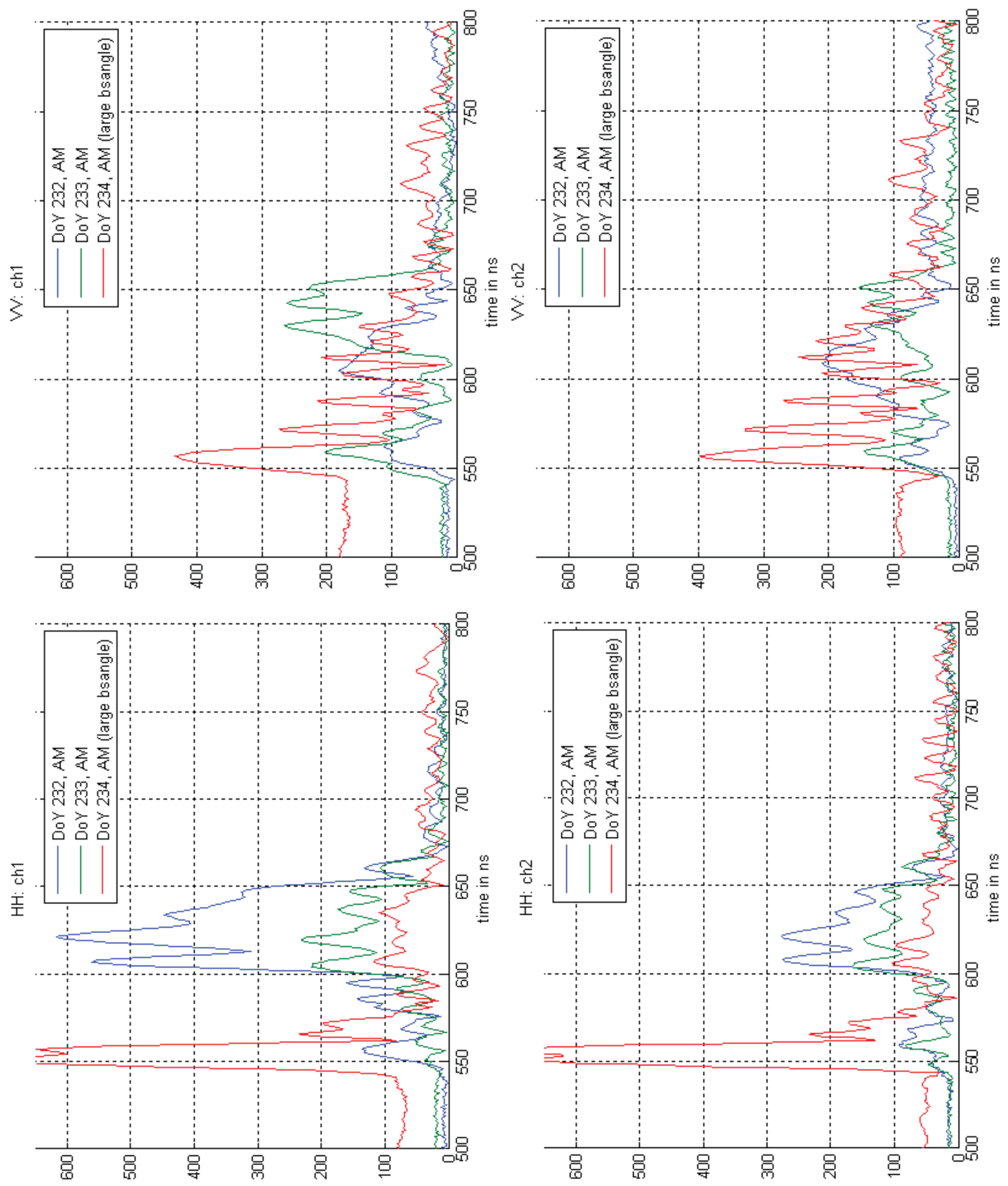

Figure A-2(c). Radar observations for DoY 232, 233, and 234 morning. Bsangle refers to large boresight angle. 'VV' and ' $\mathrm{HH}$ ' refer to antenna arrangement (vertically or horizontally). Ch refers to channel. 

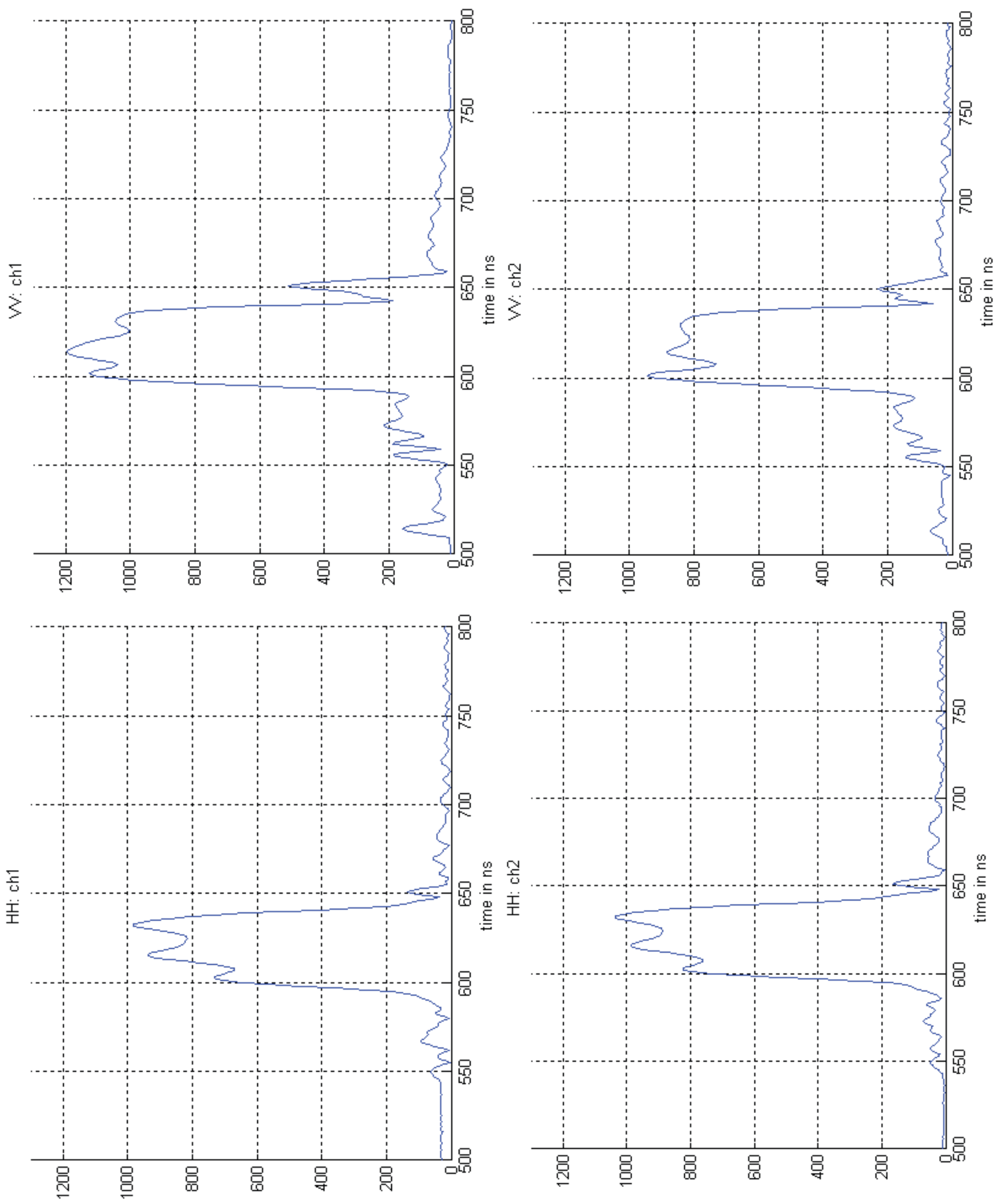

Figure A-2(d). Radar observations of Calibration Target: Corner Reflector. ' $V V^{\prime}$ and 'HH' refer to antenna arrangement (vertically or horizontally). Ch refers to channel. 

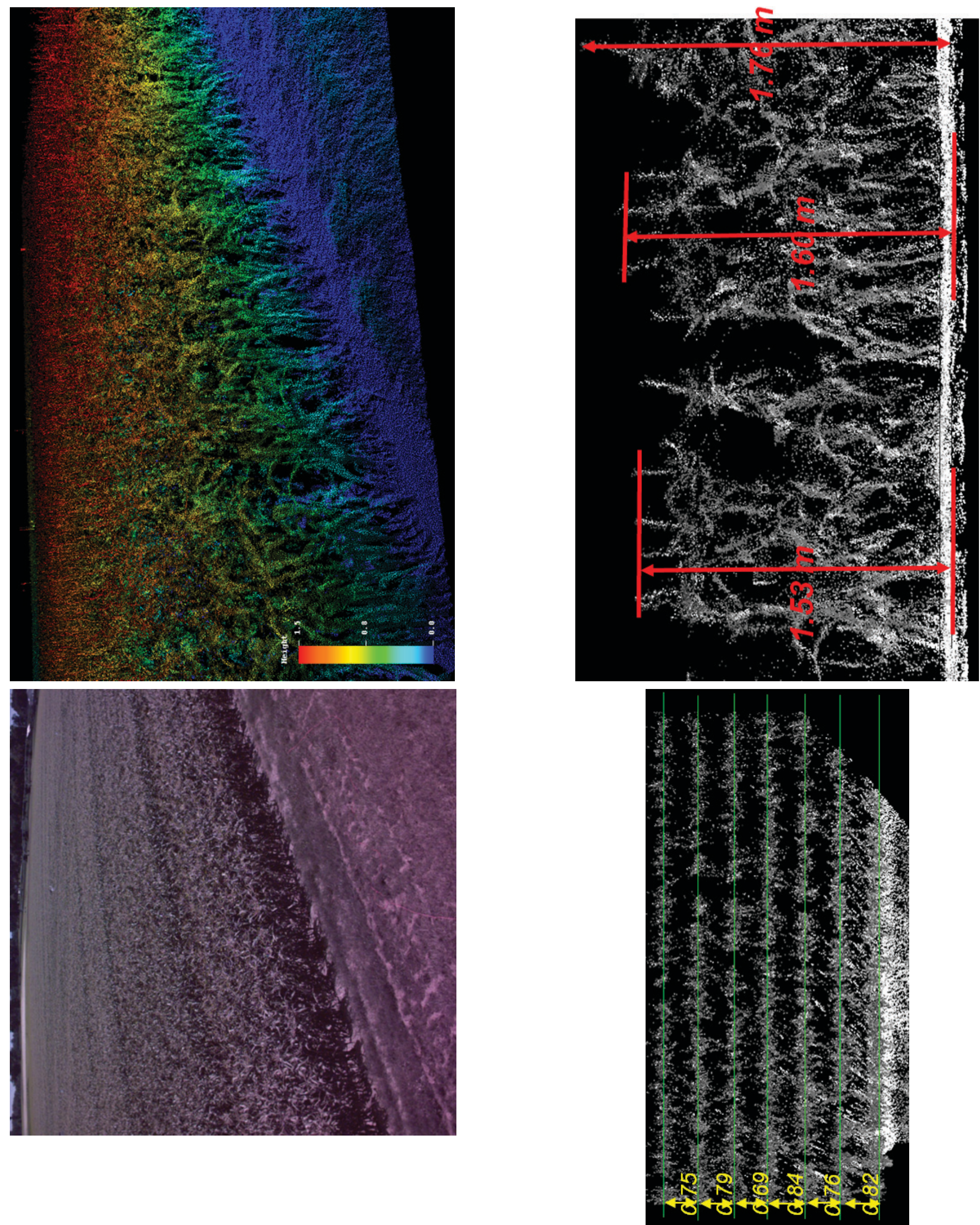

Figure A-3. LiDAR observations.

Field Observations During the Eighth Microwave Water and Energy Balance Experiment (MicroWEX-8): 43 from June 16 through August 24, 2009 


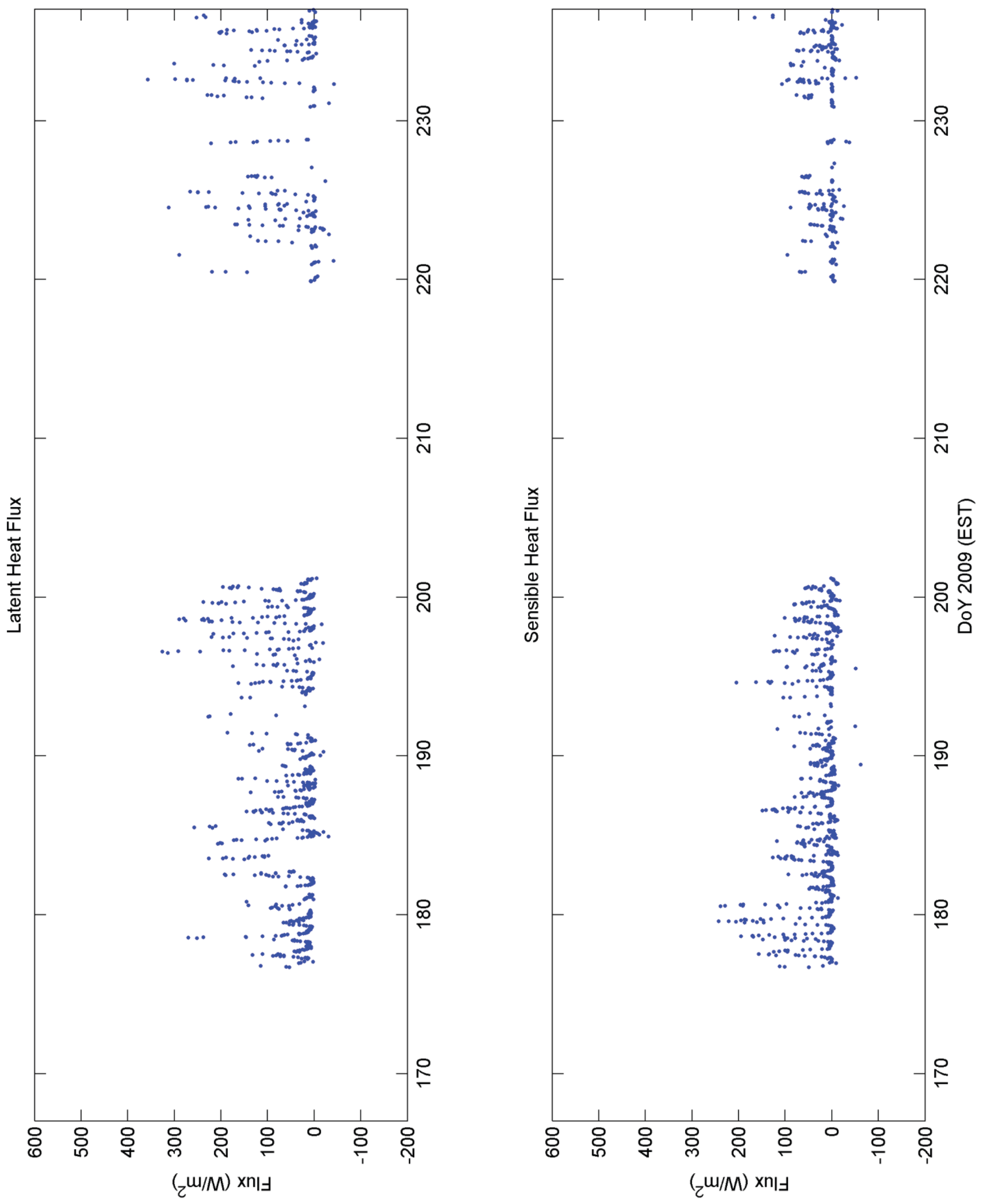

Figure A-4. Latent (LE) and sensible $(\mathrm{H})$ heat fluxes at eddy covariance station. 


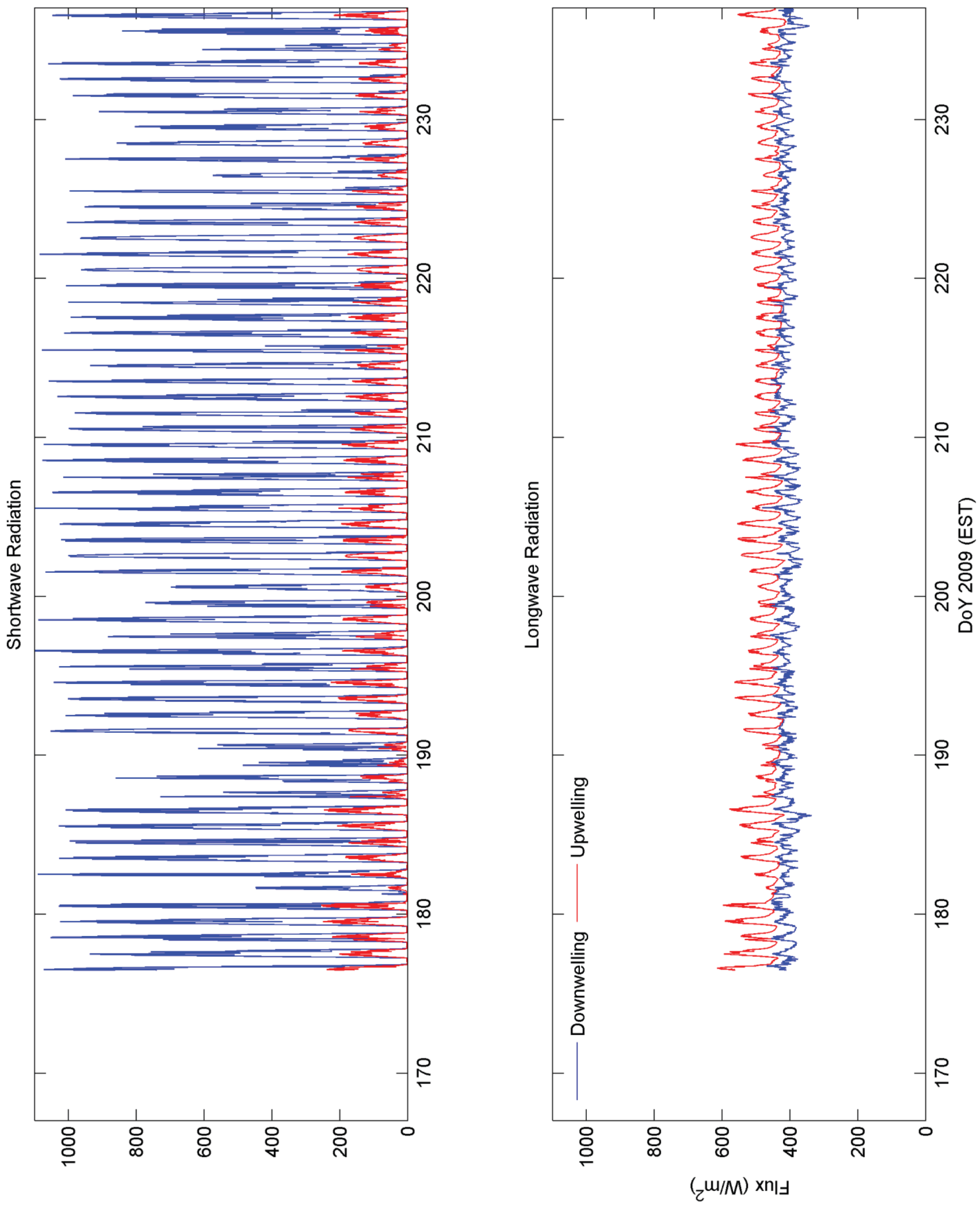

Figure A-5. Down- and up-welling short- and long-wave radiation. 


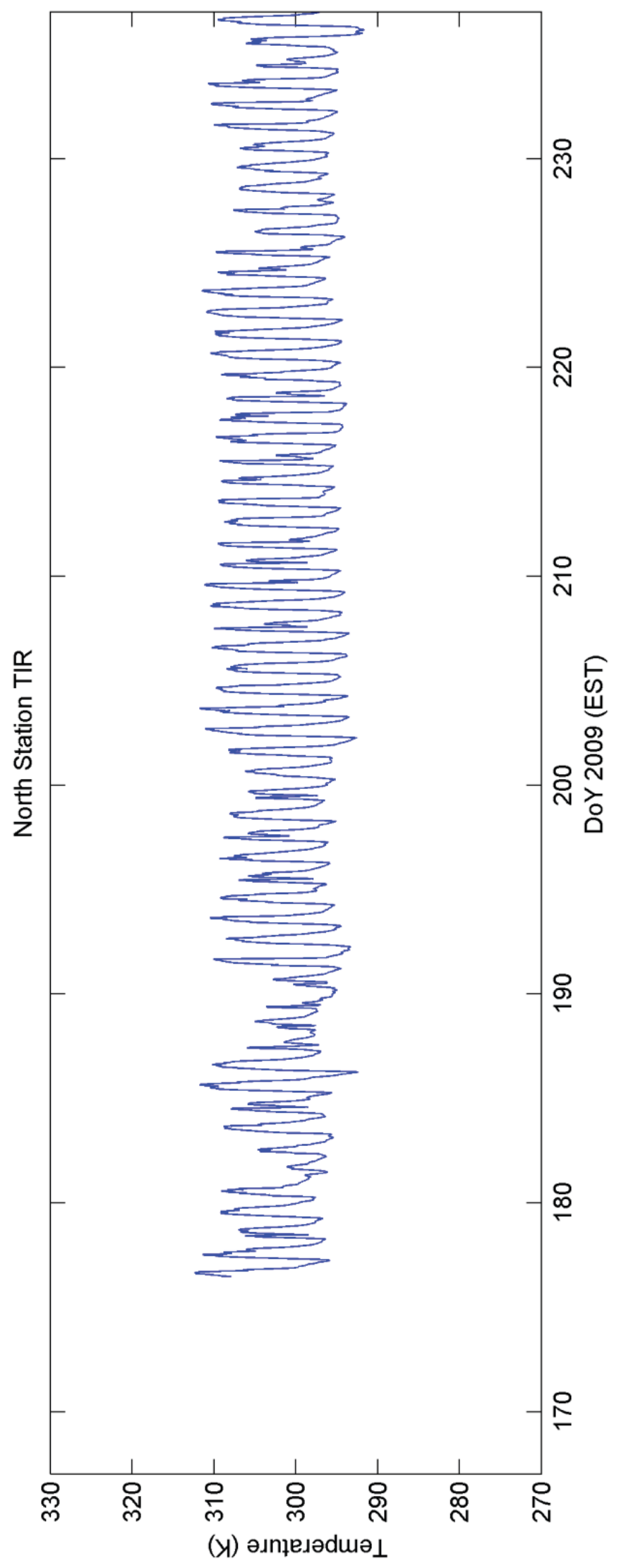

Figure A-6. Surface temperature (TIR). 


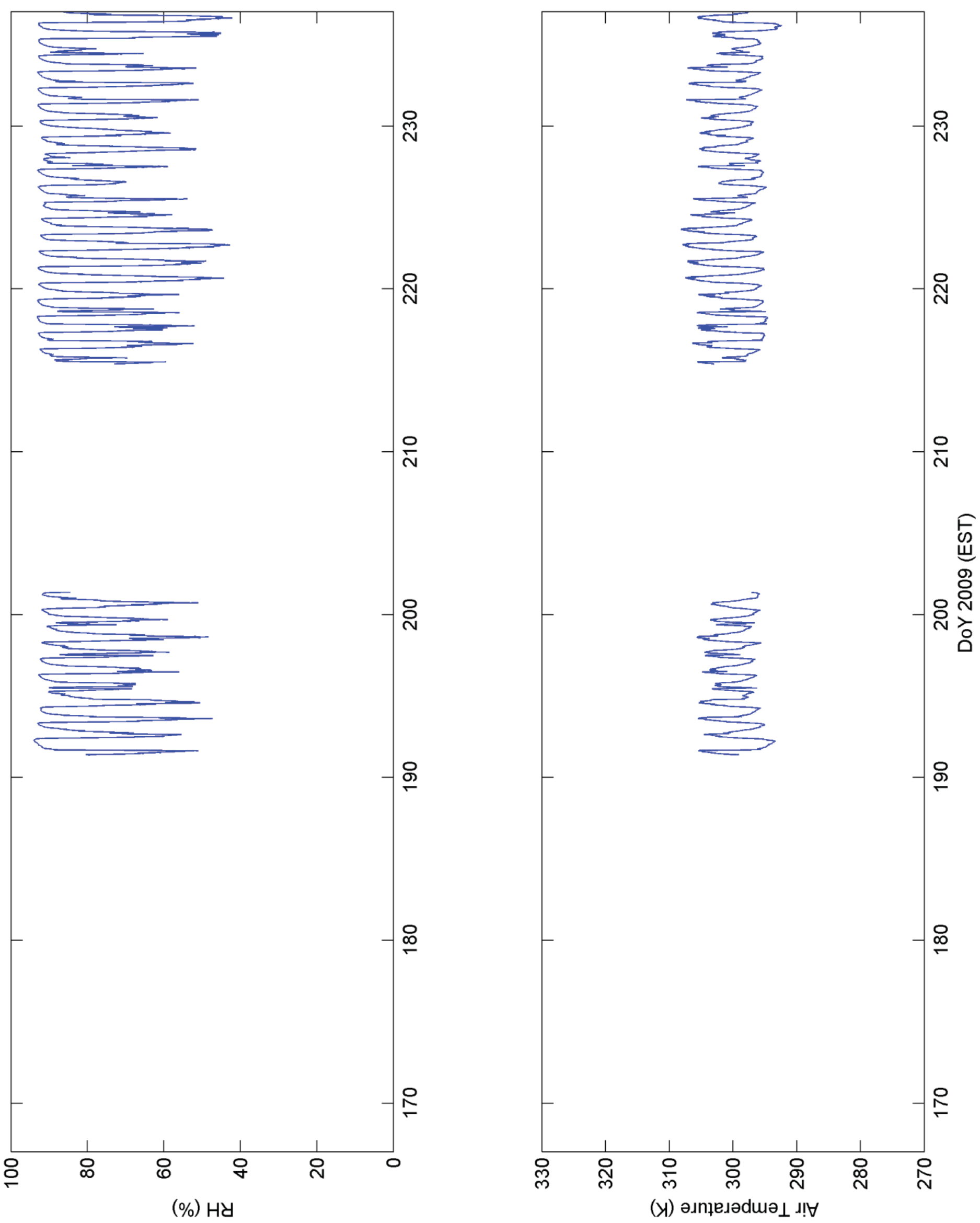

Figure A-7. Relative Humidity, Air Temperature.

Field Observations During the Eighth Microwave Water and Energy Balance Experiment (MicroWEX-8): 47 from June 16 through August 24, 2009 


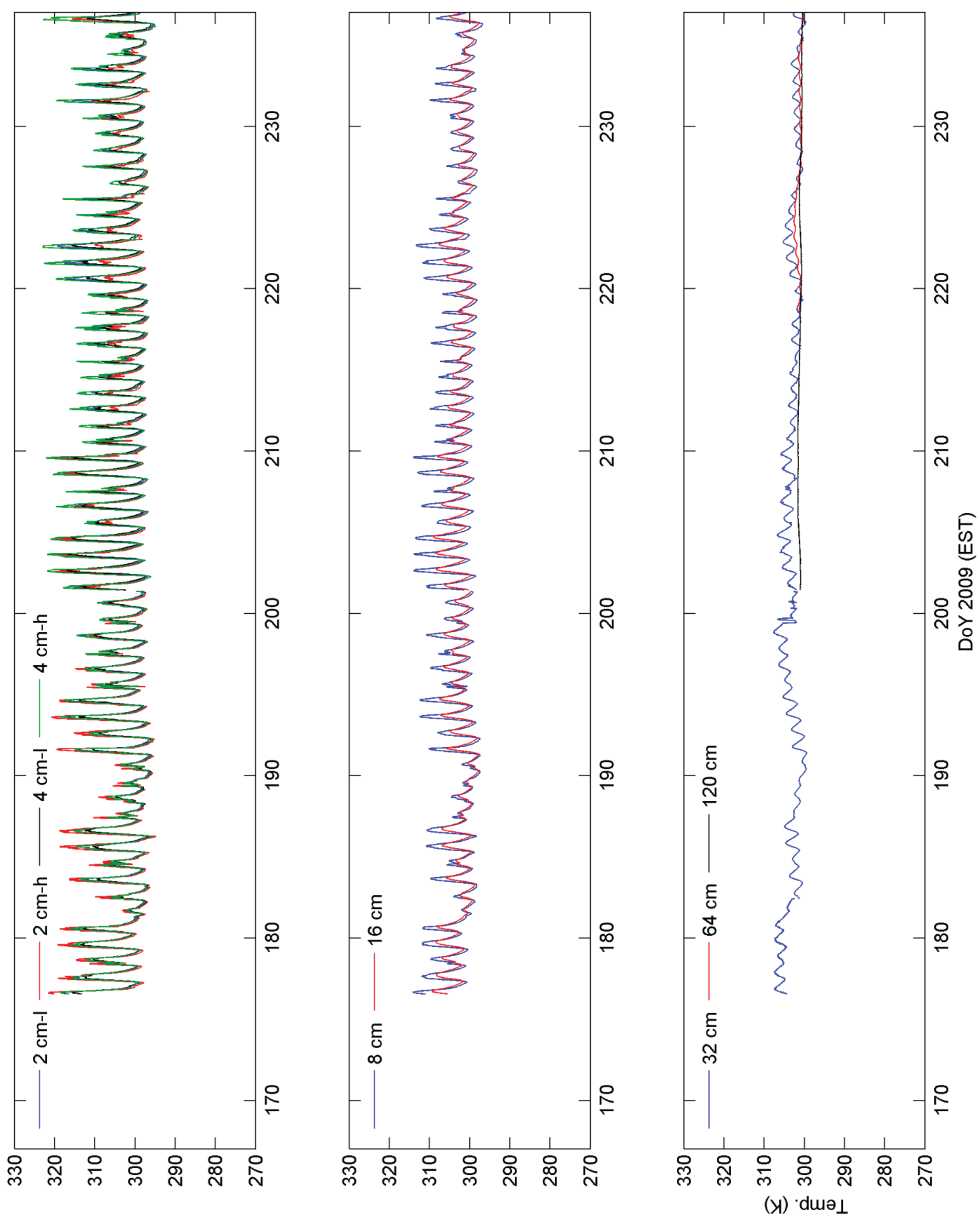

Figure A-8. North station soil temperature; l=sensor in the furrow, $\mathrm{h}=$ sensor in the row. 


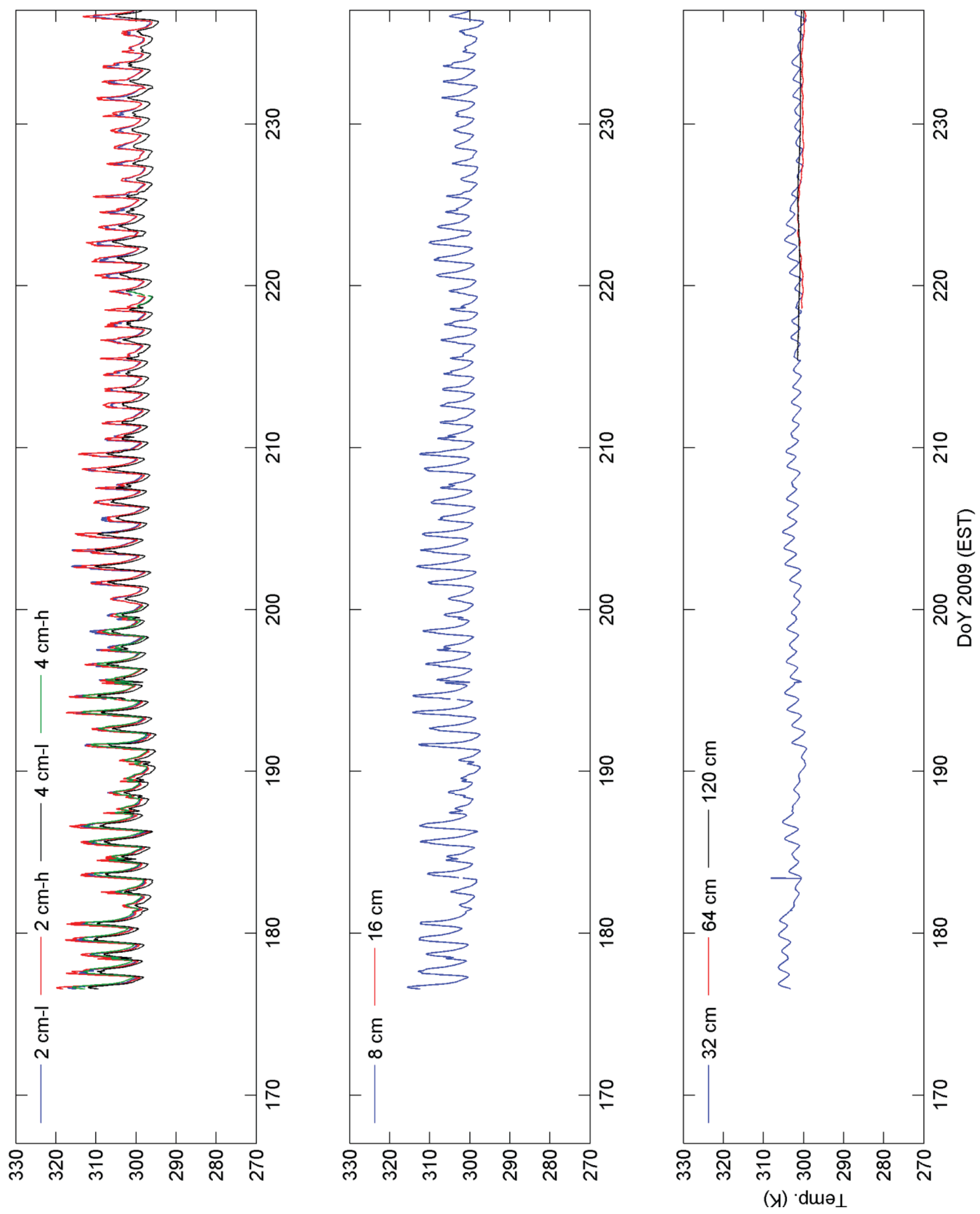

Figure A-9. East station soil temperature; l=sensor in the furrow, $\mathrm{h}=$ sensor in the row. 


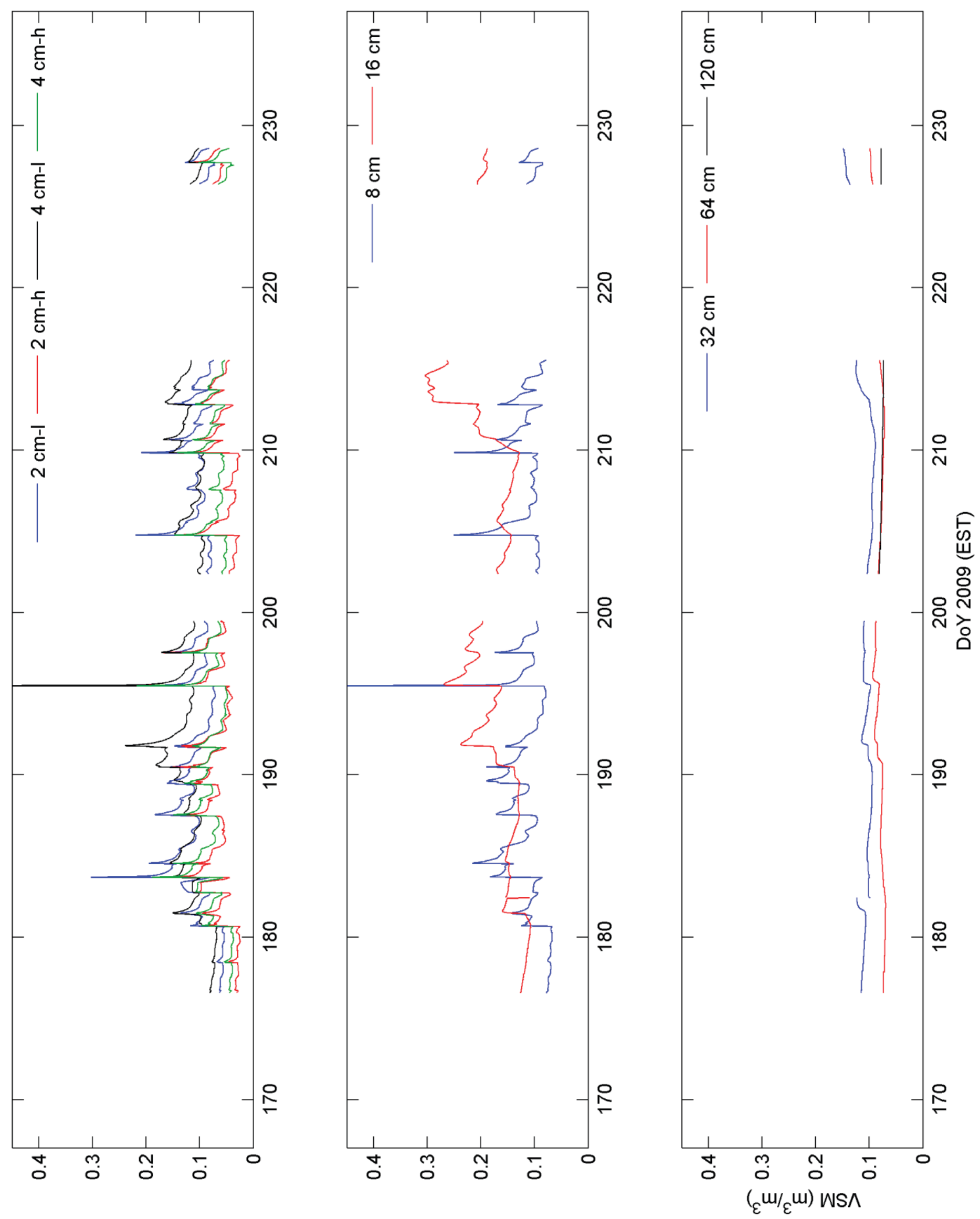

Figure A-10. North station soil moisture; l=sensor in the furrow, $\mathrm{h}=$ sensor in the row. 


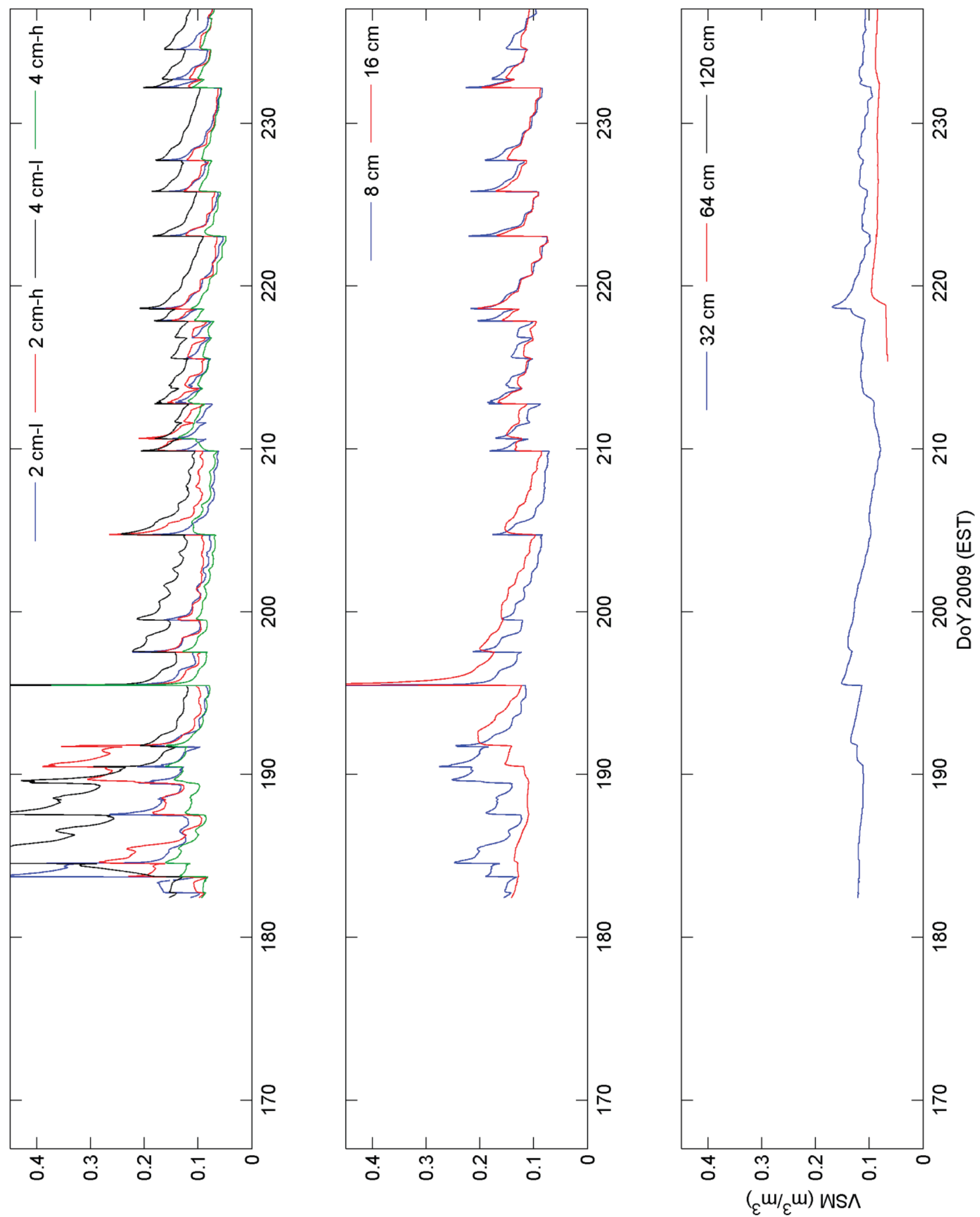

Figure A-11. East station soil moisture; l=sensor in the furrow, $\mathrm{h}=$ sensor in the row. 


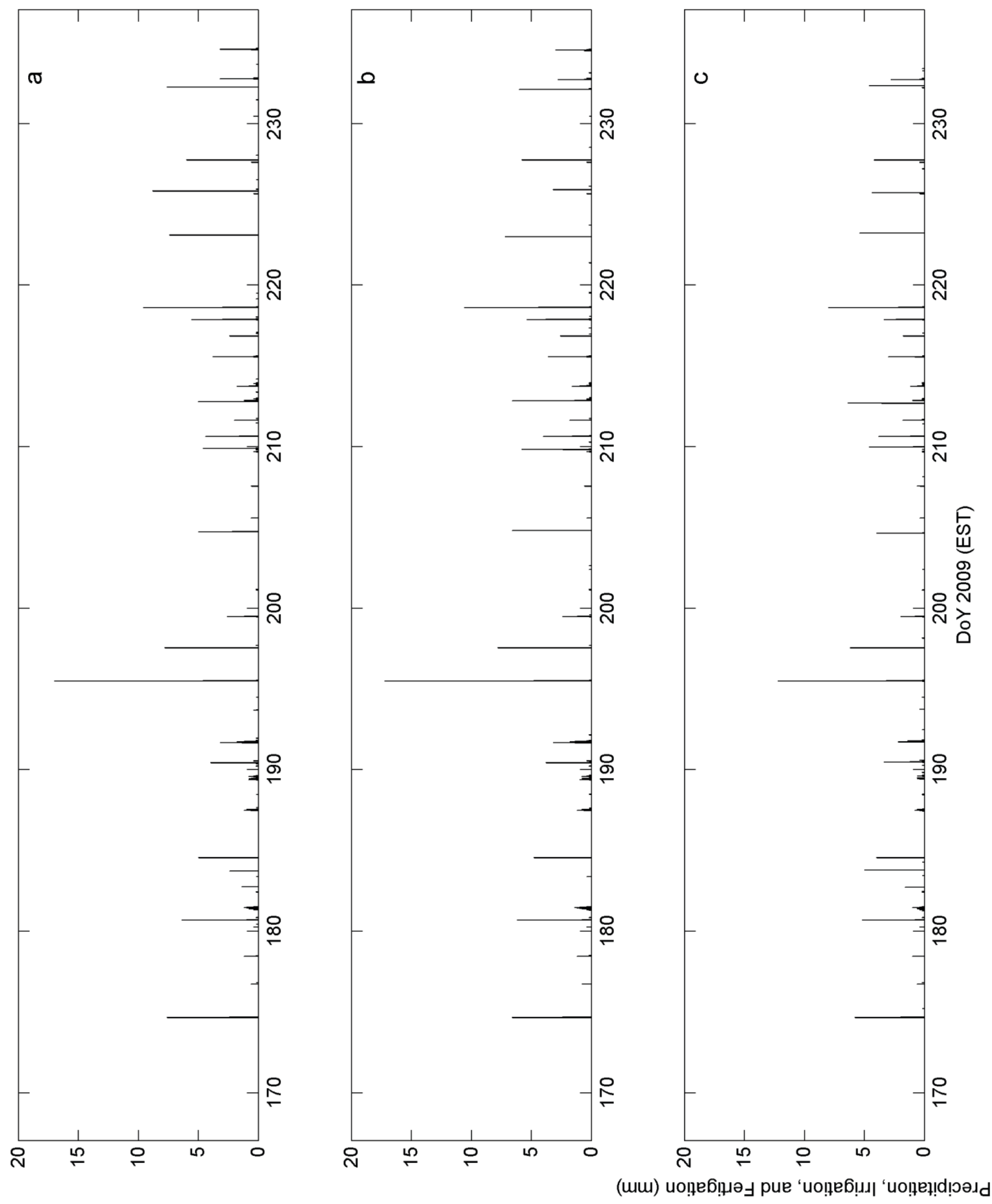

Figure A-12. Rainfall from the rain gauge at the a) east edge of footprint, b) west edge of footprint, and c) east edge of the field. 


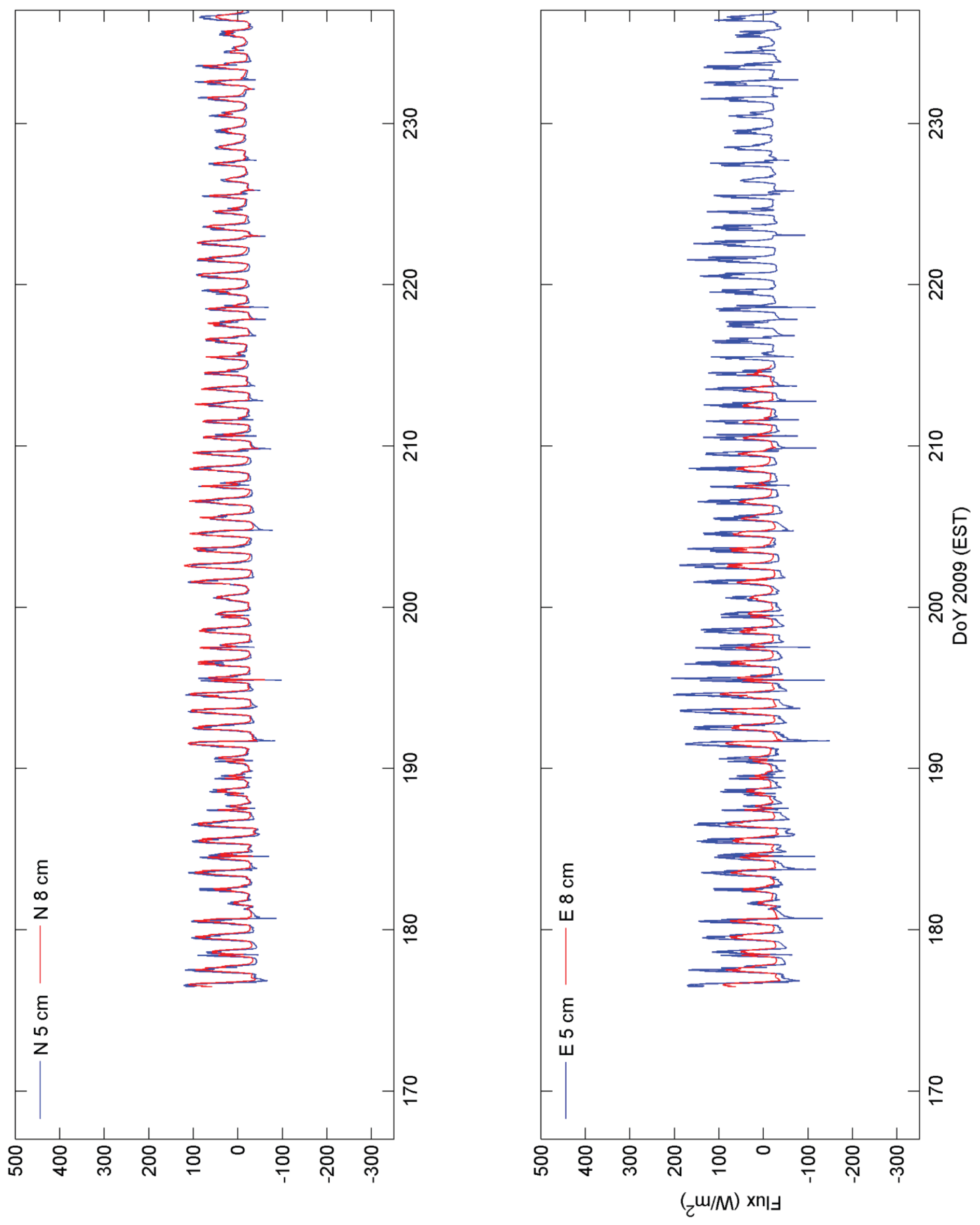

Figure A-13. North and East station soil heat fluxes. 


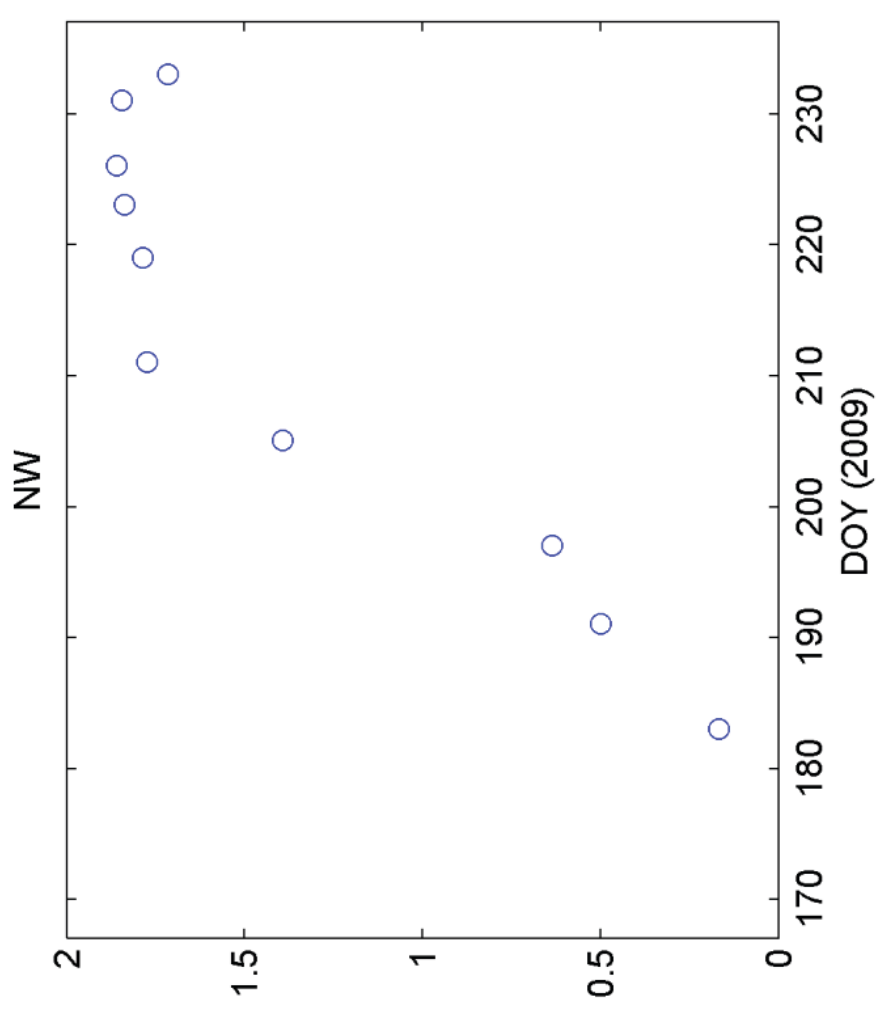

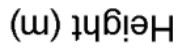

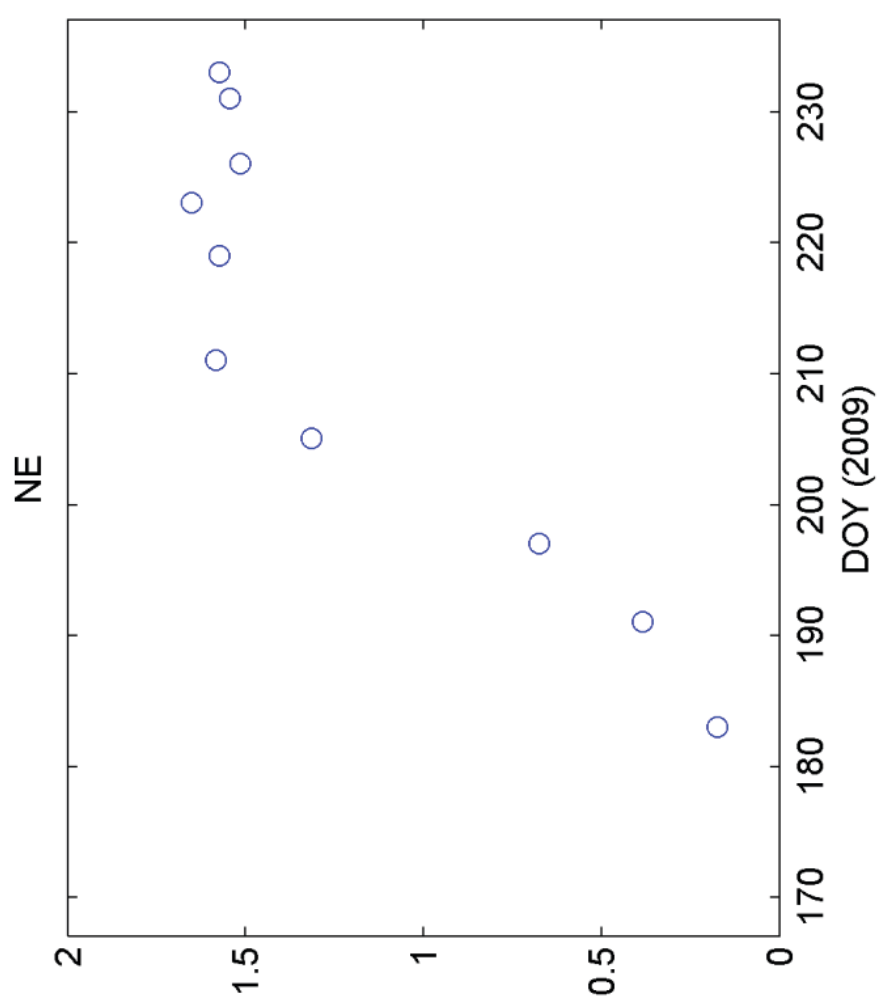

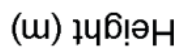

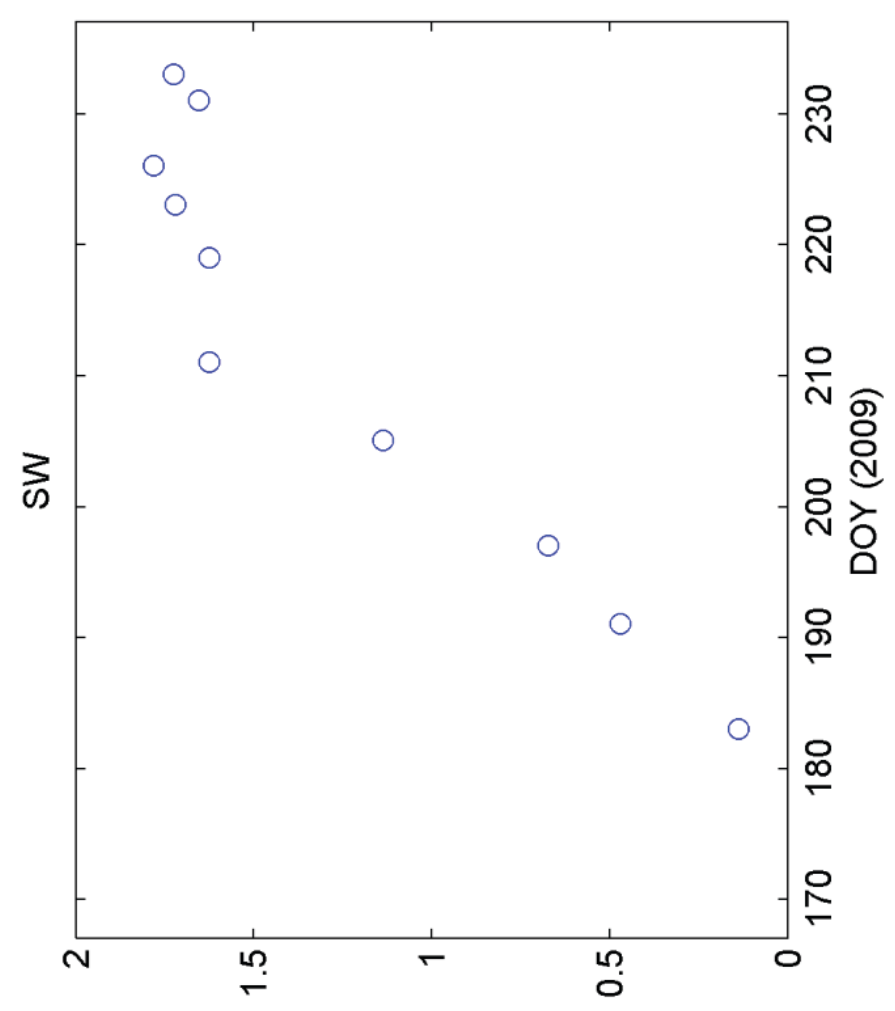

(i) +46 เәә

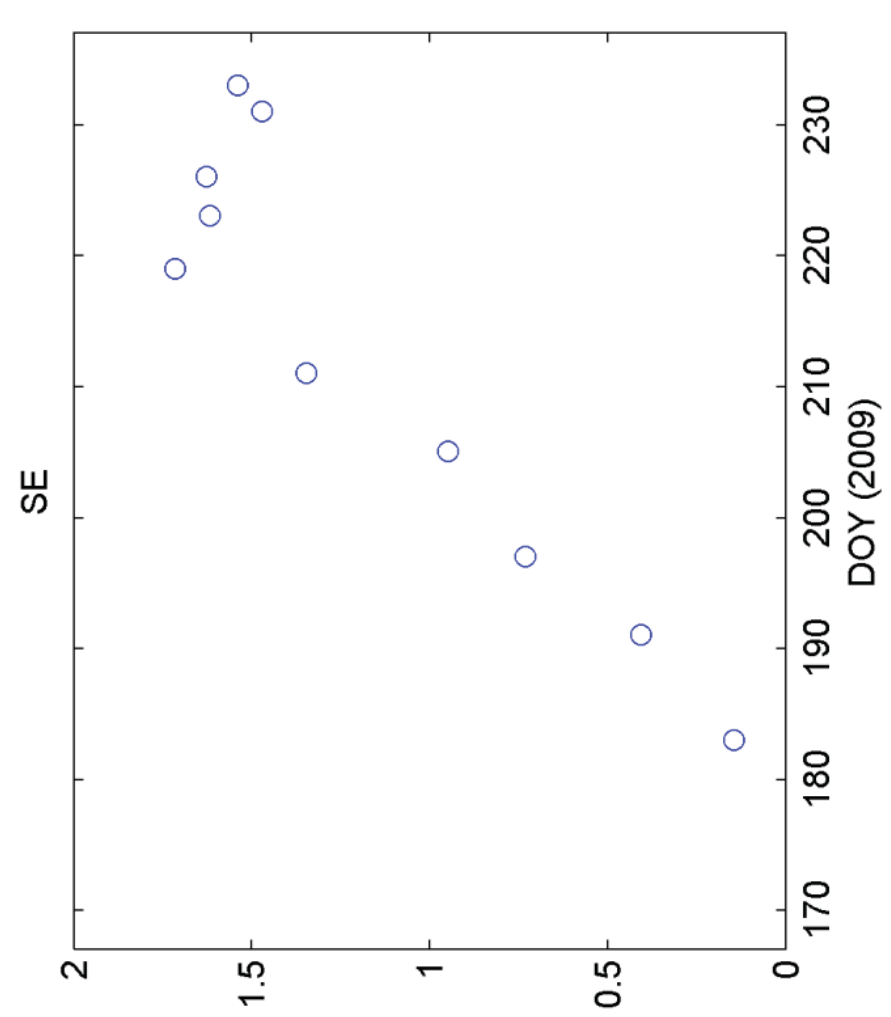

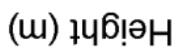

Figure A-14. Average crop heights.

Field Observations During the Eighth Microwave Water and Energy Balance Experiment (MicroWEX-8): 54 from June 16 through August 24, 2009 


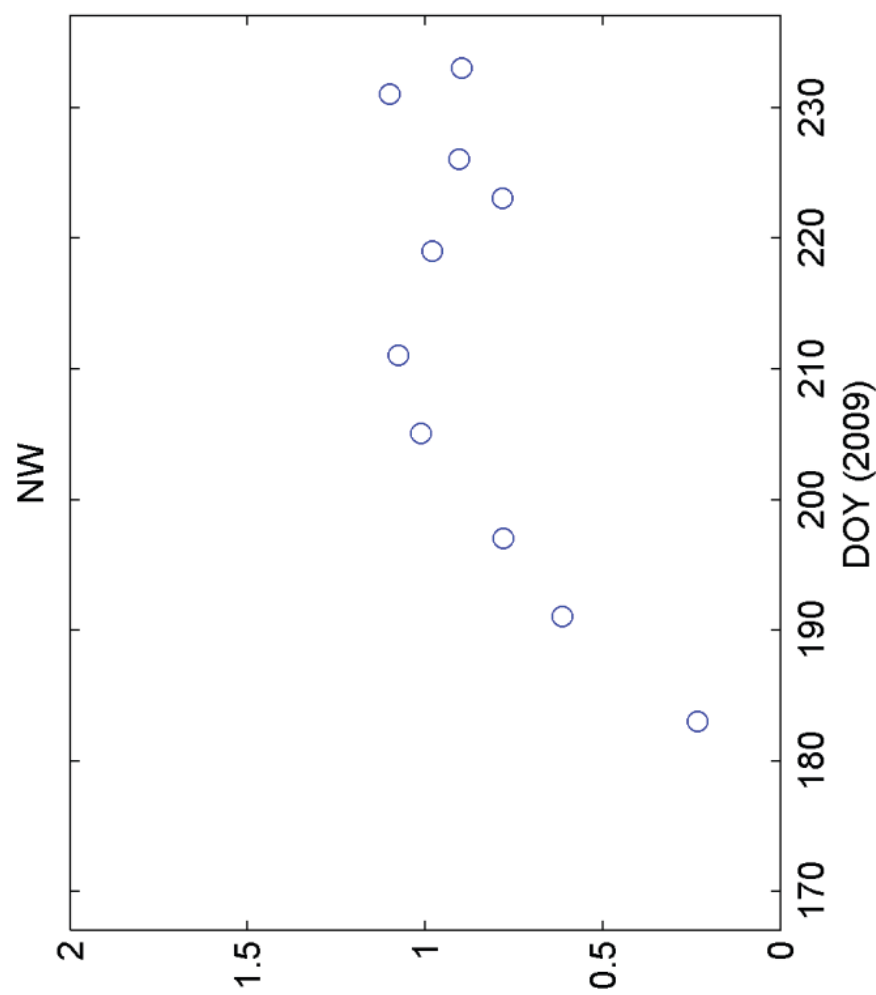

(w) บIPIM

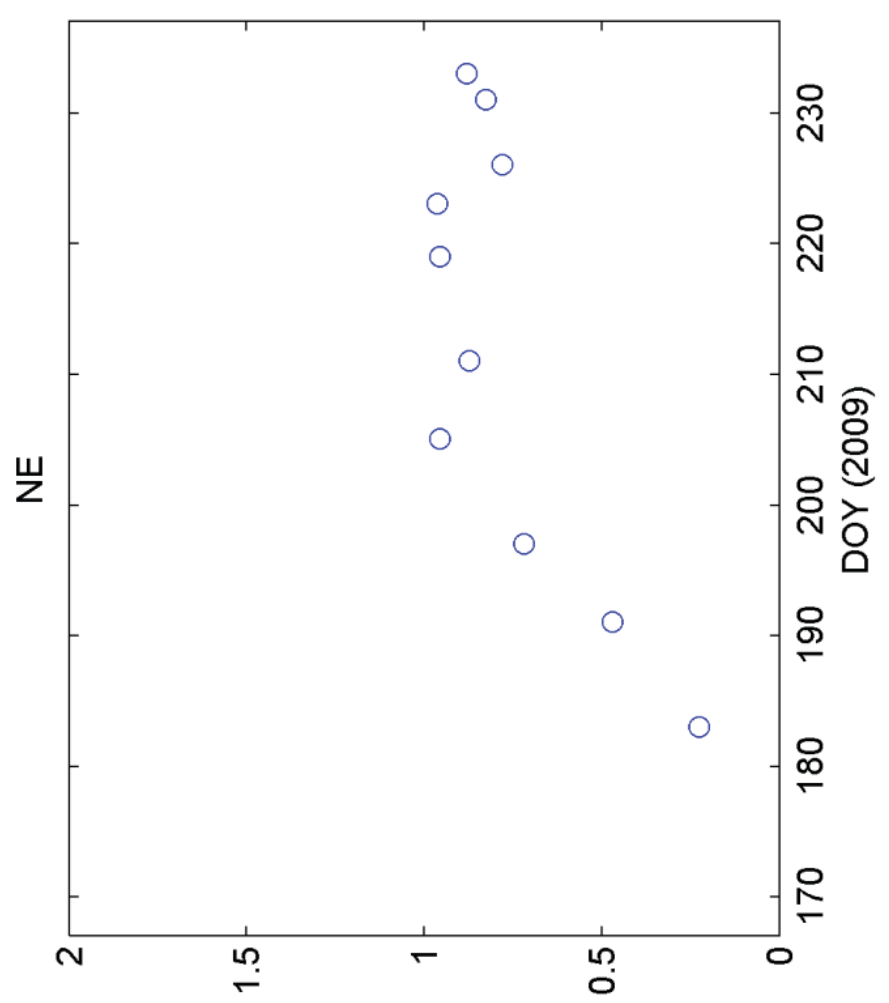

(w) ЧІР!M

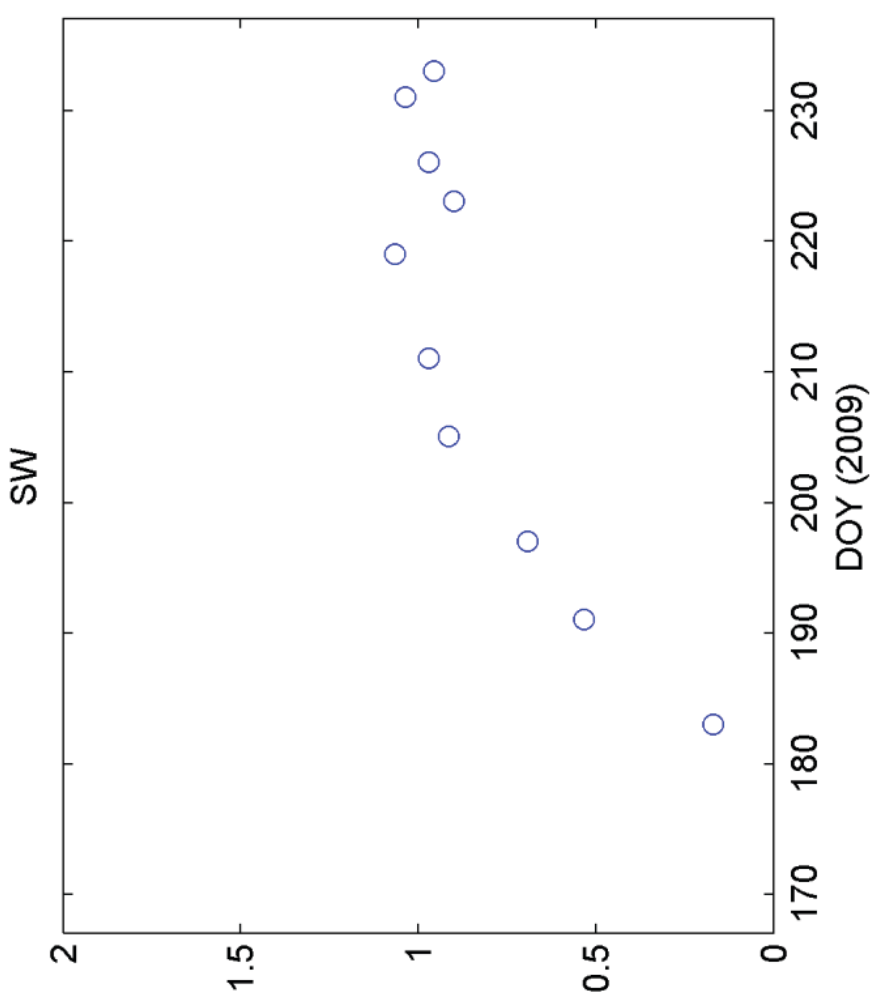

(u) чIP!M

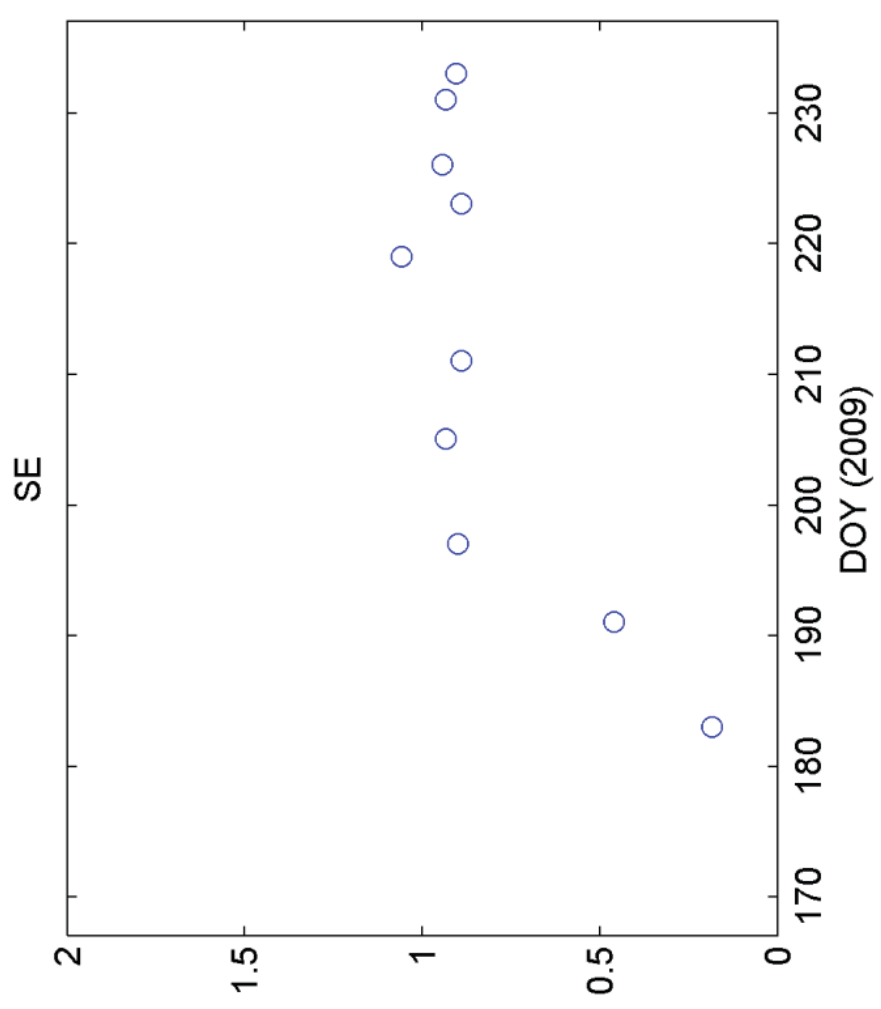

(u) чІр!M

Figure A-15. Average crop widths.

Field Observations During the Eighth Microwave Water and Energy Balance Experiment (MicroWEX-8): $\mathbf{5 5}$ from June 16 through August 24, 2009 

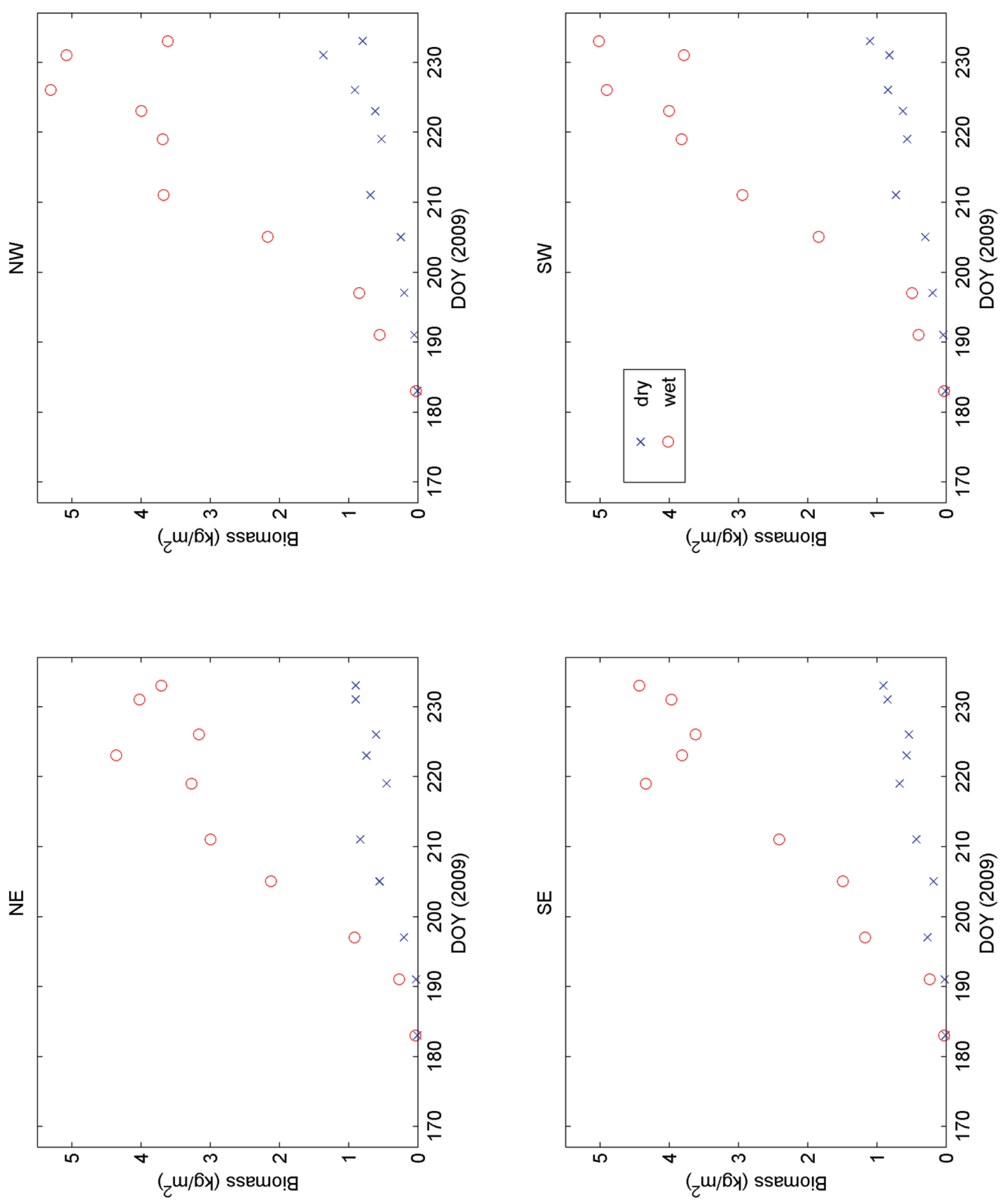

Figure A-16. Wet and dry canopy biomass.

Field Observations During the Eighth Microwave Water and Energy Balance Experiment (MicroWEX-8): 56 from June 16 through August 24, 2009 

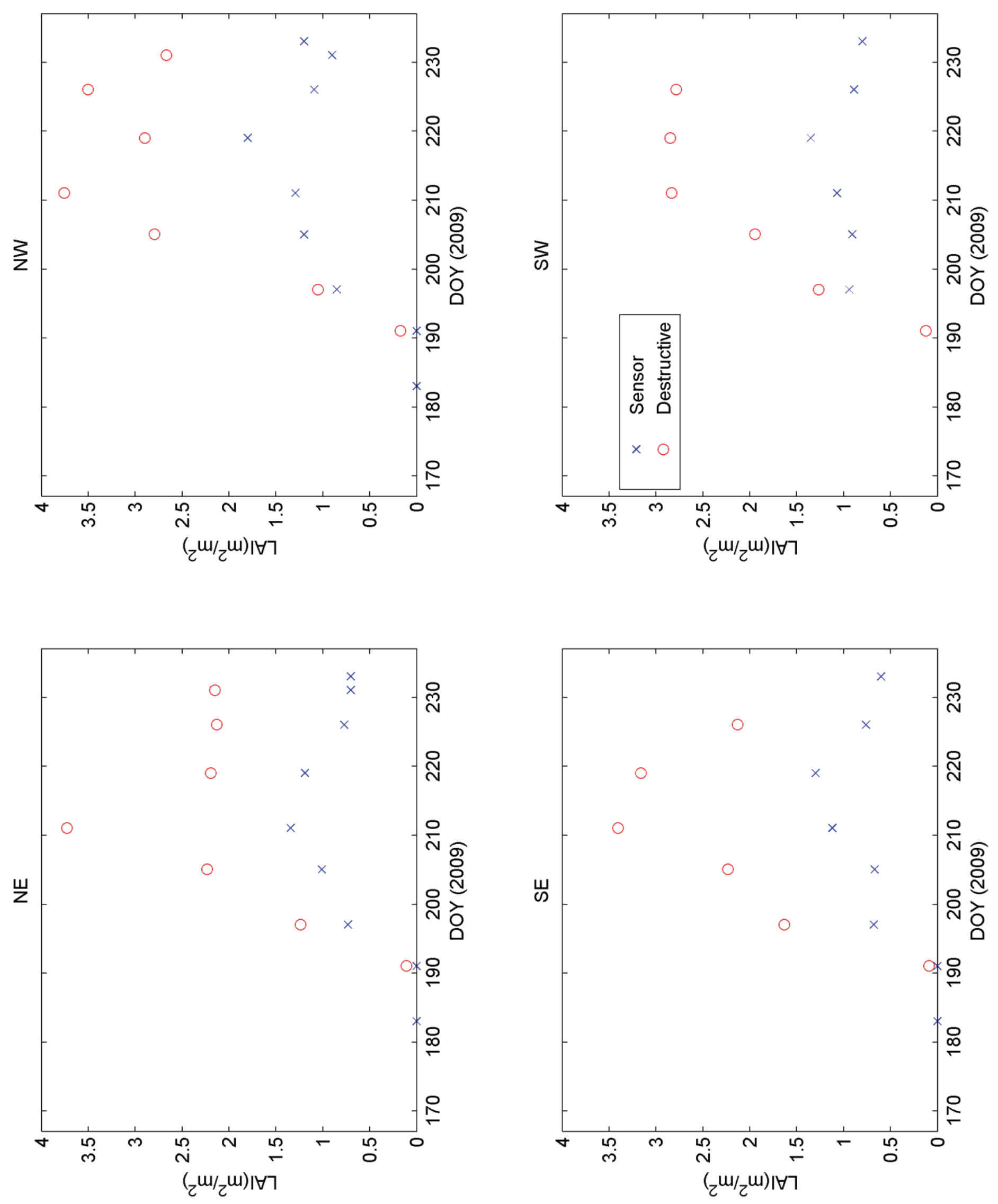

Figure A-17. Canopy LAI.

Field Observations During the Eighth Microwave Water and Energy Balance Experiment (MicroWEX-8): 57 from June 16 through August 24, 2009 


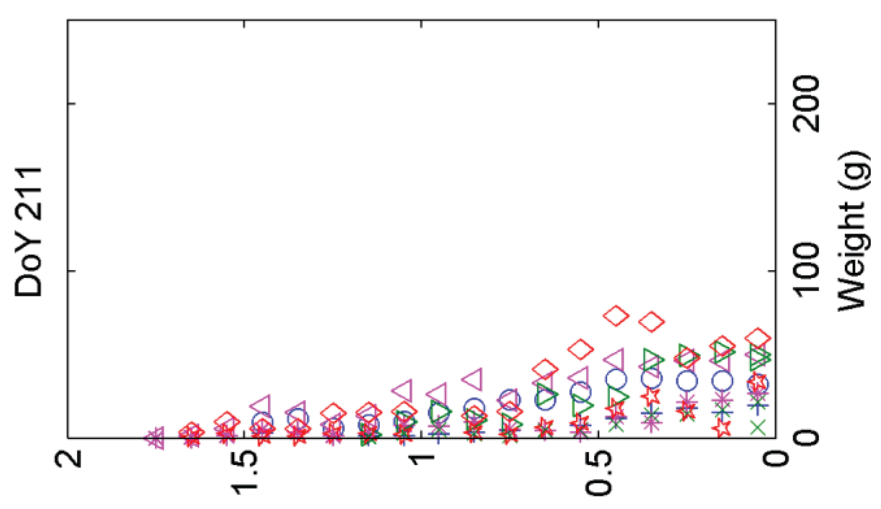

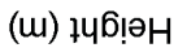
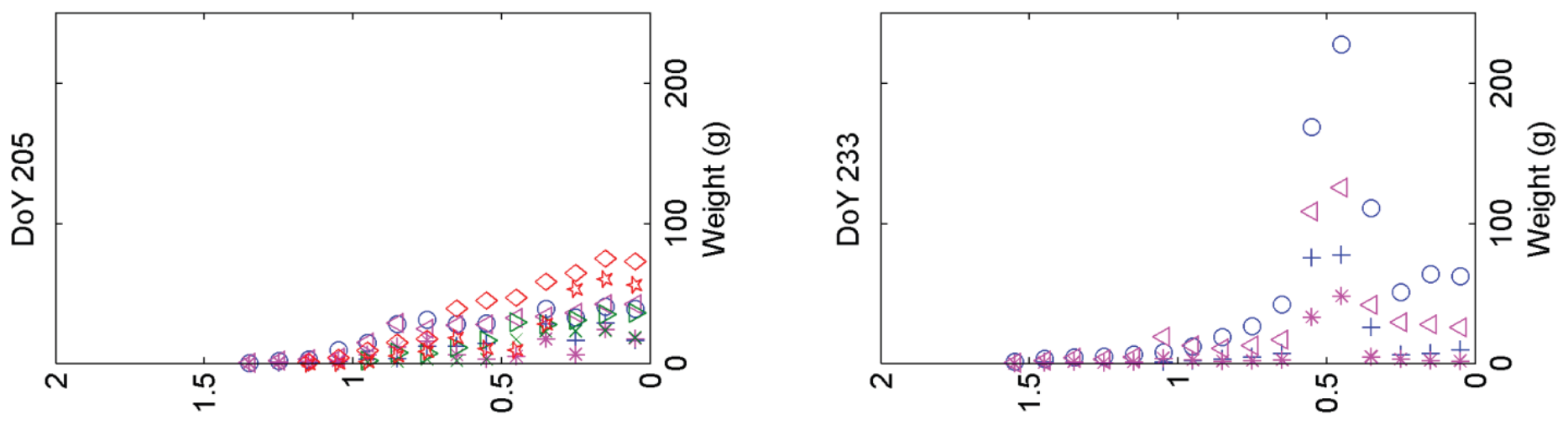

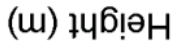

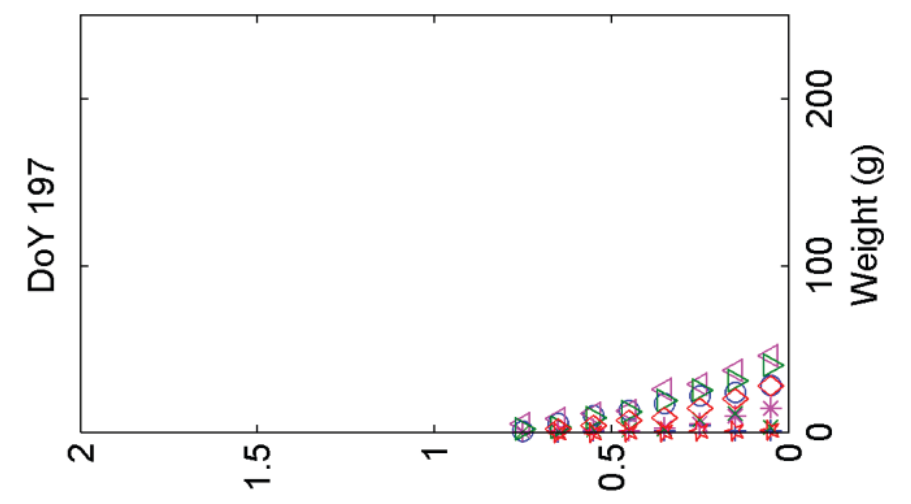

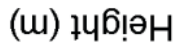

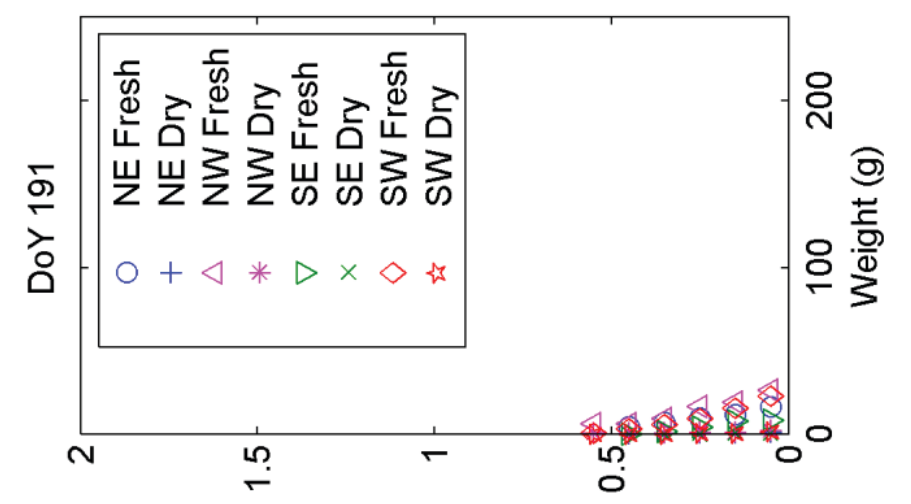

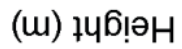

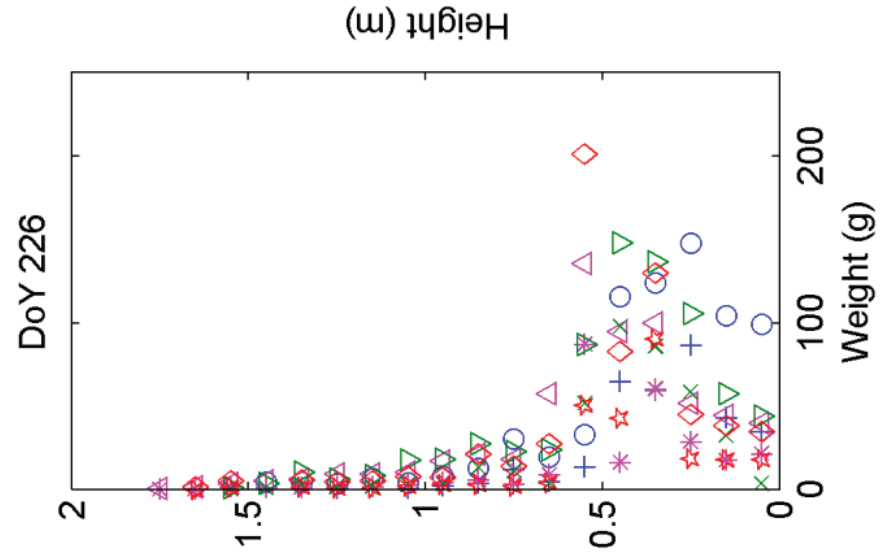

(u) $+46 !$ əेН

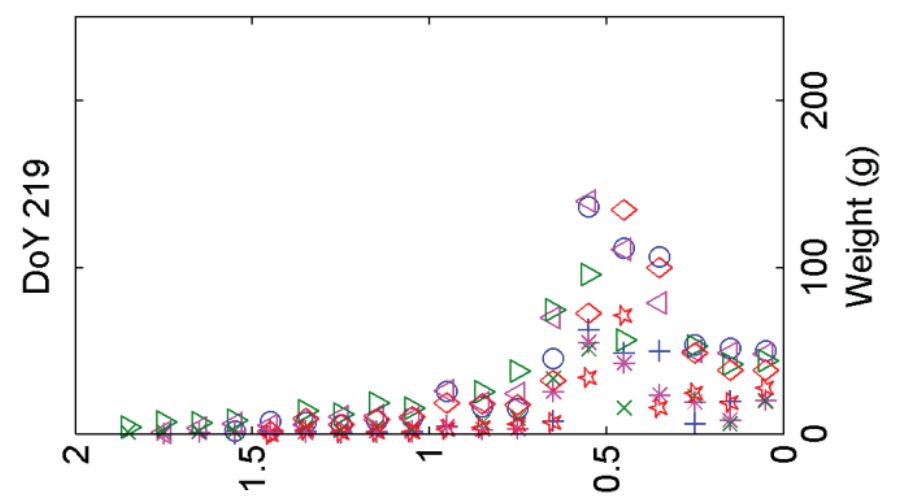

(u) $746 !$

Figure A-18. Vertical distribution of wet and dry biomass. 
(u) дәғәше!ด

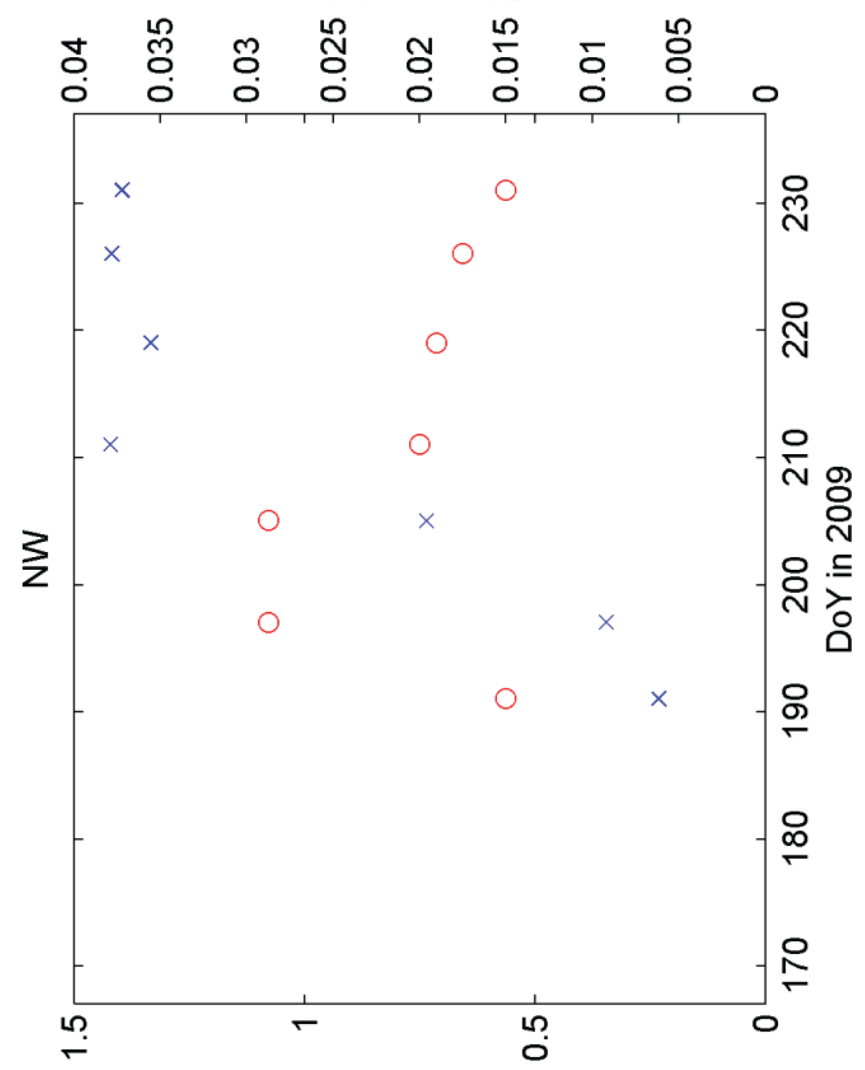

(i) чұ๐ธәэ

(u) ләғәше!

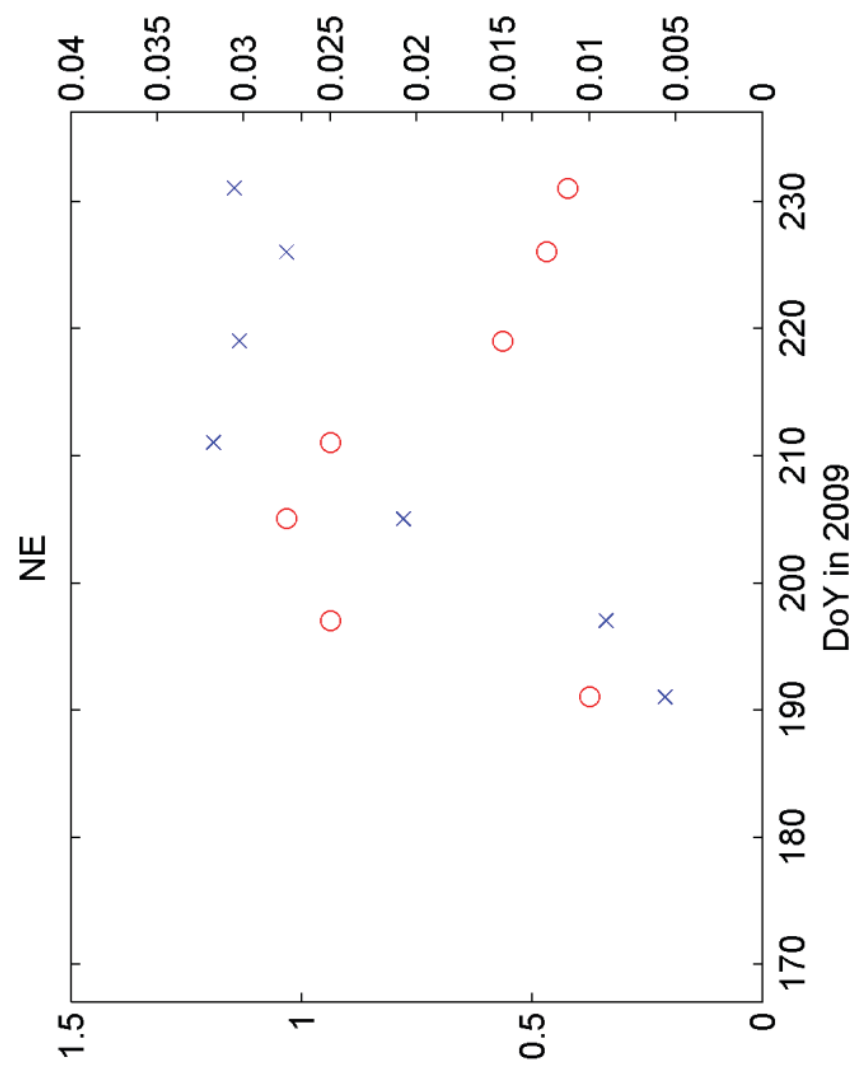

(w) чұ๐иәา (u) גәџәше!

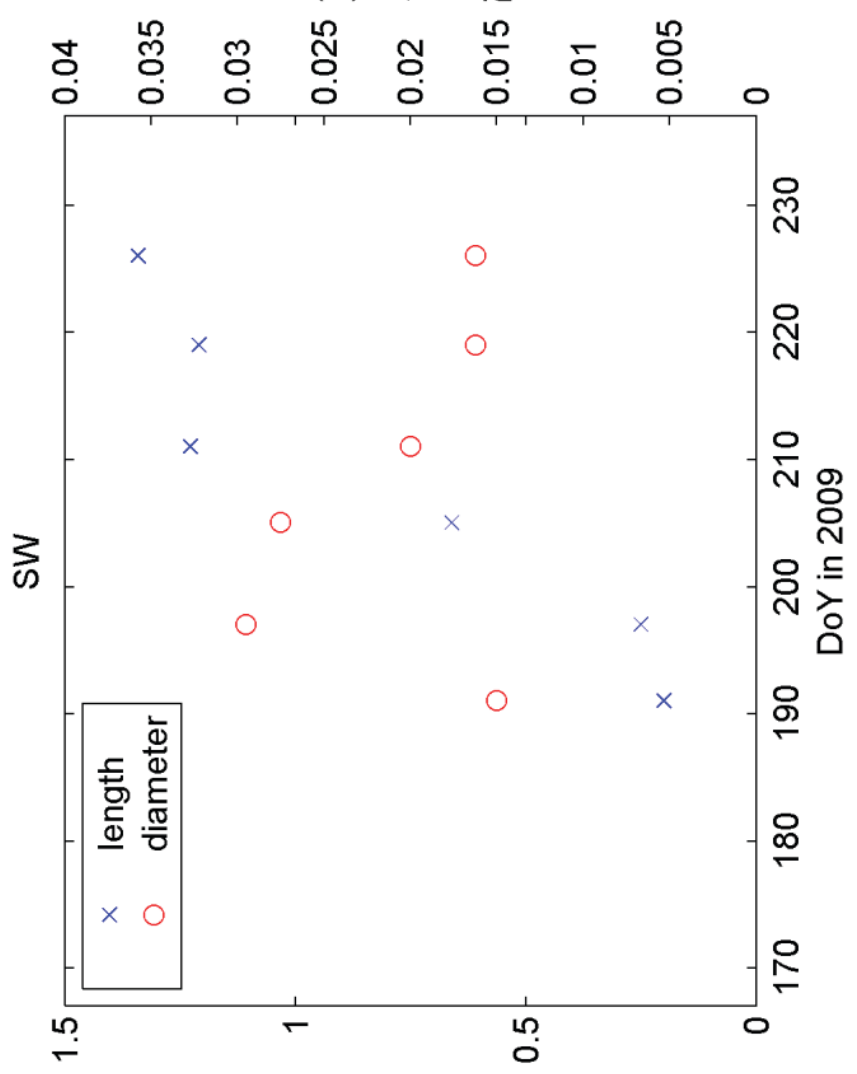

(w) чұбиәך

(u) дәэәше!

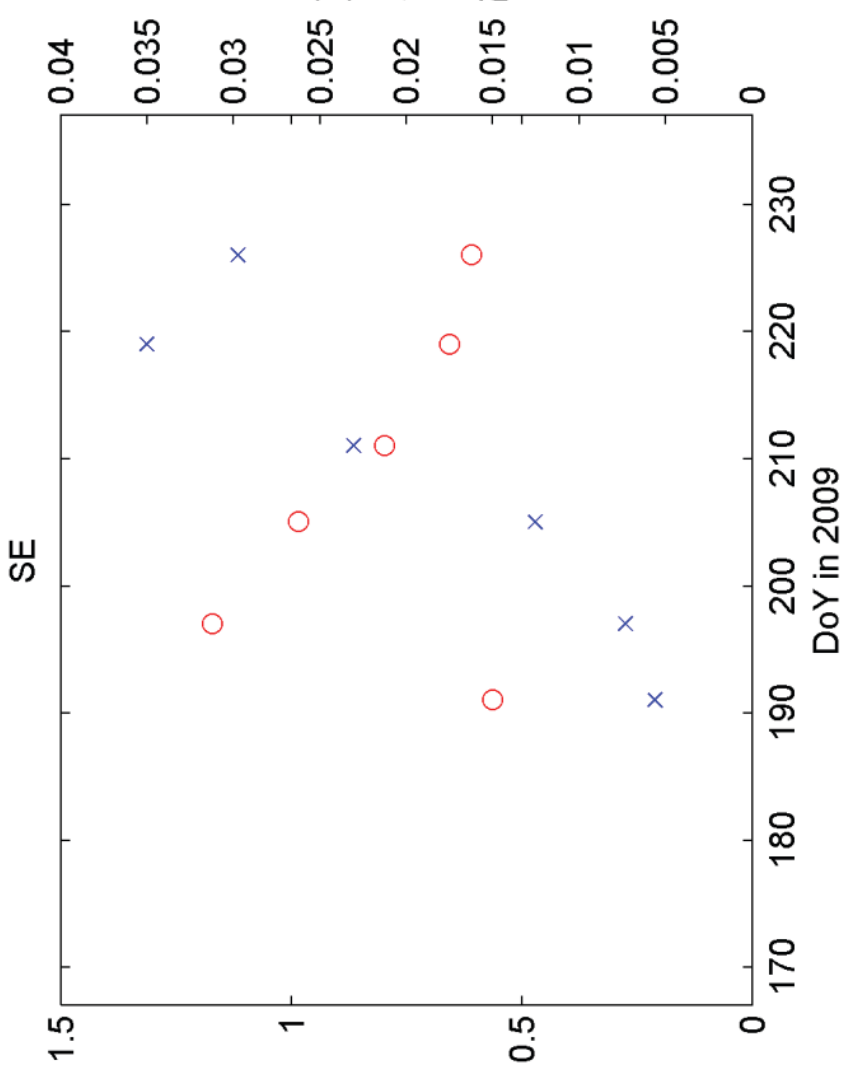

(w) чұ๐иәך

Figure A-19. Stem length and diameter. 


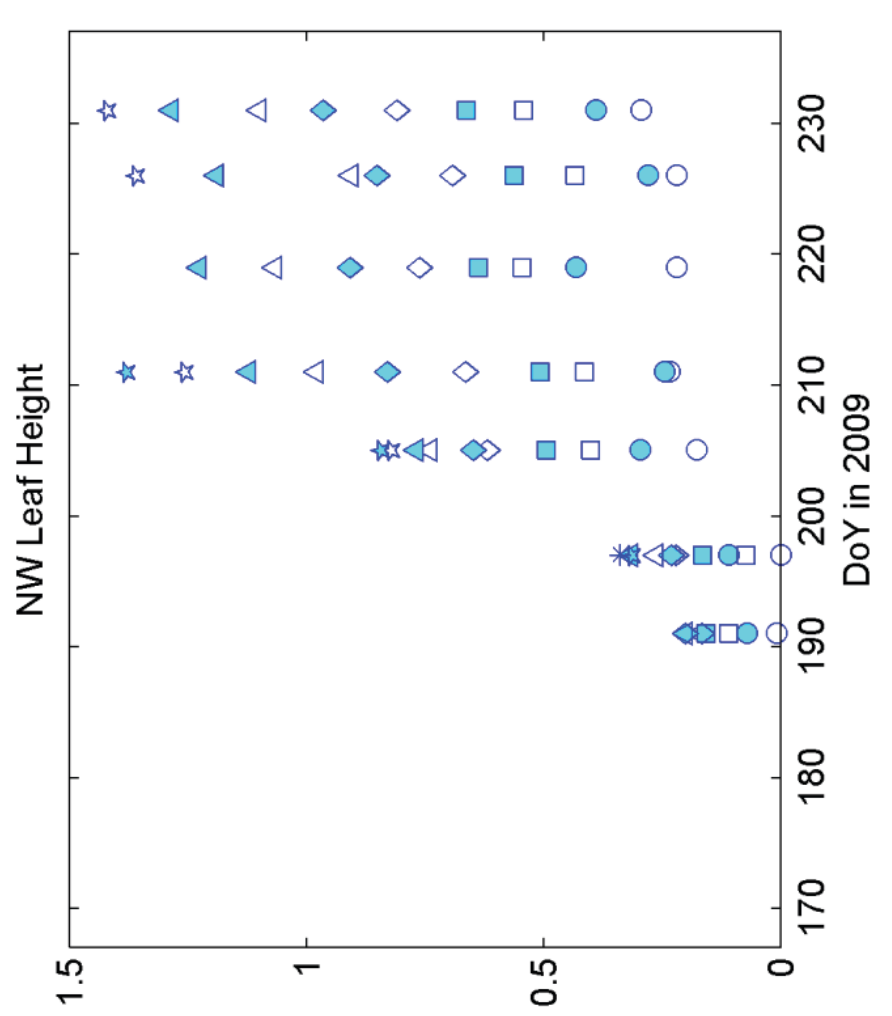

(u) ㄱбㅣㅋㅏ

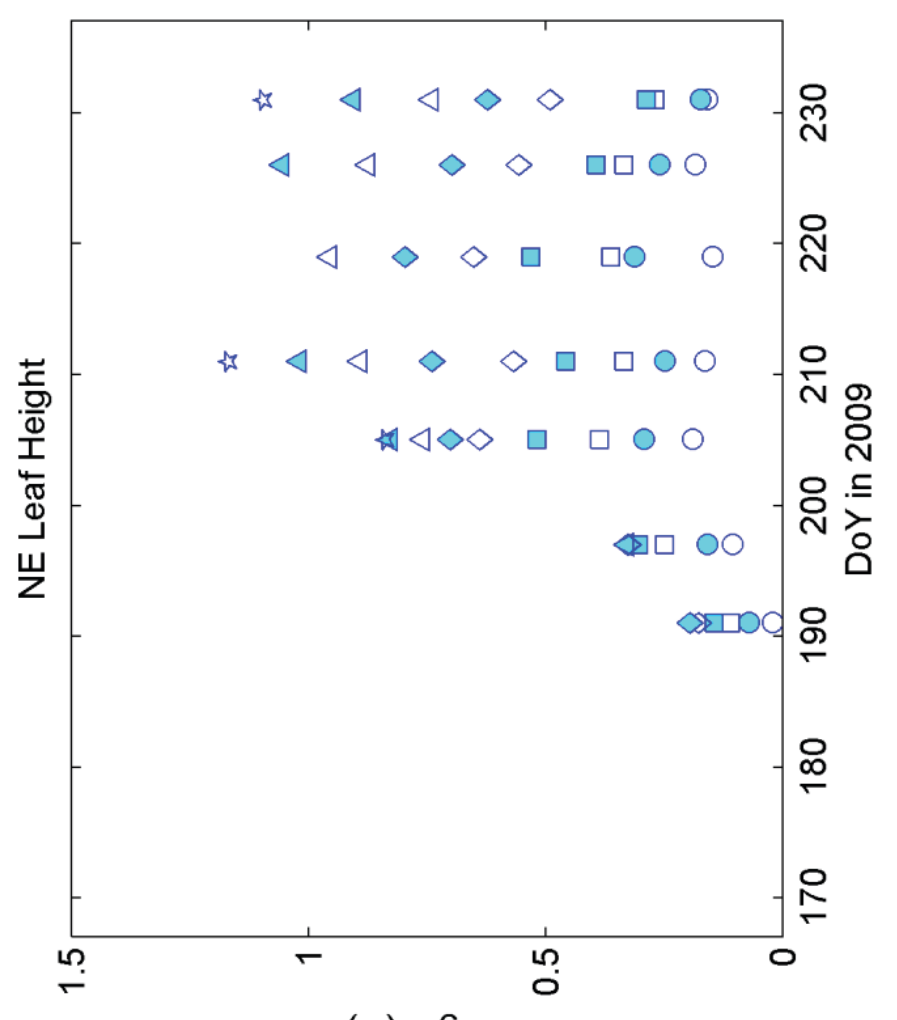

(ui) $7466 !$

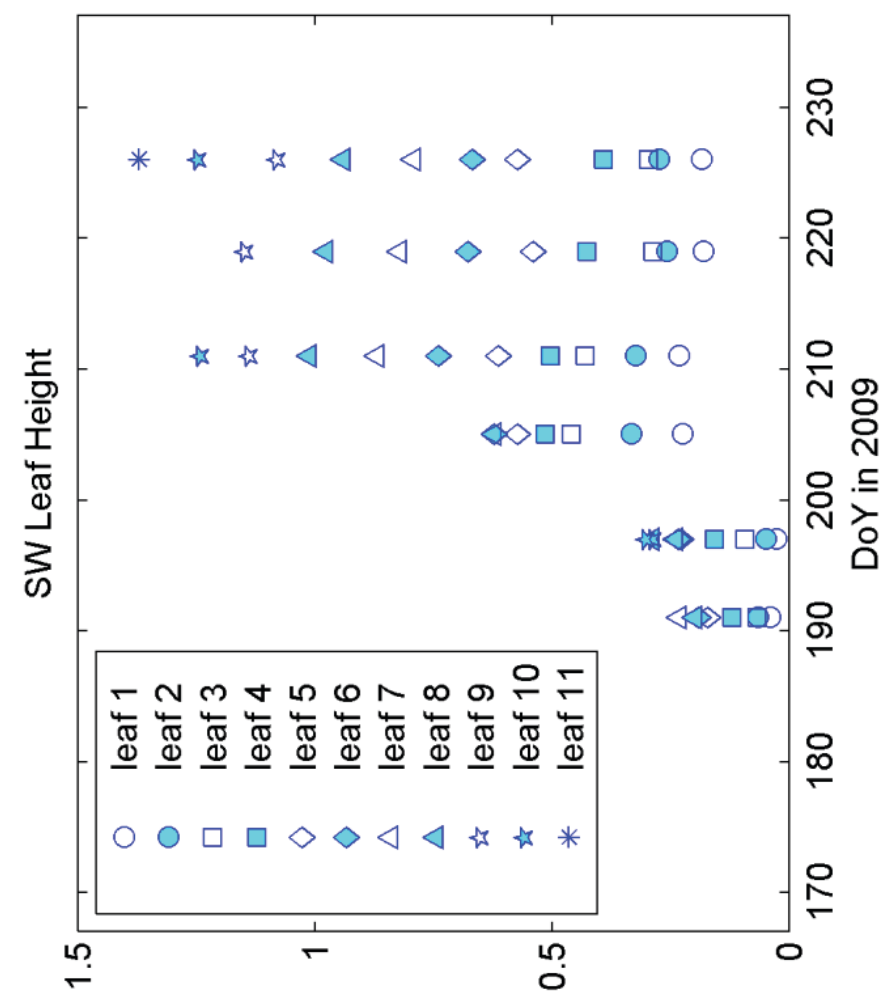

(i) 74 पाँ

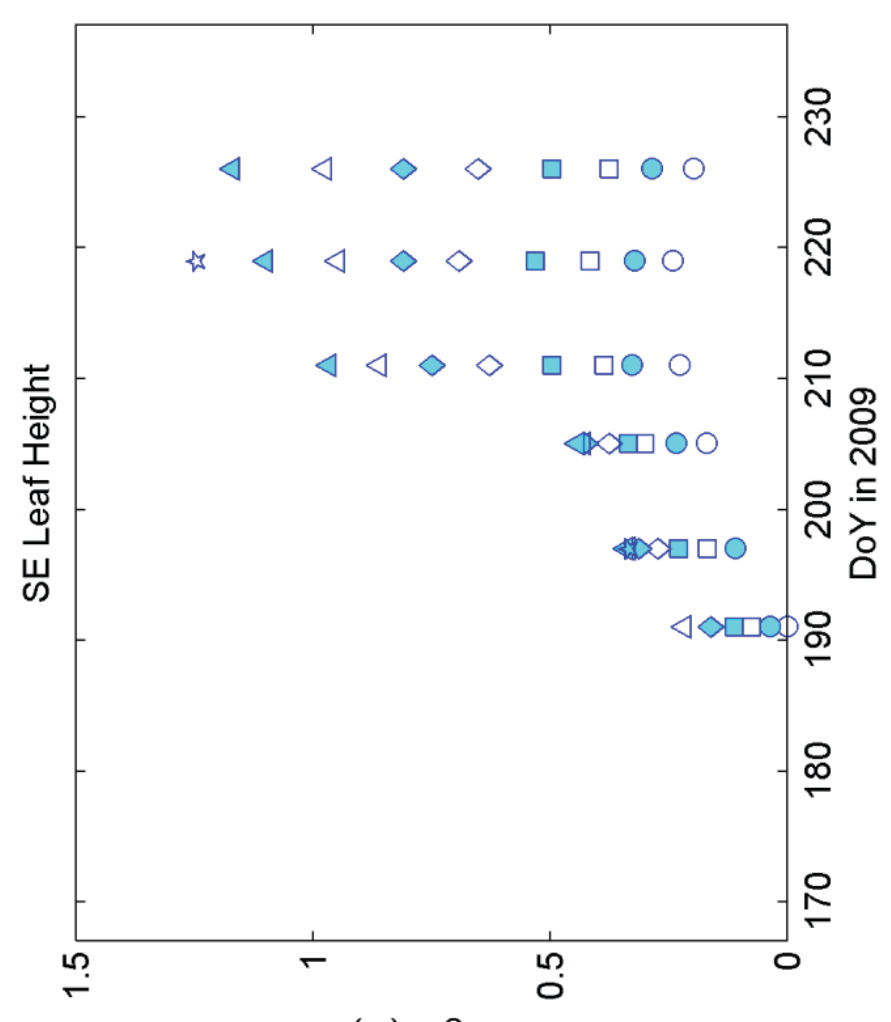

(w) ₹4ธิเәН

Figure A-20. Leaf height. 


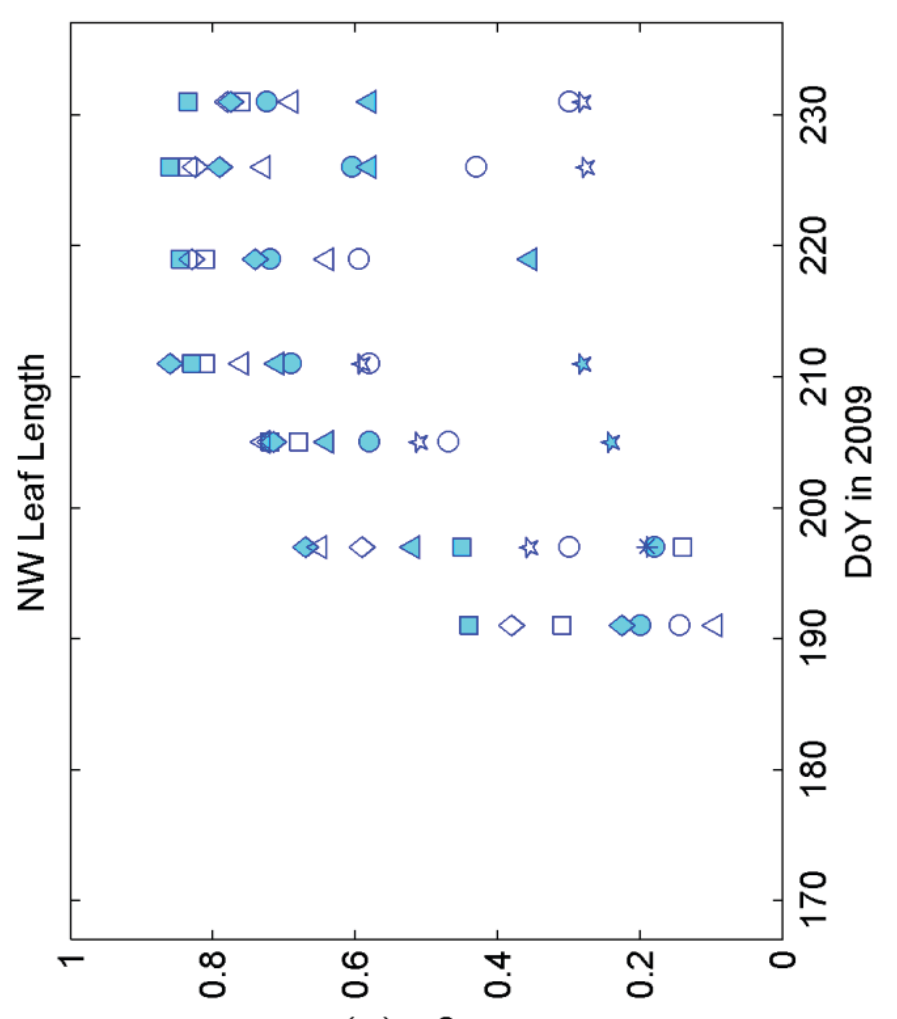

(u) บาธนәว

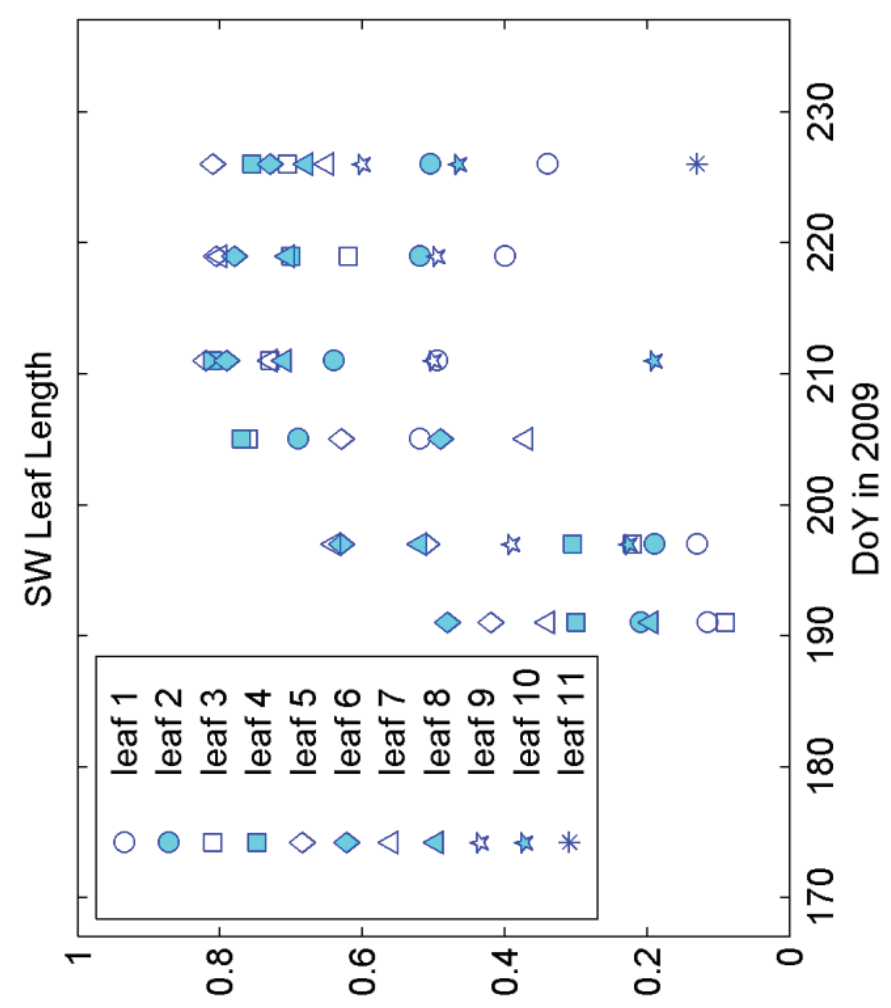

(w) чұ๐นәา

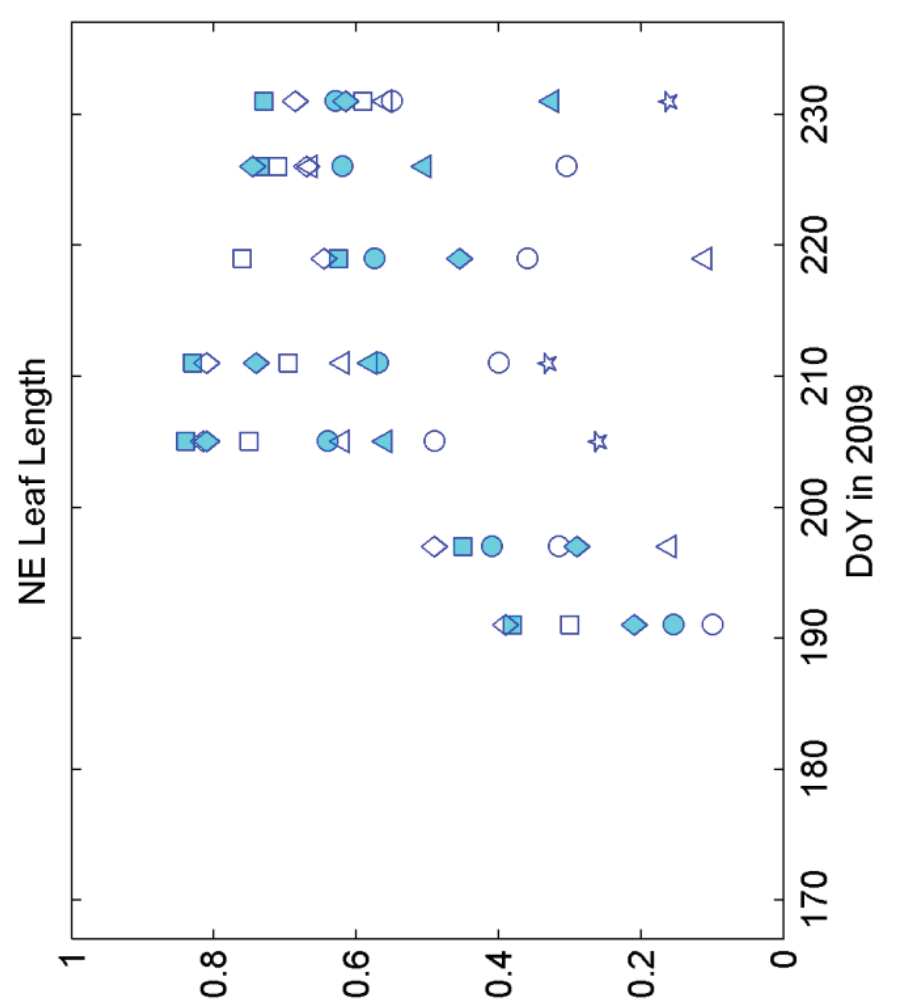

(ii) чұ๐นәәา

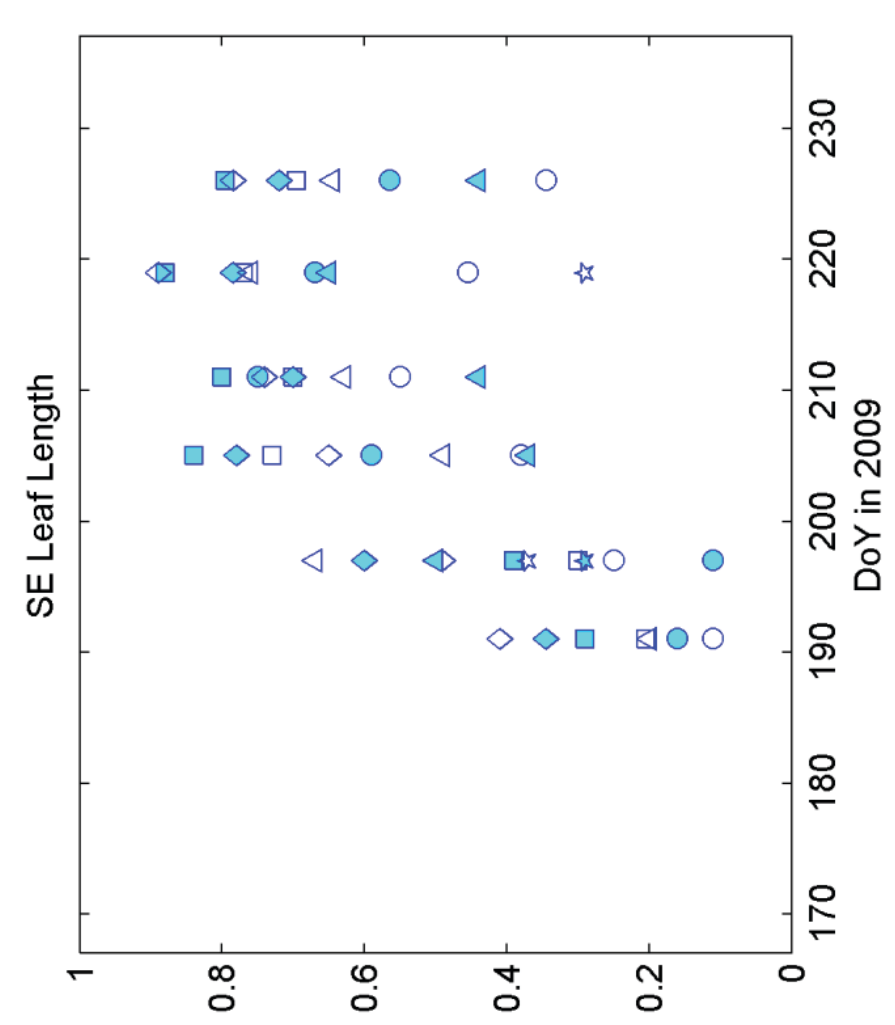

(w) чұ๐иәך

Figure A-21. Leaf length. 


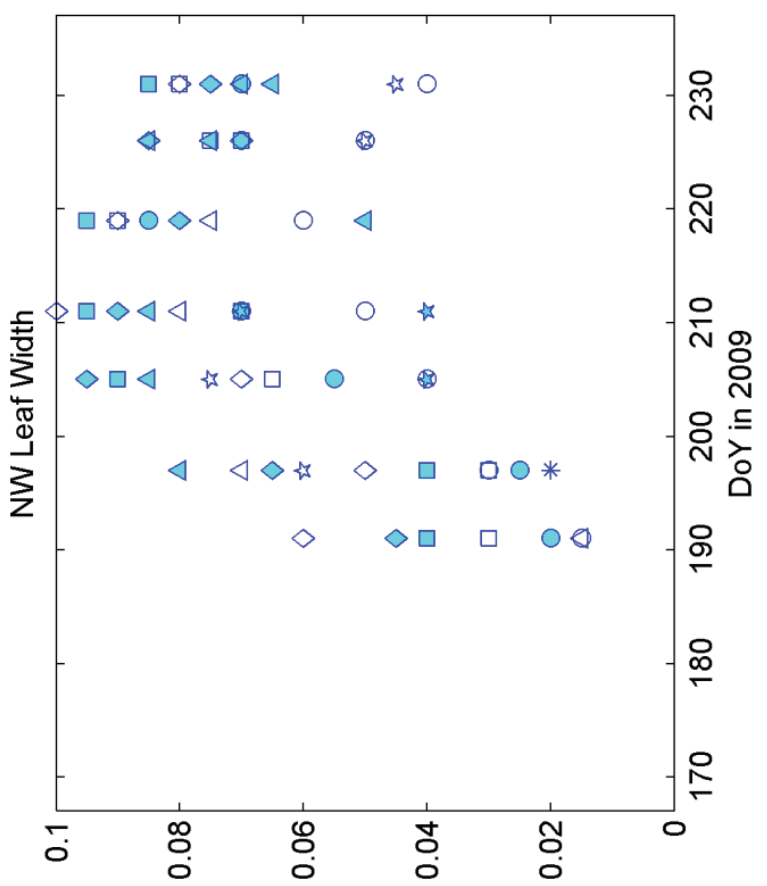

(w) чIPIM

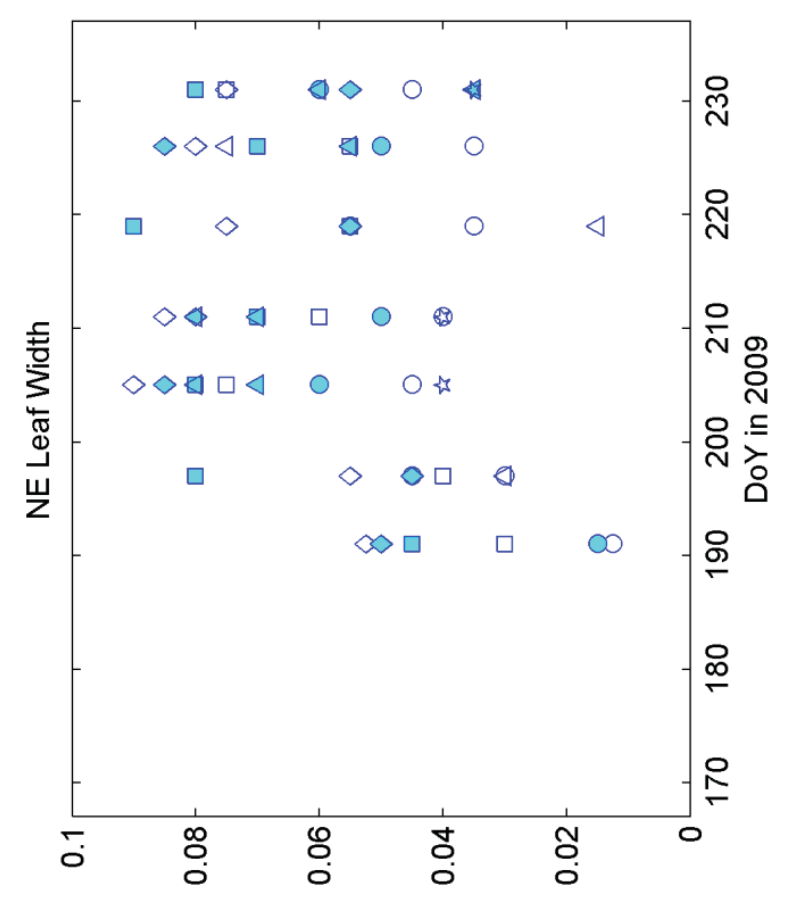

(w) чІр!M

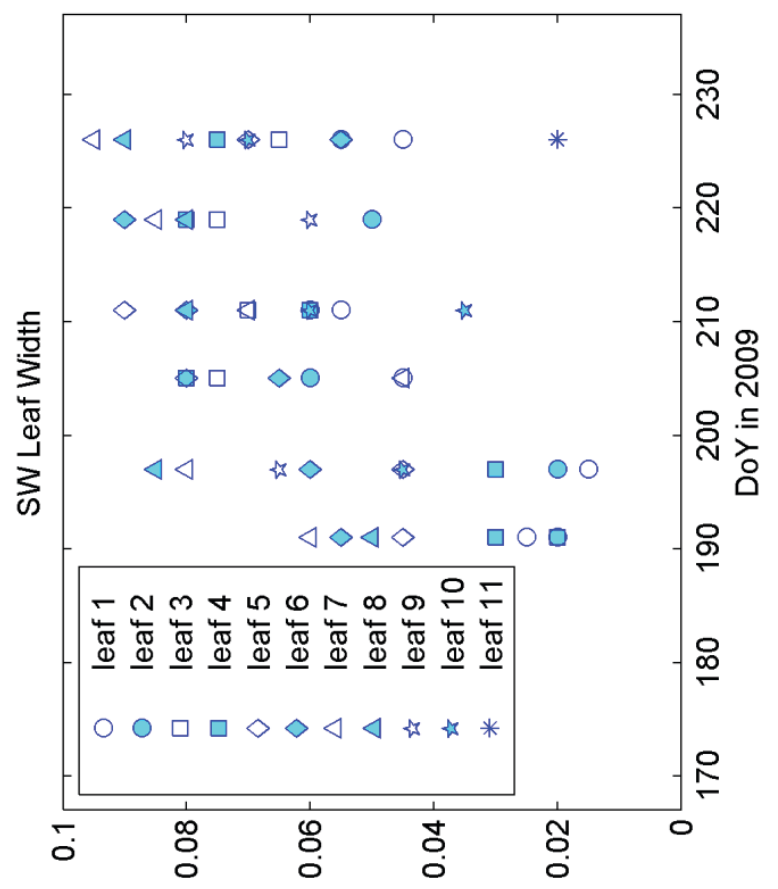

(w) บIPIM

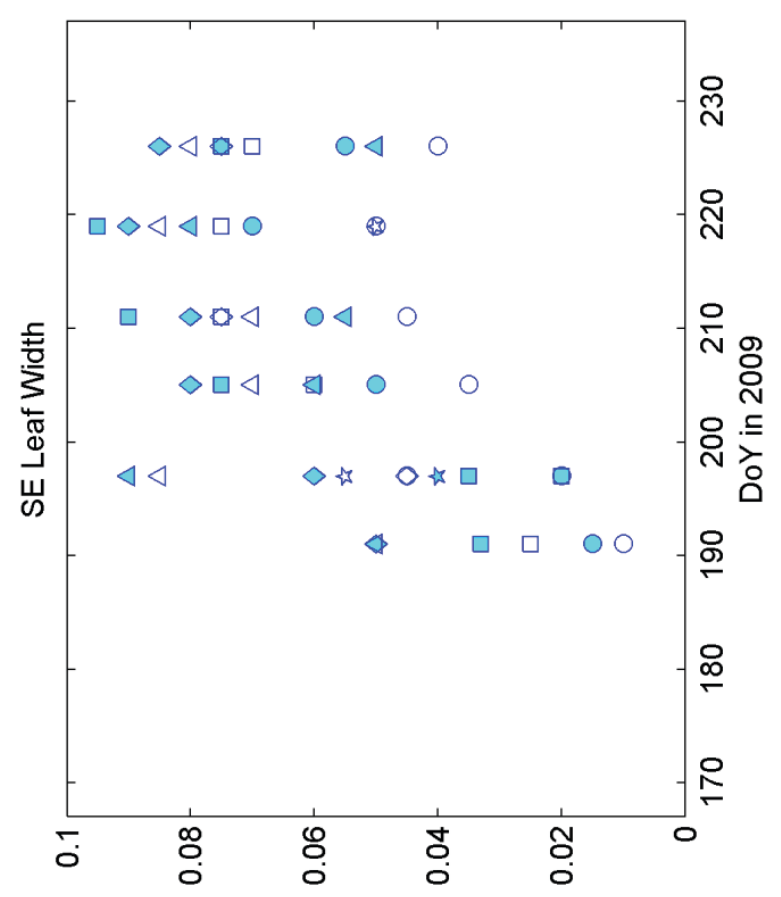

(w) ЧIP!M

Figure A-22. Leaf width. 

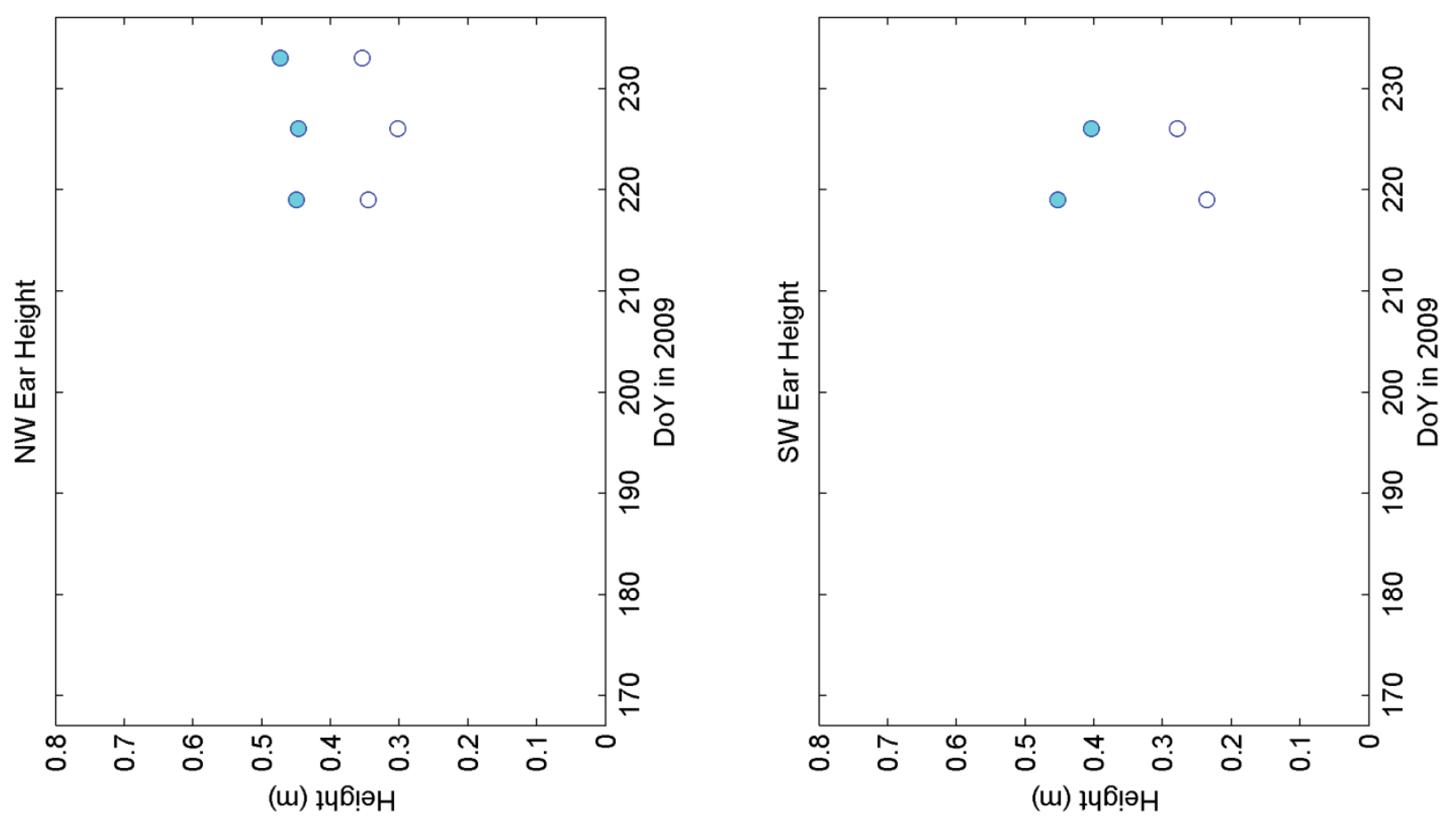

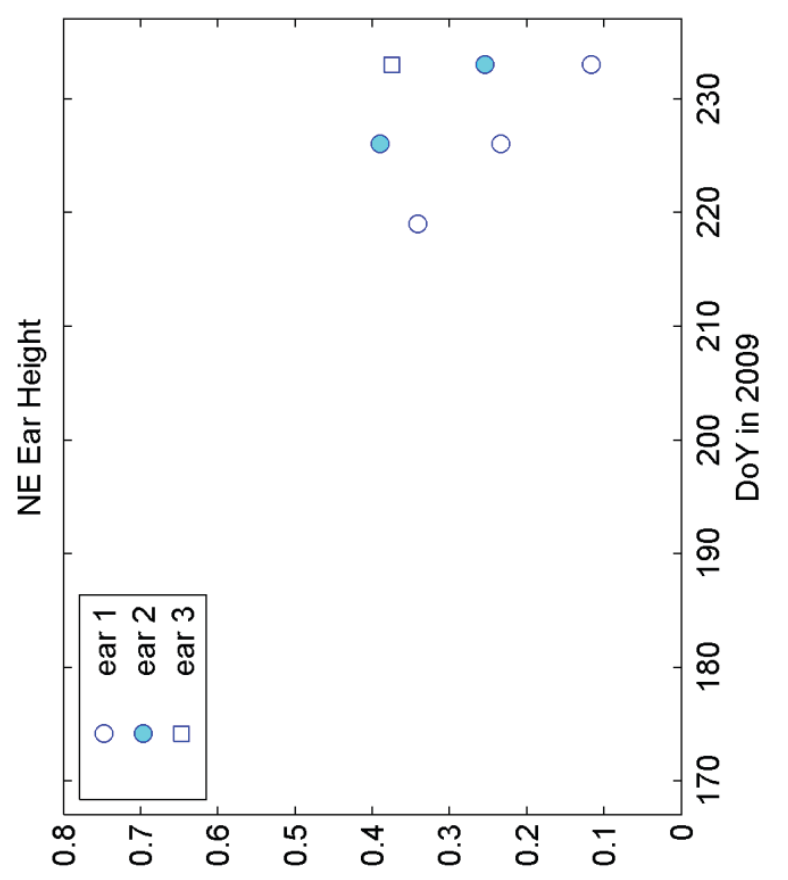

(u) $ұ$

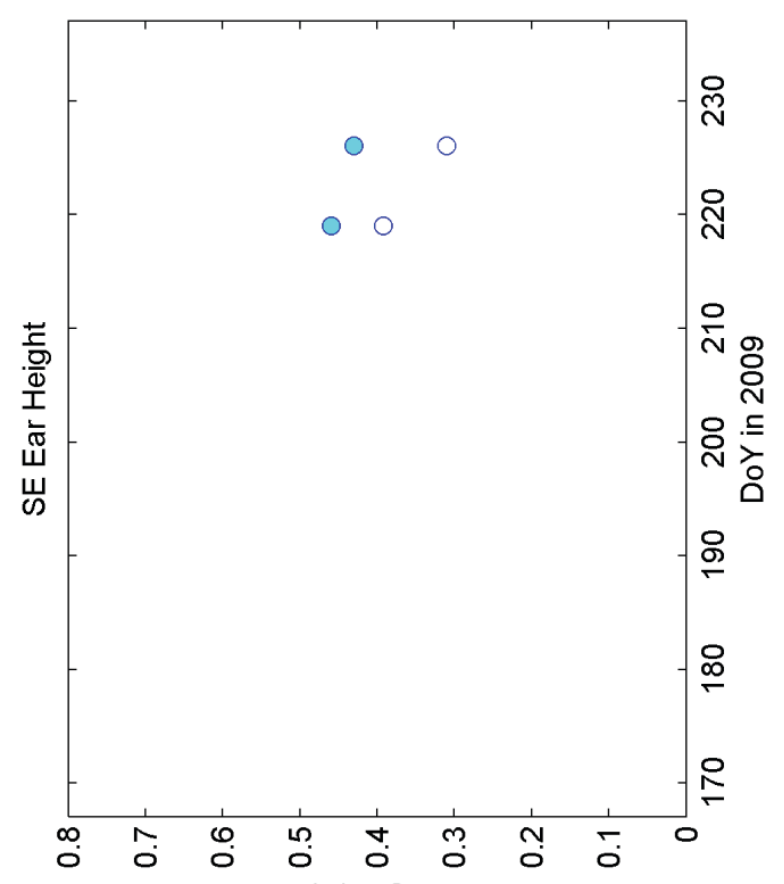

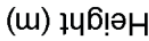

Figure A-23. Ear height.

Field Observations During the Eighth Microwave Water and Energy Balance Experiment (MicroWEX-8): 63 from June 16 through August 24, 2009 
(ii) дәғәше!

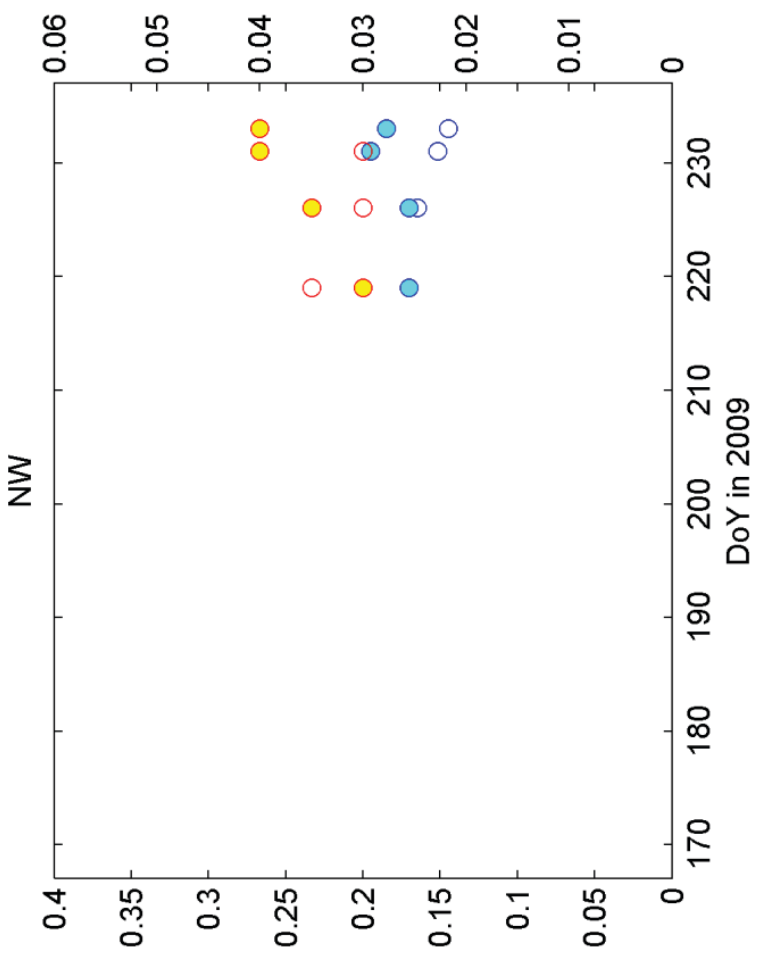

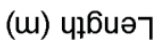

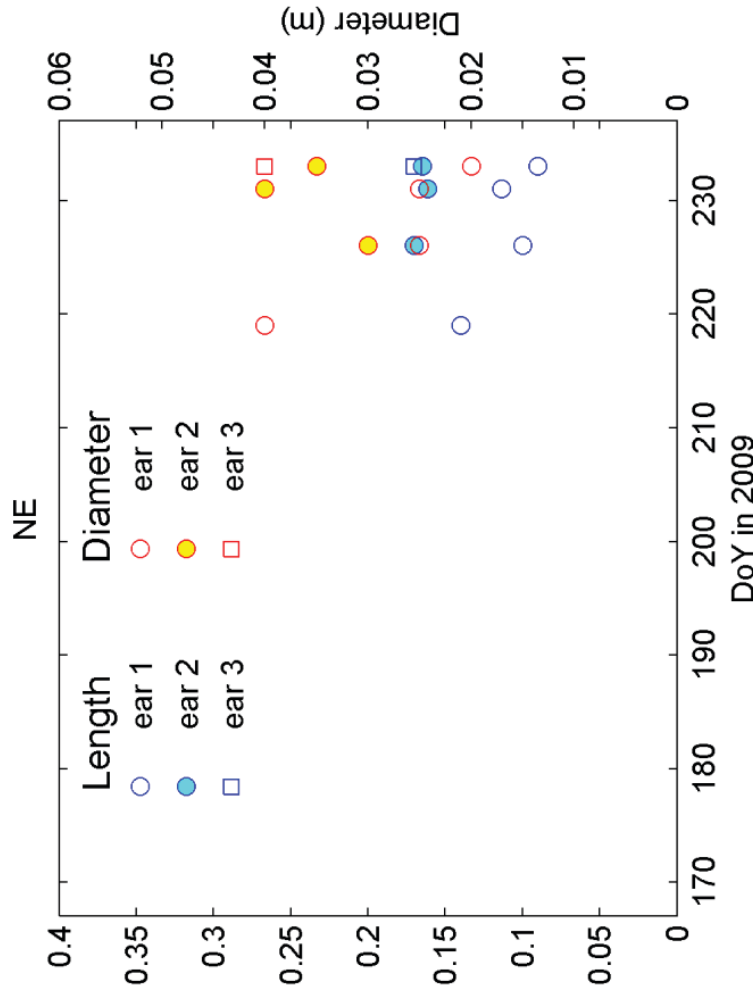

(w) чұ๐นәך

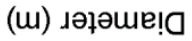

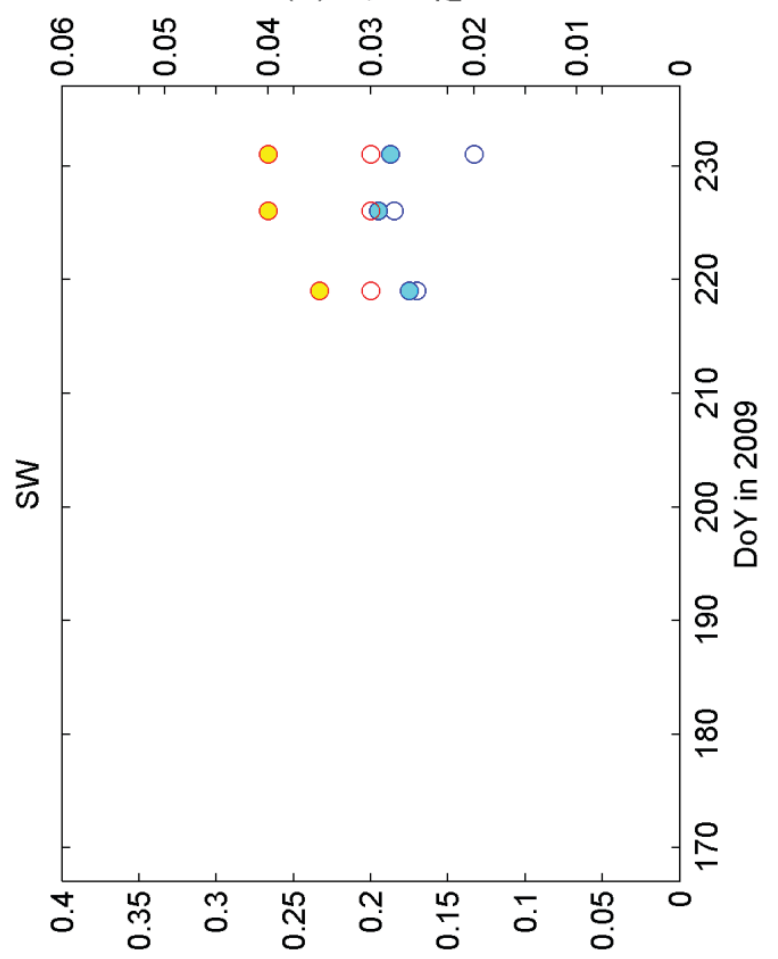

(ii) чұбиәๆ

(iu) גәғәше!

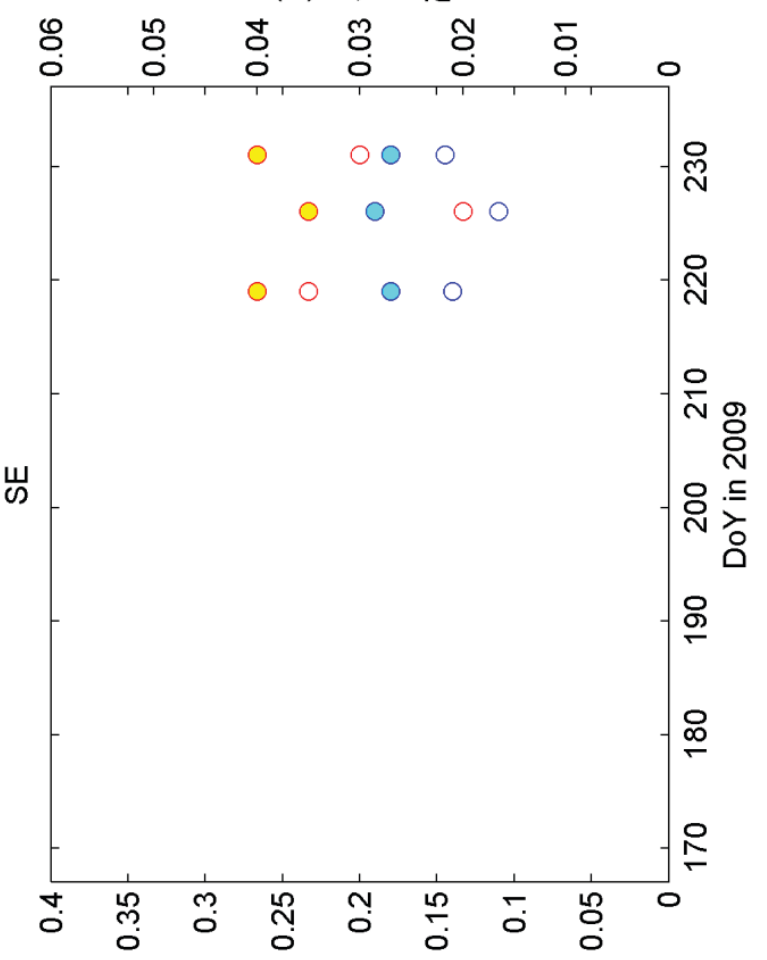

(i) чұ๐иәา 

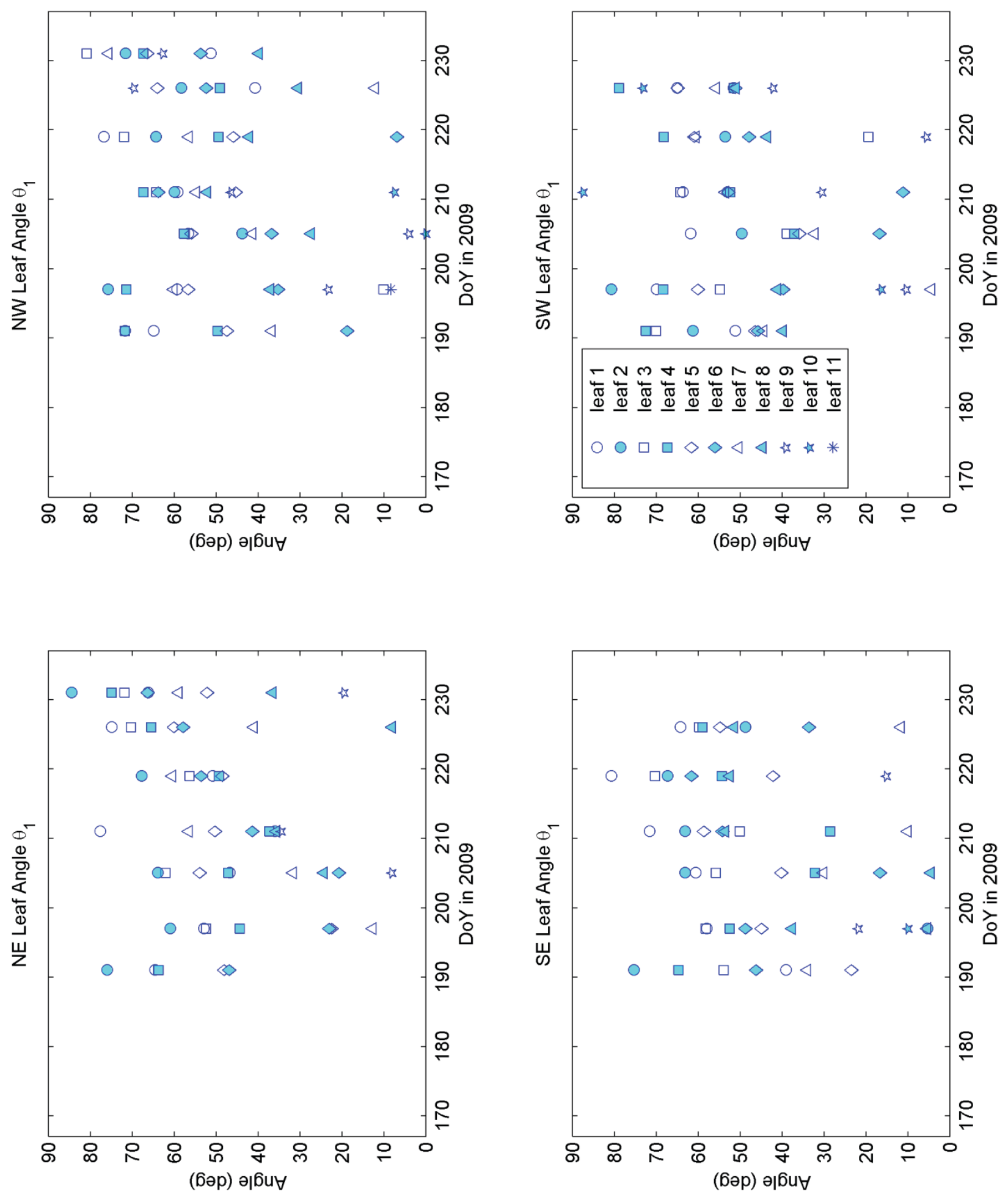

Figure A-25. Leaf angle $\left(\theta_{1}\right)$. 

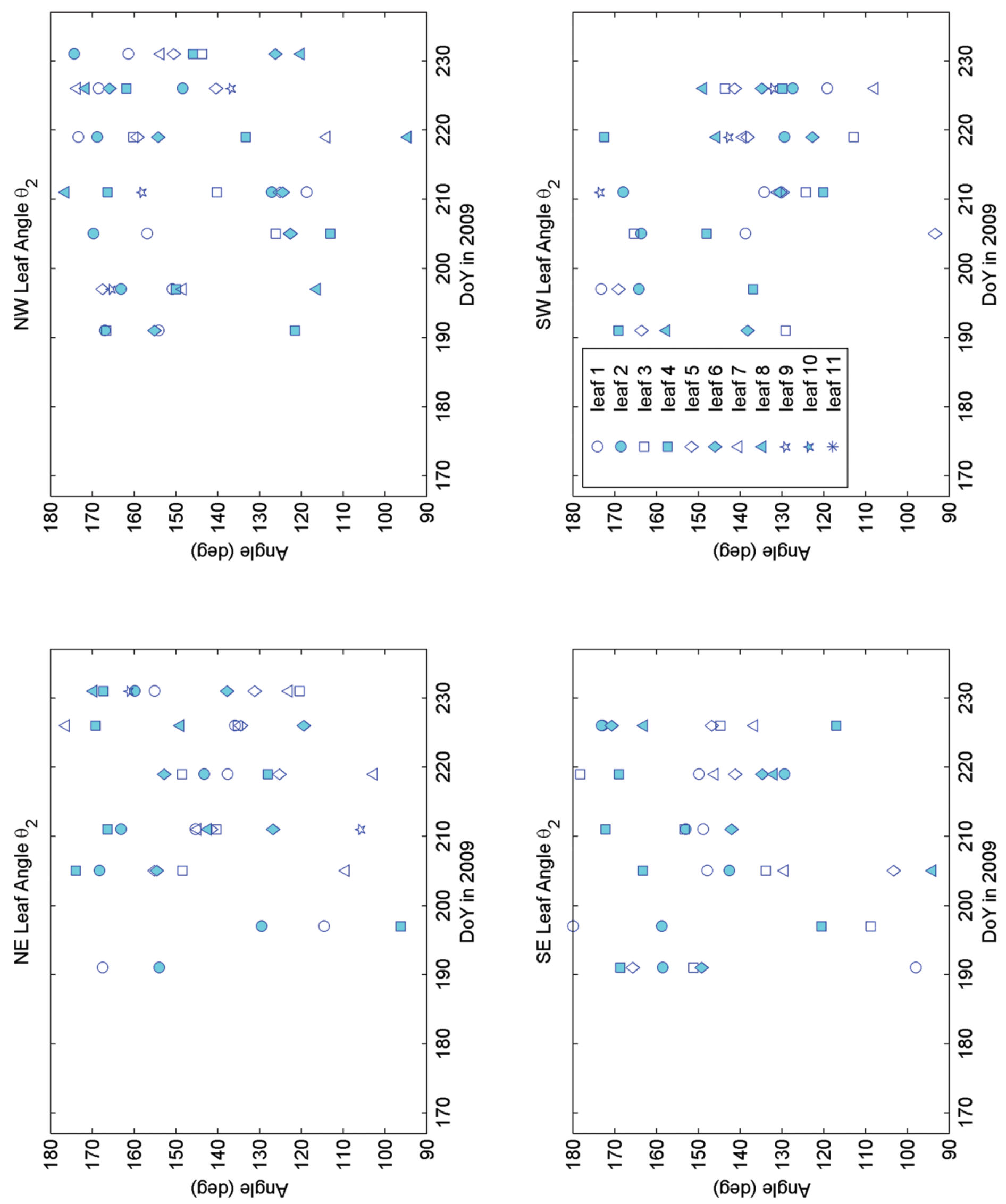

Figure A-26. Leaf angle $\left(\theta_{2}\right)$. 

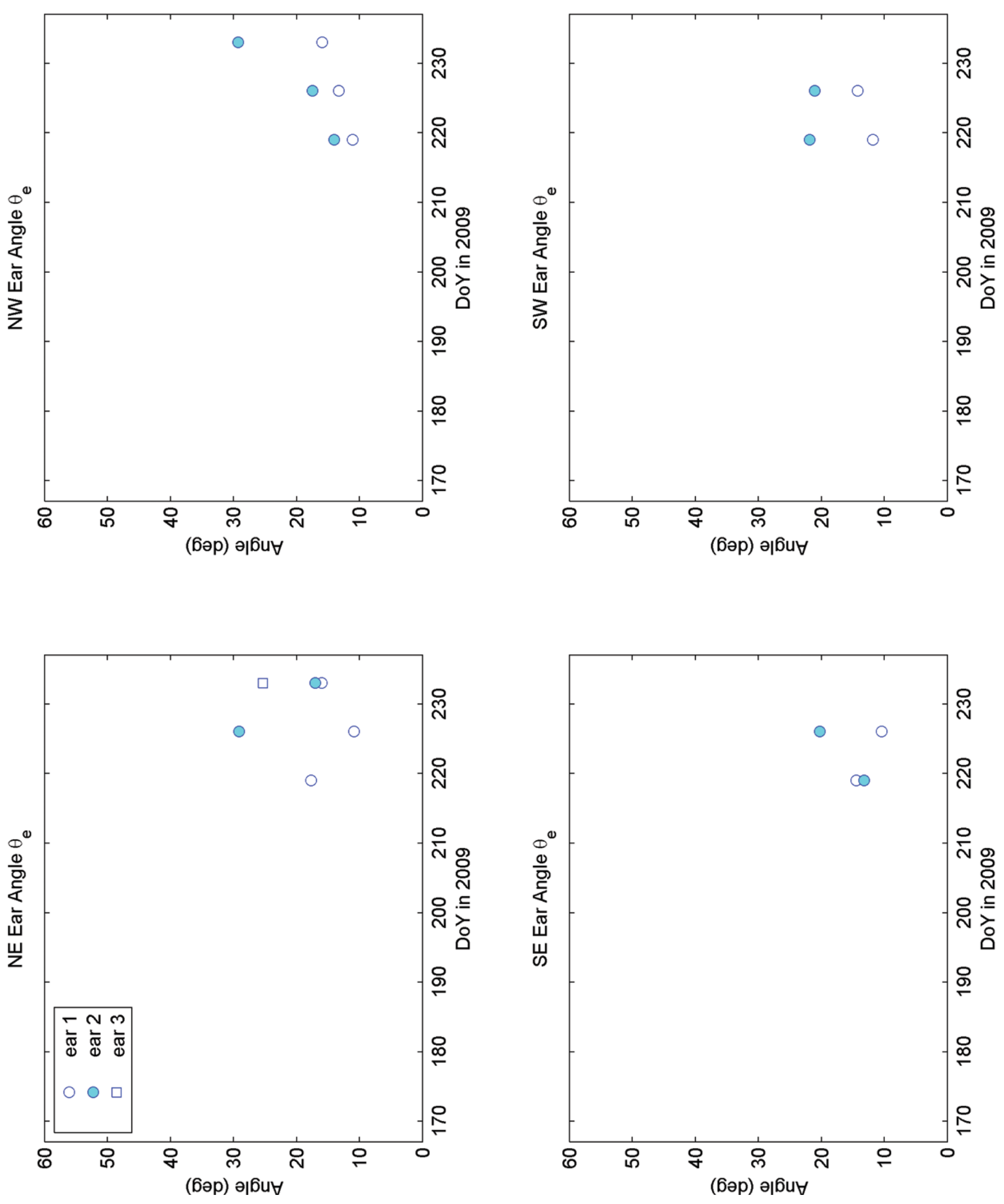

Figure A-27. Ear angle $\left(\theta_{\mathrm{e}}\right)$. 

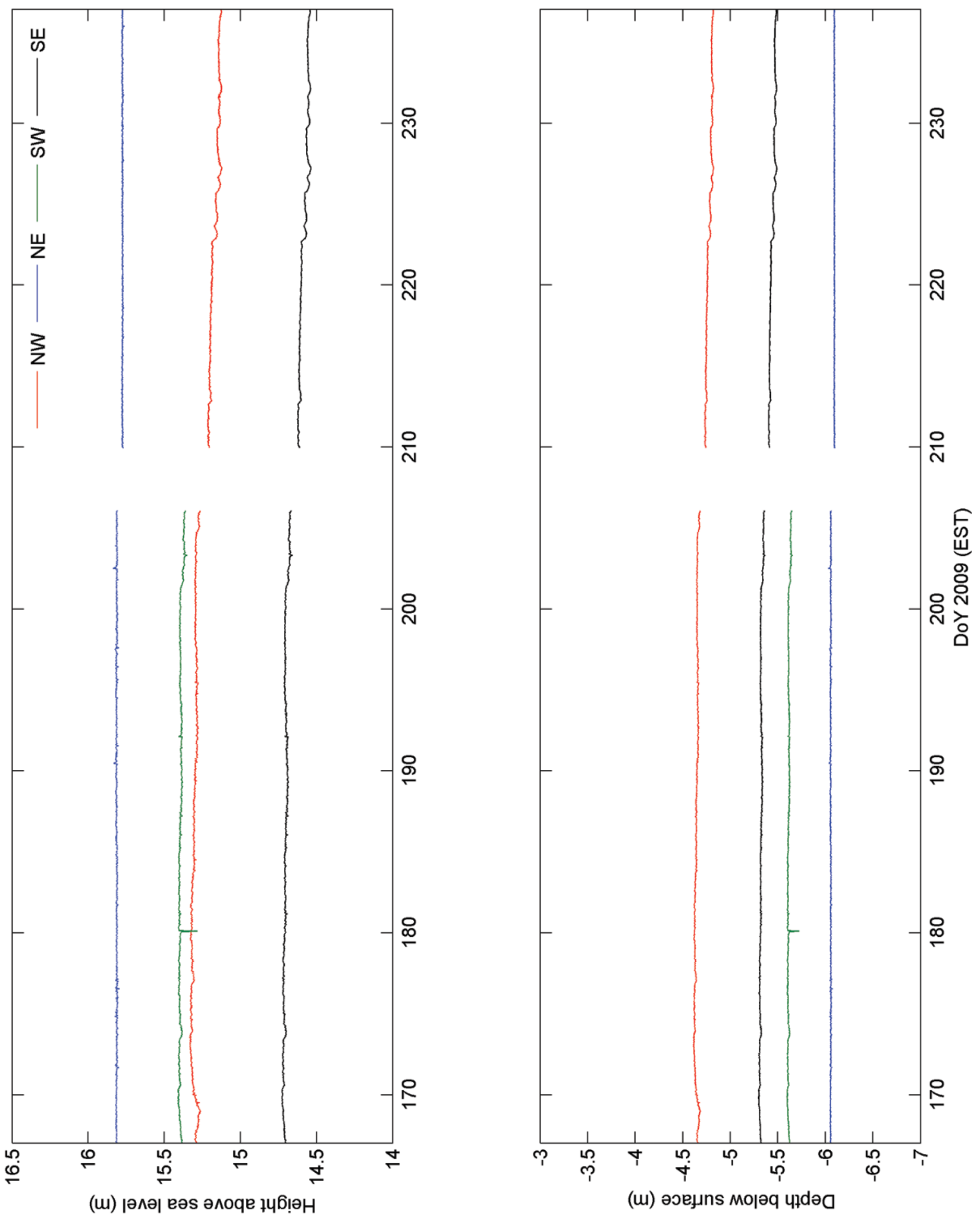

Figure A-28. Water table depth and elevation above sea level. 